$4,4+4$

THE USE OF SCATTERTNG PARAMETERS IN THE DESIGN

OF AMPLIFIERS OF SUBNANOSECOND RISETTME

Rosser S. Wilson

Narch 1972

$1, \operatorname{sen} s$,

SUMARY $_{t}$

This paper discusses techniques useful in the design of wide-band

linear amplifiers intended for pulse operation. A suitable model for high-frequency transistors is given, and use is made of the scattering characterization and of a special computer prograin to deduce elentent values in the model.

The design of a fast risetime series-shunt pair and series-series triple is carried out, and computer simulations are used to predict performance of the actual dosigns inclusive of all parasitic reactances consequent upon physical realization of the circuits.

Mótrice

This roport was prepared in an eccount of work sponsored by the United Stries Government. Neithar sponsed Gtates not the Unised States \& tomic Enery Compinion, nor eny of that employees, nos any of Comming, thots contractor, subcontrecter impliod, or surmes any mokes any. werranty, express or implod, or accuracy, comlopal Uibulity or responsibility for the accuracy, complatenses or uscfulnese of any hiformetion, hpparstes psoduct or procens discioved, or reprecents 
Sumary . . . . . . . . . . . ii

Chapter 1. Introduction

Chapter 2. Elementary Theory of the Scattering latrix . . . 5

Chapter 3. The Theory of Autconated Modelling

Using the Scattering Matrix . . . . . . . 15

Chapter 4. Modelling of Bipolar Junction Transistors

in the Snall-Signal Regime ......... 37

Chapter 5. Design of a Fast-Rise Series-Shunt Pair

Chapter 6 . Design of a Fast Rise Series-Series Triple $\cdot .4 .87$

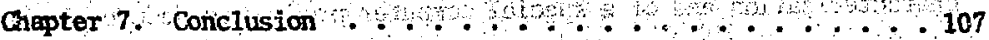

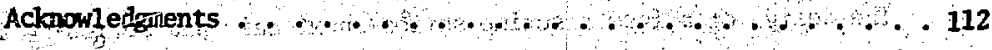

References $, \ldots, 0_{0}, 0_{0}, \ldots, 112$

Appendices

Appendix A, Use of the Automated Modelling Program.. . . . 17t

Appendix B. Fortran Progran 'MDDEL" $\ldots \ldots \ldots+\ldots$ 


\section{CHAPTER 1. INTRODUCTION}

The need often arises in experinents in high energy physics for an amplifier possesising moderate gain and having rise-times in the subnaxosecond region. Good d-c stability and zero offset between inpuit and output, as well as favoirable noise performance are additional characteristics desirable in stuch an amplifier; however, since in this paper the primary concern is with techniques of realizing the necessary transient response, suffice it to say that the $d-c$ requirenents $c a n$ be met using the operational-amplifier stabilìzing tedinique dêscribed elsentere. (I) The topic of noise minimization is an extensive one in its own right, and could provide the basis for further research.

The minimal specification to be satisfied by the cinclit in respect of transient performance mey be stated concisely thus:

(i) Rise-tinse $\leq 500$ psec.

(ii) Overshoot on step-function input $\leq 10 \%$.

(iii) Gain of $20 \mathrm{~dB}(\mathrm{X10})$ in a $50 \Omega$ system.

It is evident that the amplifier mist be capable of passing frequencies approaching one gigahertz. At the other exd of the spectrim, a passband extending down to $\mathrm{d}-\mathrm{c}$ is desirable from the aspect of reducing tilt on wide inqut pulses, and of simplisying the application of operational-amplifier d-c stabilizing methods. 
The 1ow-frequency requirement is easily satisfied by the use of direct coupling within the aplifier, however, the provision of the requisite high-frequency response is a considerably more difficult problen, and requires in addition to the use of transistors having suitably high $f_{r}$ figures the application of striplin and thin-film construction techniques in order to redice to a minimin the effects upon cincuit periomance of parasitic reactances and transversal delay around the feedback loop.

Two amplifier designs are considered in this paper, and in both series feedback is used at the input in order to raise the input inpedance of the circuit. In this way an approximation con be attained to a $50 \Omega$ iriput impedance through use, at the base of the imput transistor, of a $50 \Omega$ resistor to ground. Moreover, earlier work (2) has shown that the two configurations chosen for treaturant here, namely the series-shunt pair and seriesseries triple, are optinal from the standpoint of maximan gain-bandwidth product in comparison with altermate two- and three-stage ariangements.

A prelininary to the design of any aplifier is the determination of suitsble moxiels of the active devices intended for use therein. Such models my be deduced difectly from physical reasoning provided accurate data are available regayiatis device construction. Frequently this information is propriotary and hence is not readily available; oven if it were, manufacturine processes are often sufficiently ill-defined os to make rather inaccurate a device nodel determined solely on the basis of a device processing schedule.

The approach to transistor characterization adopted in this paper relies upon hysical reasoning only to decuce the topology of the equivalent circuit, and in this way is relieved of dependence upon details of transistor fabrication. Direct measurement of the two-port 
parameters of the transistor, in conjunction with the use of a digital computer progran devised especiaily for the task then enables values to be assigned to the elements of the model. This method has the virtue of reflecting the actual characteristics of the device, and an arbitrary increase in model accuracy is possible sinply by incorporating into the model those alditional elements necessary to deal with effects not accounted for in more elementary versions.

The two-port measurements necessary for the characterization of the transistors used in the amplifiex were done uging scattering parameters in order to circumvent the need for accurate short-or opencircuits of device ports necessary for the determination of the more comenton $Y$ - or Z-parameters. The difficulty at high frequencies of attaining these states can lead to significant inaccuracies in measurement.

Included in this paper is a canplete description of the various desigri and modelling techritiques already described in brief above Chapter 2 is devoted to a brief introduction to the scattering matrix and to the developnent of fommine useful in the renainder of the report. In Chapter 3, the theoretical aspects of autcmatic modelling are presented; along with a short description of a computer program written to realise the theory. The results of automated modelling of a high-frequency chip transistor are contained in Chapter 4. Two amplifiers were designed using the transistor characterized in Chapter 4 the design of a series-shunt feedback pair. forms the subject of ctapter 5 . Chapter 6 discusses the design of a series-series feedback triple; this particular design was accomplished using a variant of the optimization program 


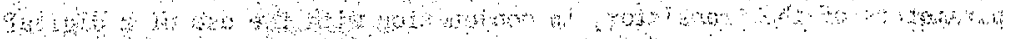

dealt with in chapter 3 . Chapter 7 concludes the report with a discussion of important results fiom the preceding chapters and with suggestions ros further work. Appendices give details of matters considered too specialized for more than preliminary mention in other parts of the paper?

and

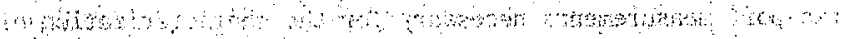

-

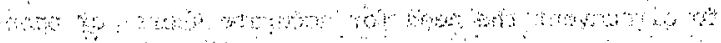

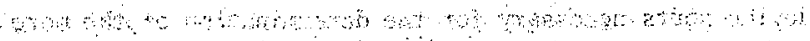

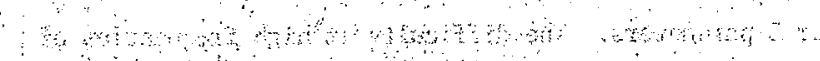

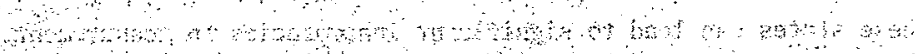

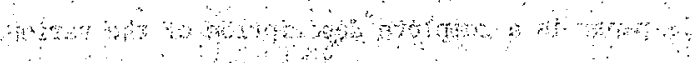

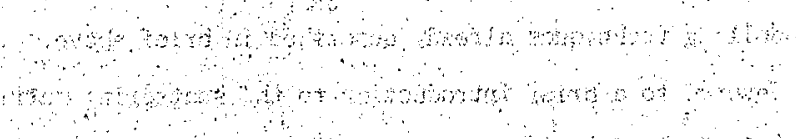

$\therefore y+0$ 


\section{CHAPTER 2. ELENENTARY IHBORY OF THE SCATIERTNG MATRIX}

The scattering parameter method of two port characterization was devised originaliy in conrection with nicrowave notwork theory, whore the description of two-port behaviour in terms of incident and reflected wave quantities is a physically realistic approach lending itself to easy visualization.

In measurements upon active devices at high frequencies, the use of scattering parameters is further conmended by the fact that at these frequencies, the open-and short circuits requist te to neasurement of the $Y$ - or $Z$-parameters are excedingly difficult to attain die to the presence of spurious reactances. such parasitics tan aiso render an active device unstable and susceptible to free osciliation when the more conventional two-pont characterizations are temployed. These and attendant problems are greatly retuced in the scattering formulation, for in this, the two ports of the device inder test are always terminated in a constant and precisely known refererie impodance.

The scuttering formulation comonly used and that to be presented in this chapter, is carried out in terms of a resistive reference inmittance. The scattering fomalism is completely general, however, and can accomodate complex reference imittances (s)

Shown in Fig. (2-1) are the basic definitions to be anplojed th the ensuing discussion which, although it will be given on the bosts of a two-port configuretion, is easily extensible to the senexal ${ }^{2}$ ont case. 


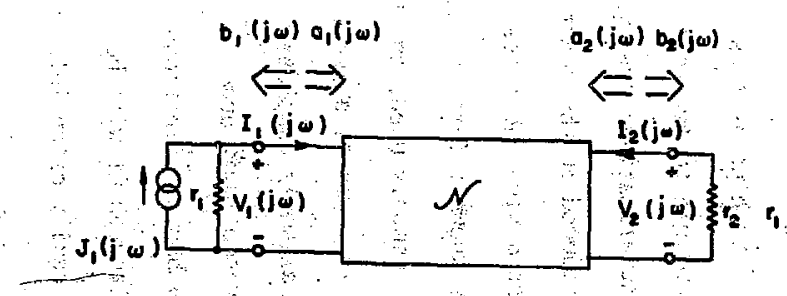

(a) Colculation of $s_{11}(j \omega), s_{21}(j \omega)$

$$
a_{2}(j \omega)=0
$$

(b) Calculotion of $s_{12}(j w), s_{2 k}(j \omega)$

\section{$x 0724-2797$}

Fig. 2-1 
The customary definition of the basis free nomalized scattering matrix is contingent upon the introduction of an hypothetical pair of vector waves comprising the wave a (jw) incident upon the two-port, and its reflected counterpart $\underline{b}(j \omega)$. The scattering matrix $\underline{S}(j \omega)$ relates the incident and refiected waves according to the formula (4)

$$
\underline{b}(j \omega)=\underline{s}(j \omega) \underline{a}(j \omega) \text {, }
$$

where,

$$
\underline{a}(j \omega)=\frac{1}{2} \underline{R}^{-\frac{1}{2}}(V(j \omega)+R I(j \omega))
$$

and, $\quad \underline{b}(j \omega)=\frac{1}{2} \underline{R}^{-\frac{1}{2}}(v(j \omega)-R(j \omega))$

By $\underline{R}$ is denoted the diagonal matrix of reference normalizing resistarices, namely,

$$
\underline{R}=\left[\begin{array}{ll}
r_{1} & 0 \\
0 & r_{2}
\end{array}\right]
$$

and $V(j \omega)$ and $I(j \omega)$ are the vectors of port vol tages and currents, respectively.

It is apparent from these definitions that a scattering matrix specification of a network must necossarily include mentian of the reference inpedances under whith the characterization was done. 
The evaluatim of the individual entries in the scattering matrix is easily undertaken through the expansion of Eq $(2-1)$ according to Eq. $(2-4)$.

$$
\left[\begin{array}{l}
b_{1}(j \omega) \\
b_{2}(j \omega)
\end{array}\right]=\left[\begin{array}{ll}
s_{11}(j \omega) & s_{12}(j \omega) \\
s_{21}(j \omega) & s_{22}(j \omega)
\end{array}\right]\left[\begin{array}{l}
a_{1}(j \omega) \\
\left.a_{2}(j \omega)\right)
\end{array}\right],
$$

whence it is evident that the following relations are obeyed:

$$
\begin{aligned}
s_{11}(j \omega) & =\frac{b_{1}(j \omega)}{\left.a_{1}(j \omega)\right|_{a_{2}}(j \omega)}=0 \\
s_{22}(j \omega) & =\left.\frac{b_{1}(j \omega)}{a_{2}(j \omega)}\right|_{a_{1}(j \omega)}=0 \\
s_{2,1}(j \omega) & =\left.\frac{b_{2}(j \omega)}{a_{2}(j \omega)}\right|_{a_{2}(j \omega)}=0 \\
s_{22}(j \omega) & =\left.\frac{b_{2}(j \omega)}{s_{2}(j \omega)}\right|_{a_{1}(j \omega)}=0
\end{aligned}
$$

Achievement at the condition $a_{k}(j \omega)=0$ is readily attained by removing any excitation from the $k$-th port, whereupon $v_{k}(j \omega)=r_{k} I_{k}(j \omega)$ and so, according to Eq. $(2-2), a_{k}(j \omega)$ will vanish. Fígure $(2-1)$ gives a summary of the actual use of Eqs. $(2-5 a)$ to $(2-5 d)$ 
In practice, scattering parameters are measured using the instrumentation arrangenent shown in scliematic form in Fig. (2-2). The dualdirecticnal couplers of that figure are passive devices giving at their two output terminals a sample of the wave traversing them in the direction of the associated arrow.

The $\underline{a}(j \omega)$ and $\underline{b}(j \omega)$ vectors are defined as the wave vectors existing at the terminals of the network under consideration. In a practical situation, where the points of evaluation of the incident and reflected waves are located some distance from the network ports, the following relation exists between a $(j \omega)$, the measured quantity corresponding to $\underline{a}(j \omega)$, and $\underline{a}(j \omega)$ itself,

$$
\left[\begin{array}{l}
\hat{a}_{1}(j \omega) \\
\hat{a}_{2}(j \omega)
\end{array}\right]=\left[\begin{array}{ccc}
k_{1} e^{-j \omega \tau_{1}} & & 0 \\
0 & & k_{2} e^{-j \omega \tau_{2}}
\end{array}\right]\left[\begin{array}{l}
a_{1}(j \omega) \\
a_{2}(j \omega)
\end{array}\right]
$$

A sinilar formula holds true in respect of $\underline{b}(j \omega)$ and its measured counterpart $\hat{b}(j \omega)$,

$$
\left[\begin{array}{l}
\hat{b}_{1}(j \omega) \\
\hat{b}_{2}(j \omega)
\end{array}\right]=\left[\begin{array}{cc}
k_{1} e^{-j \omega \tau_{1}} & 0 \\
0 & k_{2} e^{-j \omega \tau_{2}}
\end{array}\right]\left[\begin{array}{l}
b_{1}(j \omega) \\
b_{2}(j \omega)
\end{array}\right]
$$

The constants $K_{3}$ and $K_{2}$ in these two equations account for the attenuation between the waves appearing at the retwork tominals, and the corresponding samples thereof provided at the directional couplers. 


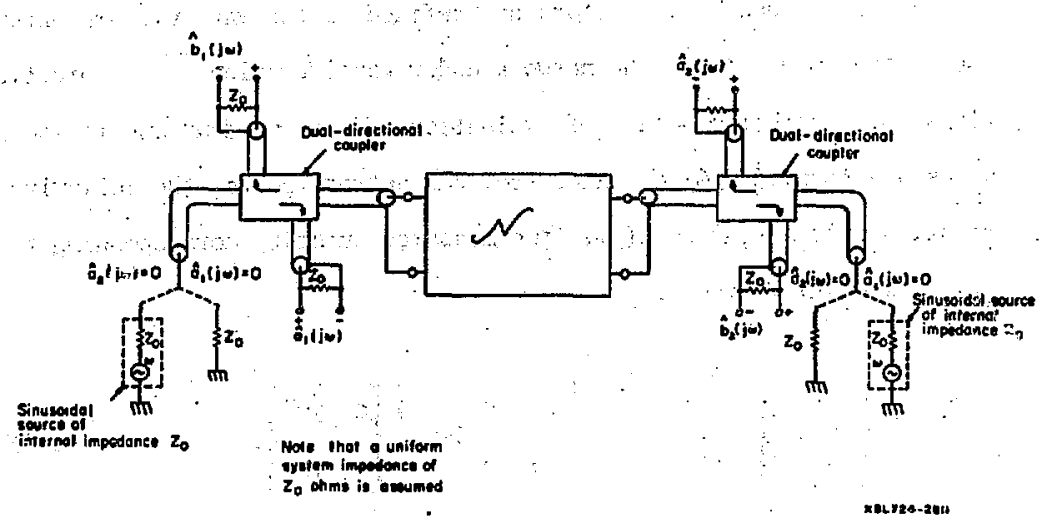

Fig. 2-2 
The linear phase (delay) operatior exponentials simulate the effects of propagation delay through the directional couplers and transmission lines, and for simplicity the transinission lines are assumed loss-1ess.

It is usual in practice to arrange that the channels associated with the two network ports are symmetric, whereupon $K_{1}=K_{2}$ and $\tau_{1}=\tau_{2}$ since then attenuation and delay in the paths are equal. For this comonly encountered case, Eqs. $(2-5 a)$ to $(2-5 d)$ can be rewritten as:

$$
\begin{aligned}
& s_{11}(j \omega)=\left.\frac{\hat{b}_{1}(j \omega)}{\hat{a}_{1}(j \omega)}\right|_{a_{2}(j \omega)}=a_{2}(j \omega)=0 \\
& s_{12}(j \omega)=\left.\frac{\hat{b}_{1}(j \omega)}{\hat{a}_{2}(j \omega)}\right|_{\hat{a}_{1}(j \omega)=a_{1}(j \omega)}=0 \\
& s_{21}(j \omega)=\left.\frac{\hat{b}_{2}(j \omega)}{\hat{a}_{1}(j \omega)}\right|_{\hat{a}_{2}(j \omega)=a_{2}(j \omega)=0} \\
& s_{22}(j \omega)=\left.\frac{\hat{b}_{2}(j \omega)}{\hat{a}_{2}(j \omega)}\right|_{\hat{a}_{1}(j \omega)}=a_{1}(j \omega)=0
\end{aligned}
$$

Equations $(2-8 a)$ to $(2-8 d)$ provide the necessary relations for direct experimental determination of the scattering matrix of an arbitrary network. They were obtained by substitution into Eq. $(2-4)$ of Eqs. (2-6) and (2:7). 
For the case of non-symetrical channels, it is easy to show that,

$$
\begin{aligned}
& s_{12}(j \omega)=\left.\frac{\hat{b}_{1}(j \omega)}{\hat{a}_{1}(j \omega)}\right|_{\hat{a}_{2}} \\
& a_{2}(j \omega)=a_{2}(j \omega)=0 \\
& s_{22}(j \omega)=\frac{\left.\left.k_{2} e^{j \omega\left(\tau_{1}-\tau_{2}\right)} \frac{\hat{b}_{1}(j \omega)}{K_{1}}\right|_{\hat{a}_{2}(j \omega)}\right|_{\hat{a}_{2}(j \omega)}=a_{1}(j \omega)=0}{} \\
& s_{21}(j \omega)=\left.\frac{K_{1}}{K_{2}} e^{j \omega\left(\tau_{2}-\tau_{1}\right)} \frac{\hat{b}_{2}(j \omega)}{\hat{B}_{1}(j \omega)}\right|_{\hat{B}_{2}(j \omega)}=a_{2}(j \omega)=0 \\
& s_{22}(j \omega)=\left.\frac{\hat{b}_{2}(j \omega)}{\hat{a}_{2}(j \omega)}\right|_{\hat{a}_{2}(j \omega)}=a_{2}(j \omega)=0 .
\end{aligned}
$$

. In many applications of the scattering paraneters to network analysis and synthesis it is necessary, by using standard techniques of analysis, to be able to compute the scattering matrix fin a given network whose topology and element values are specified. Towards this end, it is useful to deduce formulae relating the scattering parameters to network port voltages and currents.

Prosuming the cesirability of exploying nodal malysis to accomplish the task of analytic detonination of the scattering matrix, it is clear that the preferred excitation and response bases are currents and nodepair potential differences, respectively. 
Treating first the case of $s_{11}(j \omega)$ and with reference to Fig. $(2-1 a)$, substitution into Eq. (2-5a) of the appropriate scalar version of Eqs. (2-2) and (2-3) yields,

$$
s_{11}(j \omega)=\frac{V_{1}(j \omega)-r_{1} I_{1}(j \omega)}{V_{1}(j \omega)+r_{1} I_{1}(j \omega)}
$$

The variable $I_{1}(j \omega)$ can be eliminated from this expression to give a dependence vfon the excitation current source $J_{j}(j \omega)$ and port voltage $v_{1}\left(j \omega_{i}\right)$ by noting that,

$$
I_{1}(j \omega)=J_{1}(j \omega)-\frac{v_{1}(j \omega)}{r_{1}},
$$

whence substitution of this into Eq. (2-10) gives the required formula, namely,

$$
s_{11}(j \omega)=\left(\frac{2}{r_{1}}\right)\left(\frac{v_{1}(j \omega)}{J_{1}(j \omega)}\right)-1
$$

In the case of $s_{21}(j \omega)$, a sinilar development commences with a substitution into $\mathrm{Eq}$. (2-5b) from Eqs. $(2-2)$ and $(2-3)$ to give,

$$
s_{21}(j \omega)=\frac{v_{2}(j \omega)-\dot{r}_{2} I_{2}(j \omega)}{v_{1}(j \omega)+r_{1} I_{1}(j \omega)}
$$


Since in addition to Eq. (2-11), the following relation is also valid,

$$
I_{2}(j \omega)=\frac{v_{2}(j \omega)}{r_{2}}
$$

these can be inserted into $\mathrm{Bq} .(2-13)$ to yield;

$$
s_{2 i}(j \omega)=\left(\frac{2}{r_{2}}\right)\left(\frac{v_{2}(j \omega)}{J_{2}(j \omega)}\right)
$$

In sinilar fashion, the tho remaining scattering parameters can be determined as follows:

$$
s_{12}(j \omega)-\left(\frac{2}{r_{1}}\right)\left(\frac{v_{1}(j \omega)}{J_{2}(j \omega)}\right)
$$

and,

$$
s_{22}(j \omega)=\left(\frac{2}{r_{2}}\right)\left(\frac{v_{2}(j \omega)}{J_{2}(j \omega)}\right)-1,
$$

where reference is now to Fig. (2-1b).

Through the applications of these four expressions, the scattoring matrix may readily be obtained using a nodal analysis.

The description of the scattering matrix given in this chapter has of necessity been brief mid has been linited to the derivation of results useful in subsequent sections of the paper. For a more detailed exposition of the subject, the reader is referred to the references. 
The objective of the autcinatic nodelilig process is in most general terms, the determination of elent values in a pre-specified nethork (model) $N$ such that the scattering parameters of this circuit agred optimally in some sense with a given set of scattering matrices taken at a sequence of $\ell$ frequencies $\omega_{1}, \omega_{2},-, w_{i},-w_{l}$ in the band whereftr optimal agreenent is sought. The problen can bel stated matheratically as one of finding the minim of an error function those mignitude is a function of the discrepancy existing botween a given set of scattering matrices $\underline{s}^{G}\left(j \omega_{2}\right), \underline{s}^{G}\left(j \omega_{2}\right), \cdots, \underline{s}^{G}\left(j \omega_{1}\right), \ldots, \underline{s}^{G}\left(j \omega_{l}\right)$, and those calculated from $N, \underline{s}^{N}\left(j \omega_{1}, x\right), \underline{s}^{N}\left(j \omega_{2}, x\right), \ldots, \underline{s}^{N}\left(j \omega_{2}, x\right), \ldots, \underline{s}^{N}\left(j \omega_{i}, x\right), \cdots$ $\underline{S}^{\prime \prime}\left(j \omega_{l}, x\right)$. The functional deptendence upon the vector $x=\left(x_{1}, x_{2}, \ldots\right.$, $\left.x_{m}\right)^{T}$ of varioble elenents in $d$ of the $s^{\text {I }}$ accounts for the fact that variation of the $\underline{s}^{N}$ can be accouplished through chinging the valives of prescribed elements in $H$.

Although altemative thoices are certainly possible, the error function adopted in this instance is of the weightod sumor squares variety, and is expressible in the space of elements subject so variation as,

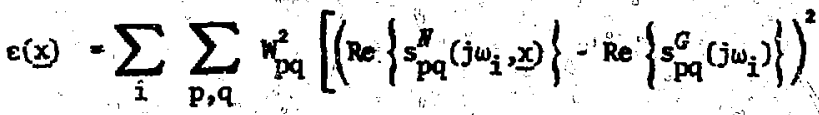

$$
\begin{aligned}
& \left.+\left(\operatorname{Im}\left\{s_{p q}^{N}\left(j \omega_{i}, x\right)\right\}-\left\{I_{n} s_{p q}^{G}\left(j \omega_{j}\right)\right\}\right)^{2}\right]
\end{aligned}
$$


The index of simmation i in Eq, (3-1) is taken over all frequencies at wich $S^{G}$ are given, the indices $\mathrm{p}$ and $q$ being used to signify sumation over all four entries in the $2 \times 2$ scattering matrices. A weight vector $\mathrm{W}$ is also included in the fomulation of the error function in ofdor to enabie preference to be given in the fitting process tô one or more entries in the scattering matrix. Note in passing that $\varepsilon(\underline{x})$ of Eq. (3-1) is a non-negative scalar possessing the property of vanishing when the $\underline{S}^{n}$ and $\underline{S}^{G}$ agree for all $w_{i}$

It transpires that the most efficient schemes of functionai minimization require both the fimction and its gradient. Differentiation of Eq. (3-1) yields for the gradient of $\varepsilon(x)$ with respect to $x$

$$
\begin{aligned}
& \frac{\partial \varepsilon(x)}{\partial x}=2 s \sum_{i} 2_{p q}\left[\left(\operatorname{Re}\left\{\frac{\partial s_{\mathrm{pq}}^{\left(j \omega_{i}, x\right)}}{\partial x}\right\}-\operatorname{Re}\left\{s_{\mathrm{pq}}^{G}\left(j \omega_{i}\right)\right\}\right)\right. \\
& +\left(\operatorname{Im}\left\{\frac{\partial s_{p q}^{A}\left(j \omega_{i}, x\right)}{\partial \underline{x}}\right\}-\operatorname{In}\left\{s_{p q}^{G}\left(j \omega_{i}\right)\right\}\right)
\end{aligned}
$$

The notation used here for the gradient is rather informal, and is expandible as, $\partial \varepsilon(x) / \partial \underline{x}=\left(\frac{\partial \varepsilon(x)}{\partial x_{1}}, \frac{\partial \varepsilon(x)}{\partial x_{2}}, \frac{\partial \varepsilon(x)}{x_{m}}\right)$. Apparently, the detemination of $\varepsilon(\underline{x})$ and $\partial \varepsilon(\underline{x}) / \partial \underline{x}$ reduces to the problen of calculating for $\delta$ its scattoring parameters at all $\omega_{i}$, and of finding at these same frequencies the gradients of all four entries in the calculated scattering trices $\underline{s}^{N}$. 


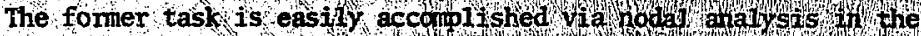
complex frequency domain and

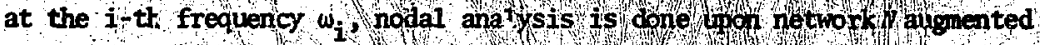
by the nomalizing reststances for thoh thesghts specified and

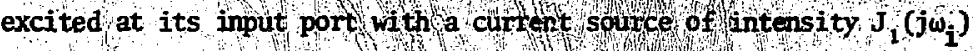

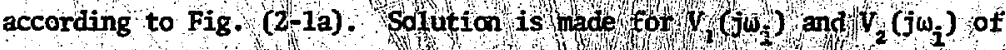
that figure, whereupon application of EqS $(z-12)$ and $(2-15)$ pemits

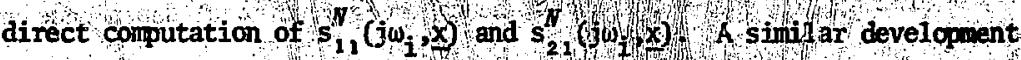
using the excitation current sounce in thp pos it ip of to (2-1b) in conjunction with Eqs $(2-16)$ and $(2-17)$ elables $s_{2}\left(j w_{2}, x\right)$ and $s_{22}\left(j w_{1}, x\right)$ to be found.

The probiem of calculating the gradsents of the two-port scattering parameters can be recast into ong of finding the gradjents of the teminal voltages of nethork $n$ to wich appopiate excitation has been applied." Differentiation pef Eqs $(2-12)$ and $(2-15)$ then yields;

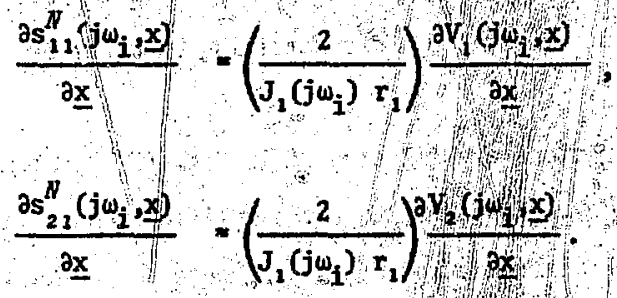

For these two equations, the exciting soury for $N$ is a current soirce of value $J\left(j \omega_{i}\right)$ comected at the input port of as in Fig $(2-1 a)$ For Eqs. (3-5) and (3-6), the source is in the 1ocation pf Fig (2-Ib), and the differentiation is dono ipon Eof $(2-16)$ and $(2-17)$ 


$$
\begin{array}{r}
\frac{\partial s_{12}^{N}\left(j \omega_{i}, \underline{x}\right)}{\partial \underline{x}}=\frac{2}{J_{2}\left(j \omega_{j}\right) r_{2}} \frac{\partial V_{1}\left(j \omega_{i}, \underline{x}\right)}{\partial \underline{x}} \\
\frac{\partial s_{22}^{N}\left(j \omega_{1}, \underline{x}\right)}{\partial \underline{x}}=\frac{2}{J_{2}\left(j \omega_{1}\right) r_{2}} \frac{\partial V_{2}\left(j \omega_{1}, \underline{x}\right)}{\partial \underline{x}}
\end{array}
$$

The voltages $v_{1}\left(j \omega_{i}, x\right)$ and $v_{2}\left(j \omega_{i}, x\right)$ are dependent upon the variable elements $x_{1}, \dot{x}_{2}, \cdots, x_{n}$ in $n$, hence their functional dependence upon $\underline{x}$.

Calculation of the derivatives on the right-hand side us Eqs. (3-3) to $(3-6)$ in the mmerically precise form required by the functional minimization algorithm is greatly facilitated through application of the concept of the adjoint network. $(5,6,7)$

The adjoint $\hat{N}$ of $N$ possessns a topology identical to that of $N$. All conductance, capacitance, and reciprocal injuctance branches in $N$ are associated in $\hat{N}$ with identical branches; voltage-controlled current sources in $N$ are associated with similar elements in the adjoint, however the roles of controlled and controlling branches are reversed in $\hat{B}$.

These definitions are illustrated in Fig. (3-1), along with other usefur teminology. Essential to the simplification of the subsequent exposition is the introduction of the augnented networks $\|^{*}$ and $\|^{*}$ connected with $\|$ and $\hat{n}$; the augnented network is simply the original network with the scattering normalizing conductances (reciprocal normalizing resistances) comected acruss its two ports. It is essential to note that the port voltages of $k$ and $k$, and of $\hat{x}^{*}$ and $\hat{N}$ are identical. 

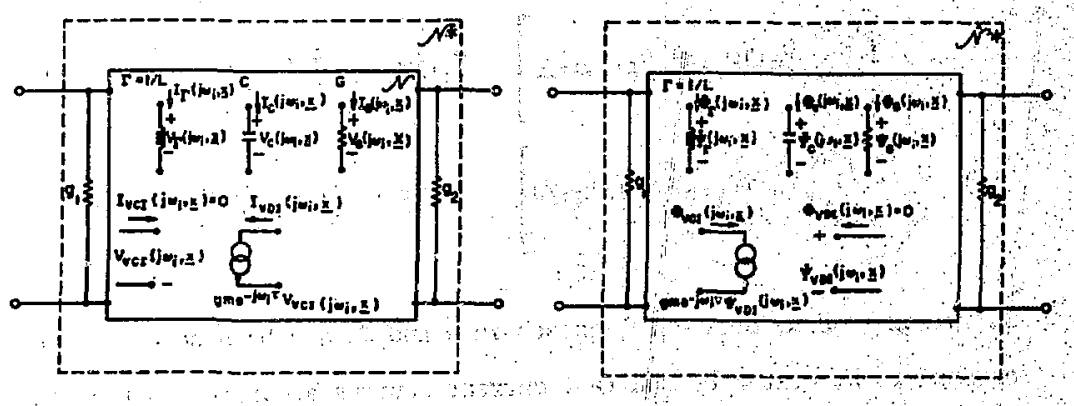

Note $g_{i}-i / r_{i}$

xoured-2tis

Fig. $3-1$ 
Given the augmented networks $\vec{W}$ and $\hat{N}^{*}$, the calculation of the voltage derivatives in Eqs. (3-3) to (3-6) becomes an exercise in the application of Tellegen's theorem. (8) Using the general notation $I_{B}\left(j \omega_{i}, x\right)$, $v_{B}\left(j \omega_{i}, x\right)$ for branch currents and yoltages in $N$, and $\Phi_{B}\left(j \omega_{i}, x\right)$, $\Psi_{B}\left(j \omega_{i}, x\right)$ for their analogues in $\hat{N}^{*}$, Tellegen's theorem states that since $\hat{W}$ and $\hat{N}^{*}$ are topologically equivalent,

$$
\left[\sum_{B} v_{B}\left(j \omega_{i}, x\right) \Phi_{B}\left(j \omega_{i}, x\right)\right]-v_{1}\left(j \omega_{i}, x\right) \hat{J}_{1}\left(j \omega_{i}\right)=0
$$

and

$$
\left[\sum_{B} I_{B}\left(j \omega_{i}, x\right) \Psi_{B}\left(j \omega_{i}, x\right)\right]-J_{1}\left(j \omega_{i}\right) \Psi_{2}\left(j \omega_{i}, x\right)=0
$$

Sumbition is done over all branches in $\hat{N}_{\text {and }} \hat{N}_{3}^{*}$ and both networks are asstmed to be driven by constant currenit sources according to Fig. (3-2a).

Now, an infinitesimal perturbation in one of the variable elements of $v$ leads to changes in the branch voltages and currents in $\mathbb{N}$; the perturbation is symbolically accomplished by altering the vector $\underline{x}$ by an infinitesimai amount $\delta x$ in the case of $N$ so that,

$$
\left[\sum_{B} v_{B}\left(j \omega_{i}, \underline{x},+\delta x\right) \Phi_{B}\left(j \omega_{i}, x\right)\right]-v_{i}\left(j \omega_{i}, \underline{x}+\delta \underline{x}\right) \hat{j}_{1}\left(j \omega_{i}\right)=0 \text {, }
$$

and,

$$
\left[\sum_{B} I_{B}\left(j \omega_{i}, x+\delta x\right) \Psi_{B}\left(j \omega_{i}, x\right)\right]-J_{2}\left(j \omega_{i}\right) \psi_{2}\left(j \omega_{i}, x\right)=0 \cdot(3-10)
$$




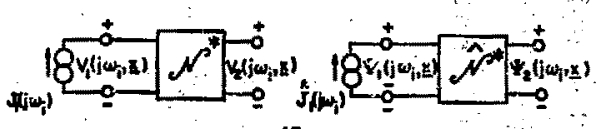

(o) Calculation of $\partial s_{11}^{m} / \partial \underline{x}$

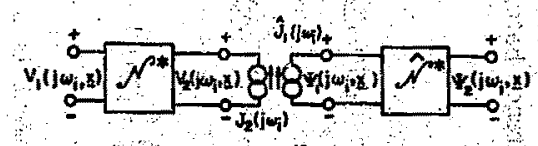

(b) Colcutation of $a s_{u}^{w / d x}$

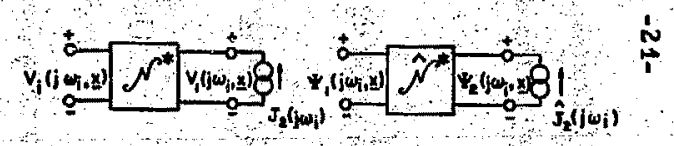

(d) Colculation of as $s_{22}^{\text {r }} / d \underline{x}$

xBL724-279O

Fig. $3-2$ 
Subtraction of Eq. (3-7) from $\mathrm{Bq}$. (3-9), followed by subtraction from the resulting expression of the difference between Eqs. (3-8) and (3-10) yields,

$$
\begin{gathered}
{\left[\sum _ { B } \left\{\phi_{B}\left(j \omega_{i}, \underline{x}\right)\left(v_{B}\left(j \omega_{i}, \underline{x}+\delta \underline{x}\right)-v_{B}\left(j \omega_{i}, x\right)\right)\right.\right.} \\
\left.-\Psi_{B}\left(j \omega_{i}, \underline{x}\right)\left(I_{B}\left(j \omega_{i}, \underline{x}+\delta \underline{x}\right)-I_{B}\left(j \omega_{i}, x\right)\right)\right\} \\
\vdots \\
-\left(v_{1}\left(j \omega_{i}, \underline{x}+\delta \underline{x}\right)-v_{1}\left(j \omega_{i}, \underline{x}\right)\right) \hat{J}_{1}\left(j \omega_{i}\right)=0 .
\end{gathered}
$$

Assume now that the perturbed element is a conductence in the $K$-th position of $x$ so that in $\underline{x}+\underline{x}+\delta x^{G}$ where, $\delta x^{G}$ denotes the vector $\left(0,0 \cdots, \cdots x_{K}^{G}, \cdots, 0\right)^{T}$, and the supesscript $G$ signifies treatment of a conductance elemest. The branch relations for the elewent $x_{K}^{G}$ are given by Eqs. (3-12) and (3-13) for the case of umperturbed and perturbed * , respectively.

$$
\begin{aligned}
& I_{x_{K}^{G}}\left(j \omega_{i}, x^{\prime}=x_{K}^{G} v_{x_{K}^{G}}^{G\left(j \omega_{i}, x\right)}\right. \\
& I_{x_{K}^{G}\left(j \omega_{i}, x^{x}+\delta x^{G}\right)}^{G}=\left(x_{K}^{G}+\delta x_{K}^{G}\right) v_{x_{K}^{G}}\left(j \omega_{i}, x^{x}+\delta x^{G}\right)
\end{aligned}
$$

In $\hat{\boldsymbol{H}}^{*}$, the branch equation,

$$
\phi_{x g}{ }^{\left(j \omega_{i}, x\right]}=x_{X}^{G}{ }_{x}^{G}\left(j \omega_{i}, x\right)
$$

will be satisfied. The subscript schene on voltage and current 
variables denotes quantities appropriate to the branch in $\hat{N}$ and $\hat{H}^{n}$ containing $x_{K^{*}}^{G}$ Stbstitution of Eqs. $(3-12)$ to $(3-14)$ into Eq. $(3-11)$ leads directly to,

$$
\begin{aligned}
& \text { - }{ }^{\Psi_{x_{K}}}\left(j \omega_{i}, x\right) v_{x_{K}^{G}}\left(j \omega_{i}, \underline{x}+\delta \underline{x}\right) \delta x_{K}^{G} \\
& =J_{2}\left(j \omega_{i}\right) v_{1}\left(j \omega_{i}, \underline{x}+\delta \underline{\underline{x}}\right)-v_{2}\left(j \omega_{i}, \underline{x}\right) .
\end{aligned}
$$

By considering the branch relations for the other umperturbed elements in $\hat{B}$ and their correspondents in $\hat{H}^{*}$ it can readily be verified that all terms on the left-hand side of $\mathrm{Eq}$. (3-11) vanish, leaving only the term wue to the branches of $\hat{H}^{*}$ and $\hat{n}^{*}$ containing $\boldsymbol{F}_{K^{*}}$. Taking the linit as $\delta x_{X}^{G}+0$ and $\delta x^{G}+0$ yields upon slight rearrangenent of Eq. (3-15),

$$
\frac{\partial V_{1}\left(j \omega_{i}, x\right)}{\partial x_{K}^{G}}=\frac{{ }_{x_{K}^{G}}\left(j \omega_{i}, x\right) V_{x_{K}} G\left(j \omega_{i}, x\right)}{\hat{J}_{1}\left(j \omega_{i}\right)}
$$

which enables direct couputation of those elements of vector $\delta V_{1}\left(j \omega_{i}, x\right) \hat{\alpha}_{x}$ arising fran conductances.

Tte gradient terms arising from voltage-controlled current sources are derived using the two-brench representation for that elonent shown in Fig. (3-1). The canonical form chosen for this elemont is one providirs both a transconductance term and a Inear phase (delay) operator $\tau$.

Considering now that position $k$ of the vector $x$ contains a delay tor $x_{X}^{\tau}$ assuciated with a voltage-controlled current source, and aploying motetion similar to that used proplously in deriving the gradient 
terms arising from conductances, the branch relations of the element in question can be written as,

$$
I_{V D I_{X_{X}^{\tau}}}^{\left(j \omega_{i}, \underline{x}\right)}=e^{-j \omega_{i} x_{K}^{\tau}} V_{V C I} x_{K}^{\tau}\left(j \omega_{i}, \underline{x}\right),
$$

and

$$
I_{V C I} x_{K}^{\tau}\left(j \omega_{j}, x\right)=0
$$

in the unperturbed $N$ : A perturbation in $N$ of $\underline{x}+\underline{x}+\delta \underline{x} \underline{T}^{\top}$, with $\delta \underline{x}^{\tau}=\left(0,0, \ldots, \delta x_{K}^{\tau}, \ldots, 0\right)^{T}$ causes $e^{-j \omega_{i} x_{K}^{\tau}}+e^{-j \omega_{i} x_{K}^{\tau}}+\delta\left(g n e^{-j \omega_{i} x_{K}^{\tau}}\right)$,

and therefore yields,

$$
\begin{aligned}
I_{V D I_{X}^{\tau}}\left(j \omega_{i}, \underline{x}+\delta \underline{x}^{\tau}\right) & =\left[\operatorname{gm} e^{-j \omega_{i} x_{K}^{\tau}}+\delta\left(g m e^{\left.-j \omega_{i}^{1} x_{K}^{\tau}\right)}\right]\right. \\
& x v_{V C x_{K}^{\tau}}\left(j \omega_{i}, \underline{x}+\delta \underline{x}\right)
\end{aligned}
$$

and,

$$
I_{v c I} x_{K}^{\tau}\left(j \omega_{i}, \underline{x}+\delta \underline{x}\right)=0
$$


Since in the adjoint $\hat{x}^{k}$, no perturbation is done,

$$
{ }^{\Phi} V_{x_{K}^{\tau}}{ }^{\left(j \omega_{i}, x\right)}=e^{-j \omega_{i} x_{K}^{\tau}}{ }^{V_{D I}}{ }_{x_{K}^{\tau}}{ }^{\left(j \omega_{i}, x\right)} \text {, }
$$

and,

$$
\boldsymbol{\Phi}_{\mathrm{VDI}_{\mathbf{X}_{\mathbf{K}}^{\mathbf{\tau}}}\left(\mathbf{j} \omega_{\mathbf{i}}, \mathbf{x}\right)}=\mathbf{0}
$$

The foregoing six equations, Eqs. (3-17) to (3-22), can be inserted directly into Eq. (3-11) with the consequence that,

$$
\begin{aligned}
& -{ }^{\psi} V_{x_{K}^{\top}}\left(j \omega_{i}, x\right) V_{V C I_{x_{K}^{\tau}}}\left(j \omega_{i}, x+\delta x^{\tau}\right) e^{-j \omega_{i}, x_{K}^{\top}} \\
& =\hat{J}_{1}\left(j \omega_{i}\right)\left[v_{1}\left(j \omega_{i}, \underline{x}+\delta \underline{x}\right)-v_{2}\left(j \omega_{i}, x\right)\right] \text {. }
\end{aligned}
$$

By taking the limit as $\delta x_{K}^{\tau}+0$ and $\delta x^{\tau}+0$, using the ilientity,

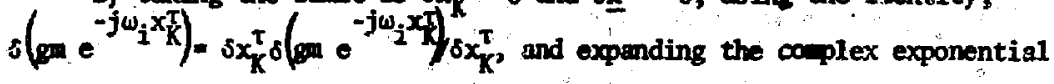
according to Buler's theorem, it con readily be shomn that,

$$
\begin{aligned}
\frac{\partial v_{1}\left(j \omega_{i}, x\right)}{\partial x_{K}^{\tau}} & =g \omega_{i}\left(\sin \omega_{i} x_{K}^{\tau}+j \cos \omega_{i} x_{K}^{\tau}\right) v_{V I}\left(j \omega_{1}, x\right) \\
& x v_{V C I_{x_{K}^{\tau}}\left(j \omega_{i}, x\right)}
\end{aligned}
$$


It is now possible to deduce the contributions to the gradient of the scattering parabeters arising from each type of element in $N$. Substituting $\mathrm{Eq}$. (3-16) into Eq. (3-3) yields, for conductances,

$$
\frac{\partial s_{11}^{D}\left(j \omega_{i}, x\right)}{\partial x_{K}^{G}}-\left(\frac{2}{r_{1} J_{1}\left(j \omega_{i}\right) \hat{J}_{1}\left(j \omega_{i}\right)}\right) \Psi_{K} G\left(j \omega_{i}, x\right) v_{x_{K}^{G}}\left(j \omega_{i}, x\right) .
$$

For the remaining types of passive elements, it is easy aiso to show that, for capacitors,

$$
\frac{\partial s_{11}^{N}\left(j \omega_{i}, x\right)}{\partial x_{K}^{C}}=\left(\frac{j 2 \omega_{i}}{r_{1} J_{i}\left(j \omega_{i}\right) J_{1}\left(j \omega_{i}\right)}\right){ }_{x_{K}}^{C}\left(j \omega_{i}, x\right) v_{x_{K}^{C}}^{C}\left(j \omega_{i}, x\right),
$$

and for reciprocal inductances,

$$
\frac{\partial s_{11}^{N}\left(j \omega_{i}, x\right)}{\partial x_{K}^{\Gamma}}=\left(\frac{2}{j \omega_{i} r_{1} J_{1}\left(j \omega_{i}\right) \hat{J}_{2}\left(j \omega_{i}\right)}\right) x_{K}^{\Gamma}\left(j \omega_{i}, x\right) v_{x}\left(j \omega_{i}, x\right)
$$

For the two parameters characterizing the voltage-controlled current source, the gradient terms taken in respect of the delay $\tau$ are given by substitution of Eq. (3-24) into Eq. (3-3) to yield,

$$
\begin{aligned}
& \frac{\partial s_{11}^{N}\left(j \omega_{i}, x\right)}{\partial x_{K}^{\tau}}=\left(\frac{2-\omega_{i}}{r_{1} J_{1}\left(j \omega_{1}\right) \hat{J}_{1}\left(j \omega_{i}\right)}\right)\left(\sin \omega_{i} x_{K}^{\tau}+j \cos \omega_{i} x_{K}^{\tau}\right) \\
& x V_{\mathrm{VII}_{x_{K}^{\tau}}}\left(j \omega_{i}, x\right) \mathrm{V} \mathrm{VI}_{x_{\mathrm{K}}^{\tau}}\left(j \omega_{i}, x\right),
\end{aligned}
$$


and for the gradient with respect to the transconductance gm, it can be shown that,

$$
\begin{aligned}
& \frac{\partial s_{11}^{N}\left(j \omega_{i}, x\right)}{\partial x_{K}^{g n}}=\frac{-2}{r_{1} J_{1}\left(j \omega_{i}\right) \hat{J}_{1}\left(j \omega_{i}\right)}\left(\cos \omega_{i} \tau-j \sin \omega_{1} \tau\right) \\
& x v_{x_{k}}\left(j \omega_{i}, x\right) V_{V C I_{x}}\left(j \omega_{i}, x\right)_{i}
\end{aligned}
$$

The formulae given in Eqs. (3-25) to (3-29) are applicable in their stated form for calculation of the gradients of the additional three entries in the scattering matrix of $\mathrm{F}$; only the subscripts on the normalizing resistor and scattering variables noed be changed, and the excitation modes in $\boldsymbol{\|}$ and $\hat{\boldsymbol{n}}^{*}$ for the three remining cases are illustrated in Fig. $(3-2 b)$ to $(3-2 d)$.

All gradient-based multidimensional minimization algorithns endenvour to reduce the problea of finding the $80 c a l$ miniman of a famction to one of successive linear seskches. The mowns ployed ivi dotemining the direction of search, as well as the actual realization of the search, account in largo mosure for the ptolifiortion of computation techniques avaliable tody to solve the problem of functional minimization.

The wothod adsptyed in this work is twe to R. Flotchor, ${ }^{(\theta)}$ and represents a significant iliprovenent owor earlfier wrsions of the variable wetric algorith. $(10,11)$ Althouph in this now algoritha, a linoar search is done at every iteration, it is not nocessary as in 
the Fletcher-Powell procedure that it locate a minimum along the line of search; rather, only at least, an arbitrary prespecified decrease in the error function undergoing minimization is sought.

A defining property of all variable-metric algoritlms is the retention of an approximation $\underline{H}^{-1}(x)$ to the inverse Hessian matrix of second derivatives of the error function; the appraximation is inproved as the minim is approached, and converges at the minimum to the true inverse Hessien $\underline{H}^{-1}(x)$. To cowience the theoretical exposition of the method, Iet the error finction $f(x)$ of $\mathrm{Eq}$. (3-1) be expended into a mult variate Taylor's series about a point $\underline{x}_{p}$, and let only three terms of the series be retained so that, (12)

$$
\varepsilon\left(\underline{x}=\varepsilon\left(\underline{x}_{p}\right)+\left(\underline{x}-\underline{x}_{p}\right)^{T} \frac{\partial \varepsilon\left(\underline{x}_{p}\right)}{\partial \underline{x}}+\frac{1}{2}\left(\underline{x}-\underline{x}_{p}\right)^{T}-\underline{H}_{\underline{p}}\left(\underline{x}_{p}\right)\left(\underline{x}-\underline{x}_{p}\right)\right.
$$

In ondor that $\mathrm{Eq}$. (3.30) be valid, it is necessary that $E(x)$ be twice differentible and that its Hessian matrix $\underline{H}(\underline{x})$ be non-singular for w1 $x$ in a sufjiciently largo noighborhood of $\underline{x}_{p^{*}}$ Each entry $h_{i j}$ in $H(x)$ is defined according to convontion os $h_{i j}=\partial^{2} \varepsilon(x) / \partial x_{i} \partial x_{j}$. Setting the gradient of the right-hand side of Eq. (3-30) equal to zoro at the minimm $x_{0}$ of $e(x)$. since there the gradient vanishes, mobles lefinition of the Newton-Raphson formula, (13) $\mathrm{Eq} .(3-31)$.

$$
x_{0}=\underline{x}+\underline{H}^{-1}(x) \frac{\partial \varepsilon(x)}{\partial \underline{x}}
$$


STUDY OF NUCLEAR STRUCTURE FROM THE ANALYSIS OF $\gamma$ RAYS

$$
\begin{gathered}
\text { FOLIONING } \mu^{-} \text {CAPTURE IN Al, Si, Ca, AND Co. } \\
\text { L. Edward Temple, Jr. } \\
\text { Lawrence Berkeley Laboratory } \\
\text { University of California } \\
\text { Berkeley, California }
\end{gathered}
$$

\section{ABSTRACT \\ An analysis of $\gamma$ rays emitted following $\mu$ - capture in $\mathrm{Al}, \mathrm{Si}, \mathrm{Ca}$,} and Co has been carried out with the intention of studying the structure of the nuclear states excited in the muon capture reaction. The results of this experiment are correlated and compared with the results of single nucleon pick-up reactlons, photoexcitation and electroexcitation studies, and thermal neutron capture experiments as well as with theoretical nuclear structure calculations. These correlations reveal the similarities of the various excitation techniques and show how muon capture studies compliment and extend the Information one can obtain about nuclear structure.

The close correlation of the states populated in ${ }^{39} \mathrm{~K}$ following muon capture in ${ }^{40} \mathrm{Ca}$ with those populated in the single nucleon pickup reaction ${ }^{40} \mathrm{Ca}(t, \alpha){ }^{39} \mathrm{~K}$ indicates that single hole states are populated preferentially in the residual ${ }^{39} \mathrm{~K}$ nucleus when a single neutron is emitted following the muon capture. An identiflcation of the statea formed in ${ }^{28} \mathrm{~A} 1$ following muon capture in ${ }^{28} \mathrm{Si}$ with levels thought to be configuration mixed particle-hole states is made.

The results of the photoexcitation reaction ${ }^{40} \mathrm{Ca}\left(\gamma, \mathrm{p} \gamma^{\prime}\right)^{39} \mathrm{~K}$ are compared with the ${ }^{40} \mathrm{Ca}\left(\mu^{-}, v_{n}\right)^{39} \mathrm{~K}$ results and indicate the presence of a glant resonance mechanism in the muon capture process. The relative frequency of populating $\mathbf{l d}_{5 / 2}$ proton hole states to that of populating 
where $\xi$ is taken as a scalar muliple $B$ of a direction of linear search chosen in analogy with $\mathrm{Eq}$ ( $(3-32)$ so that,

$$
\underline{\xi}-\beta \underline{\hat{H}}^{-1}\left(\underline{x}_{k-1}\right) \frac{\partial \varepsilon\left(x_{k-1}\right)}{\partial x}
$$

In order to force a sufficient decrease in $\varepsilon(x)$ on an iteration; it suffices to require that,

$$
0 \leqslant\left(\varepsilon\left(\underline{x}_{K-1}\right)-\varepsilon\left(\underline{x}_{K}\right)\right) / \xi^{T} \frac{\partial \varepsilon\left(\underline{x}_{K}\right)}{\partial \underline{x}} \ll 1
$$

Inequality (3-34) can ultimately be satisfied by trying values of $B=1, w, w^{2}, \ldots$ with $0 \leqslant w<1$, however, the empirical device was adopted of fitting a cubic interpolating polynamial (14) to the error function if $B^{-}-1$ does not satisfy the criterion of Eq. (3-34). By re-evaluating $\varepsilon(x)$ and its gradient at the minimm of the interpolating polynomial, an estimate of the miniman of $\varepsilon(x)$ and its gradient there along the direction of search, Eq. (3-33), may be obtained; this strategy injects an elowent of independonce into the successive $\xi_{,}$, so improving the approximation $\underline{\hat{H}}^{-1}\left(\underline{X}_{K}\right)$ to $\underline{\mathrm{K}}^{-2}\left(\mathrm{X}_{\mathrm{K}}\right)$. Experience has show that usually the choice $\beta=1$ will be taken, hence the efficiency of the algorithm in requiring an average of very nearly one flunction and gradient evaluation per iteration. 
The, formula used in updating the matrix $\hat{\mathrm{H}}^{-1}(\underline{x})$ are two, namely,

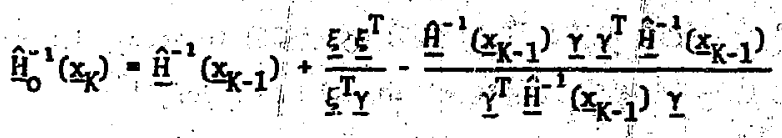

and,

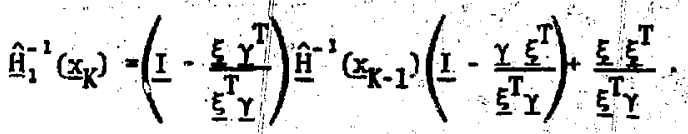

Equation (3-35) is that deduced bj Fletcher and Poiell; (15) Eq. (3-36) is derived frcm it by observing that Eq. $(3-35)$ obeys the equality $\underline{\hat{H}}^{-1}\left(x_{K}\right)_{Y}=\xi$. Then, solving Eq $(3-35)$ for an updating relation for $\hat{H}\left(x_{K}\right)$ which will hence force $\hat{H}\left(x_{K}\right) \xi_{Y}=Y$, and interchanging $\underline{Y}$ and $\underline{\xi}$ in the resulting expression leads directly to Eq. (3-36).

Both Eqs. (3-35) and $(3-36)$ are the extreno, penbers of a general class of updating formula generated by the scalar parameter $\varphi$ according to the convex relation,

$$
\hat{H}_{\varphi}^{-1}\left(x_{K}\right)=(1-\varphi) \hat{H}_{0}^{-1}\left(x_{K}\right)+\varphi \hat{H}_{1}^{-1}\left(x_{K}\right)
$$

Fletcher proves in his description of the updating method $(16)$ thet mabers of the class given by $\mathrm{Eq}_{\mathrm{H}}(3-37)$ possess the property that through their use, convergence in a certain sense of $\hat{\mathrm{H}}^{-1}$ to $\mathrm{H}^{-1}$ is assured through tendancy of the eigenvalues of $\hat{\mathrm{H}}^{-1}$ to those of $\mathrm{H}^{-1}$. 
In order to decuce a criterion for the choice on a particular iteration of using Eq. (3-35) or (3-36) to accomplish the updating of $\underline{\hat{H}}^{-1}$, it is useful to examine the relation, (17)

$$
\tilde{\hat{H}}_{\hat{K}}^{-1}\left(\underline{x}_{K}\right)=\underline{\hat{H}}^{-1}\left(\underline{x}_{K-1}\right)+\frac{\left(\underline{\xi}-\underline{\hat{H}}^{-1}\left(\underline{x}_{K-1}\right) \underline{Y}\right)\left(\underline{\xi}-\underline{\hat{H}}^{-\underline{2}}\left(\underline{x}_{K-1}\right) \underline{Y}\right)^{T}}{\underline{Y}^{T}\left(\underline{\xi}-\hat{H}^{-1}\left(\underline{x}_{K-1}\right) \underline{Y}\right)}
$$

This formula is in fact a menber of the class governed by Eq. (3-37), but with a parameter $\hat{\varphi}$ corresponding to $\varphi$ being given by,

$$
\hat{\varphi}=\frac{\underline{\xi}^{T} \underline{Y}}{\left(\underline{\xi}^{T} \underline{Y}-\underline{r}^{T} \hat{\hat{H}}^{-1}\left(x_{K-1}\right) \underline{Y}\right)}
$$

lor $\underline{E}^{\mathrm{T}} \underline{Y}$ strictly positive, a property guarainteed by Eq. (3-34), and with $\underline{\hat{H}}^{-1}$ positive definite, it is demonstrable that $\hat{\varphi}$ cannot lie in the closed interval $[0,1]$. Now, if $\underline{\xi}^{T}>\underline{\gamma}^{T} \hat{H}^{-i}\left(\underline{x}_{K-1}\right) \underline{\gamma}$, then $\hat{\varphi}>1$ hence use of Eq. (3-36) is proper, whereas if $\underline{\xi}^{T} \underline{Y}<\underline{\underline{Y}}^{\mathrm{T}} \underline{\hat{H}}^{-1}\left(\underline{x}_{K-1}\right) \underline{Y}$, then $\hat{\varphi}<0$ and so Eq. (3-35) should be used for updating $\underline{\hat{H}}^{-1}$.

$A$ means is needed of sensing when the pivinim of $\varepsilon(x)$ has been determined, hence use is ade of the fact that there the Euclidean norn : the gradient vector vanishes so that at the winimum $x_{0}$, $\left\|\partial\left(x_{0}\right) / \partial x\right\|=0$. In practice, convergence is assumed when $\left\|{ }^{\partial\left(x_{2}\right)} / \partial x\right\| \leq \varepsilon$, where $\varepsilon$ is a small number, and where $x_{a}$ denotes the upproximation to the minimm $x_{0}$ of $\varepsilon(x)$. 
As is the cese with wot multidinonitional mininization algorithes, comvergmice occurs wot rapidly when the eurfilce bolng traversed is fres of elengnted contours. In an effort to echivive this condition, the gradient vector is scaled to unity at comencent of minimization. By so doing, it we found that ss wch is a fivefold decrease in miber of iterstions roquired for comprence wis attained in comperisoif to the unscaled case. Let $\underline{z}$ be the square matrix hiving scale factors on the diagonal and zeroes elsewhere, and let $\underline{x}^{\prime}$ reprosant the vector of variabie paraneters so sciled as to case the initial gradient vector to be unity. Then, writing,

$$
\underline{x}=\underline{z}
$$

differentiation of both sidos of this equation followed by application of the chati-rule yields,

$$
\frac{\partial e\left(\underline{x}^{\prime}\right)}{\partial x^{\prime}}=z^{-2^{\partial \varepsilon}(x)} \frac{}{\partial x}
$$

The matrix $\underline{Z}$ is detornined so that the initial Iradient vector, $\partial c\left(x^{\prime}\right) / \partial x^{\prime}$ bocomes unity, whences:

$$
\underline{z}=\underline{1} \frac{\partial \varepsilon(\underline{x})}{\partial \underline{x}} \text {. }
$$

The theory described in the precedine porticus of this chepter has been translated into Fortriten IV code, and fors the basis of a digital computer progren especially dosigned for artomated nodelling. 
A full 1 isting of the code forms the subject of Appendix B, and containod in Appendix $A$ are ingtructions for use of the progran.

In order to maxinize the efficiency of the error-furiction and gradient conputation section of the program, use has been made of sparse-matrix techniques in the solution of nodal equations, The nonzero structure of the nadjal adtance matrix is reconded by a pointer systew, and the bodal equations are then reordered by an algorithn (18) wich seeks to minimize the riber of aditional non-zero entries introduced into the adaittence metrix by the process of decomosing it into the product of a lower triengular mintrix having ones on the diagonal and zeroes above, and an uper triangular matrix having zeroes above the dingonal. $(19,20)$ Froin these tho matrices, a sequatice of fcrward substitution followed by back substiturion is exployed to solve for nodal potentials. Purther coputational efficiency is realized by maing use of the fact that the nodal advittance matrix of the adjoint notwork is the transpose of that for the original network, hence only. one docomposition of the adrittance matrix is required per frequency point, (21)

Storage spece is economized in the minimization routine by storing only the uppor portion of the inverse fiossian matrix; this is possible owing to the nuorical symetry of the matrix.

Figure (3-3) gives a simple flow-chart of progran cperation. Input data cards are read in free-fonmat by a routine (22) called by the wain progran, which then passes control to the sparse-matrix and 
pointer set-up subprogrums, whereupon the mininization routine is imoled and repeatedly calls a subroutine to evalinte the error function and its gradient. Final element values are printed upor conclusion of the mintinization, and exceution is termineted. Error traps are incorporated to catch elementary faults in input data, thereby avolding possible wastes of progran tjoc arising from faulty or inproperly specified paranoters. 


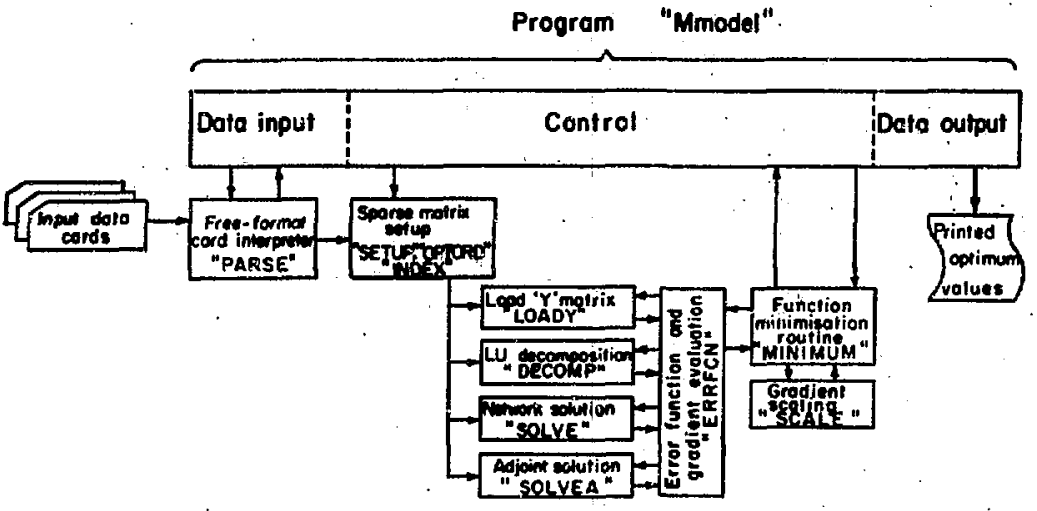

Fig. 3-3 


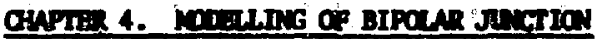

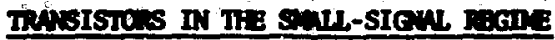

The use of modolling techniques in the desion of circuits enployIng bipolar junction trasisters is dictated by the necessity of obtaining an malytically tractbio representation of a device charicterized by the solutions to rather coplex partial differential equations. The ectunl choice of nodol configurntion and degree of coplexity is a conprouise between several factors. In particular, the caplexity of the modil is hervily dependent upon the sccuracy expected of it, wherees its conficuration is governed by the nothork structure required to siminte the physical phenome repponsible foir transistor operation.. Those two considerations are, of course, interdependent, so that the optiml equivalent cincuit would be one so contrived as to yield maxianl accuracy and yet requitre it ninima nuber of elements in its realization.

It is carrenient in dertsing wodel for the bipolar junction transistor or, for that attor, for any physically realized dovice, to partition the wodel into to companents.

The prinary or intrinsic portion of the bodal eccounts for the physical processes directly rosponsible for device oporntion. Additional to this are those wodel elements necessary to describe spurious parasitic offects extermm to the active repion of the device.

The model adopted to charecterize the bipolar junction transistor for the purposes of the worik described in this peper is the 'mbrid-pi' conflguration to which a delay oprrator $a^{-j w T}$ has been added to the 
voltag-controlled carmunt source in order to account for the effects of phas-shift throun the divice curied by poles mon-doninent relative to the cisto tho initial 20 d/dacade fall in foriand current tronsfor ratio. Since the effective lonis inpeed upon the device by the type of circuits treated here are of the oriar of $100 \mathrm{a}$, ad ihereas the derice output resistence is componly of the oridr of thouserids of chis, no sccount has been token of cutput resistance arister from bese-width molulation effects. The ipportint extrinsic elements of the molal are the tao incuctences in the Ibase' and 'enitter' leais of the hybrid-pi circuits; these reactmoes art Included to simlate the inductive effects of tive to bonding leads noceswary to whe consection betwen the tromistor chip sing characterized and the trumbission line of the tert fixture. Fibure (4-1) shows the coplete nodil.

For the hybrid-pi model, certain of the alenents cen be estinted an the besis of comonly wailsble informetion, as follous: (23)

$$
\begin{aligned}
& \text { - }-q / I_{c} / / x \\
& x_{T}=B_{F}(0) / / 2 \\
& c_{\pi}-\frac{\pi}{2 \pi f_{T}}-c_{\mu}
\end{aligned}
$$

In the ebrve equation, I represents the quiescent device coliector current, $B_{F}(0)$ the static formand current traser ratio, and $f_{T}$ the bota transition fruquary. The physical consturts $q, k$, and $T$ denote, reopectively the electroxic chare, Boltran's contant, and rolvin topprature. Tho reminins

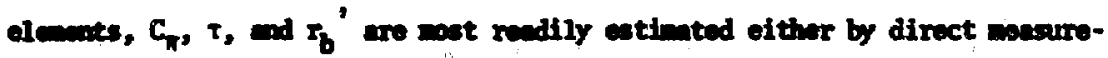

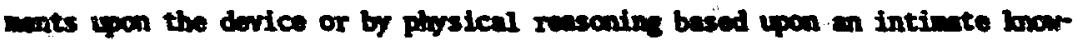
1ats of the dovico contruction, but in this work en initial guss wes ade of them values on the basis of pruvices experience with hifh-frequency devices. 


\section{$-39$.}

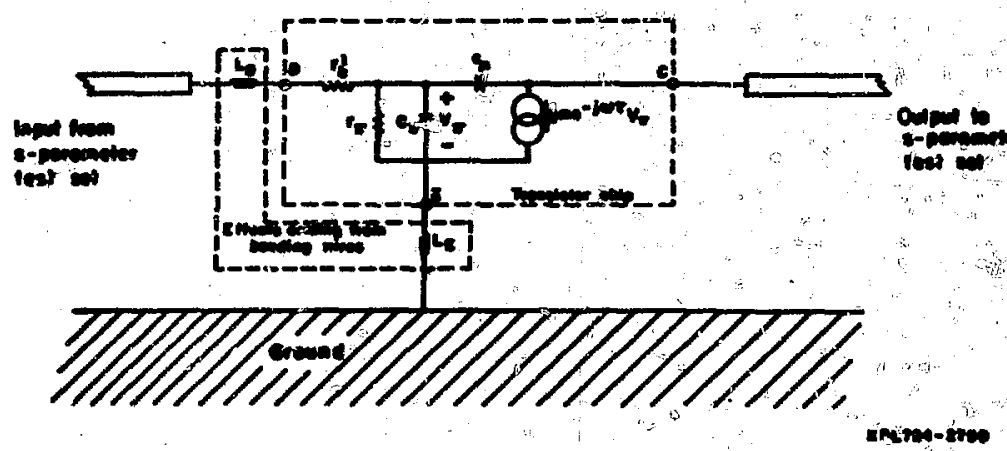

Ir. 4-1 
The transistor chip type $F$ PA $35820-A_{,}{ }^{(24)}$ monufactured by the Heriett-Packard Conpuny Merowave Division, was chosen for the applifier doscribed here for the reasons to be outlined in Chapter 5 , and the opprating point was elocted to be $I_{c}=10 \mathrm{~m}$ and $V_{C E} \neq 5$ V. On this besis, estimtes can be calculated for $z_{n}, r_{n}$ and $C_{n}$ using the knowiedge thit $B_{F}(0) \approx 35$ and $f_{T}=4$ Giz. Therefore, $=0.38 \Omega^{-1}, r_{\pi}=100 \Omega$, and

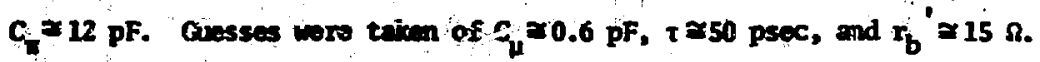
Th. wodiline progrim rofined those valuos to gn $=0.3458 \mathrm{\Omega}, \tau_{\pi}=96.45 \mathrm{\Omega}$, $C_{\mathrm{T}}=14.87 \mathrm{pF}, \mathrm{C}_{\mu}=0.5253 \mathrm{pF}, \mathrm{T}=20.33 \mathrm{psec}$, and $x_{b}^{0}=9.46 \Omega$.

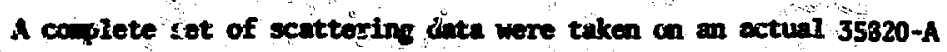
Citp in the comon-enittor configurution using a howlett-Packard Type m45A ycattering perreoter test set, Type s405s Vector woltweter, and Tpe inooe tromistor twat fixture, (25) This equipunt provides a corvaliant realization of the basic masument arragedent of Fig. (2-2). Disa werv tekm at $m$ operating point of $10 \mathrm{~m}$ and for $\mathrm{V}_{\mathrm{CE}}$ of $+3,+5$, and $+8 \mathrm{~V}$ at frequencies $50,75,100,200,400,600$, and $800 \mathrm{MHz}$; the data taken fir $V_{C E}=+5 V$ are plotted in polar form in Figs. (4-2) therainh (4-5).

In onder to single out the wo perasitic inductances of Fig. (4-1) frow further considoration durine the wdolling process, a set of scattering intrices were mosured at froquencies $200,406,600,800$, ad $1000 \mathrm{Htz}$ for the chip-to-teat-fixture bonding lowds. These data won provided to the automted podalling progrem togethex with estimates of 1.5 uH for canch inductance, a topological description of the ' $L$ ' of Inductances rosultin after the transistor chip hed boen short-circuited, and a set of weights set unifonly to unity. The refined values roturnod by the progrom wore $L_{E}=1.345$ at and $L_{B}=1.763$ nH. 


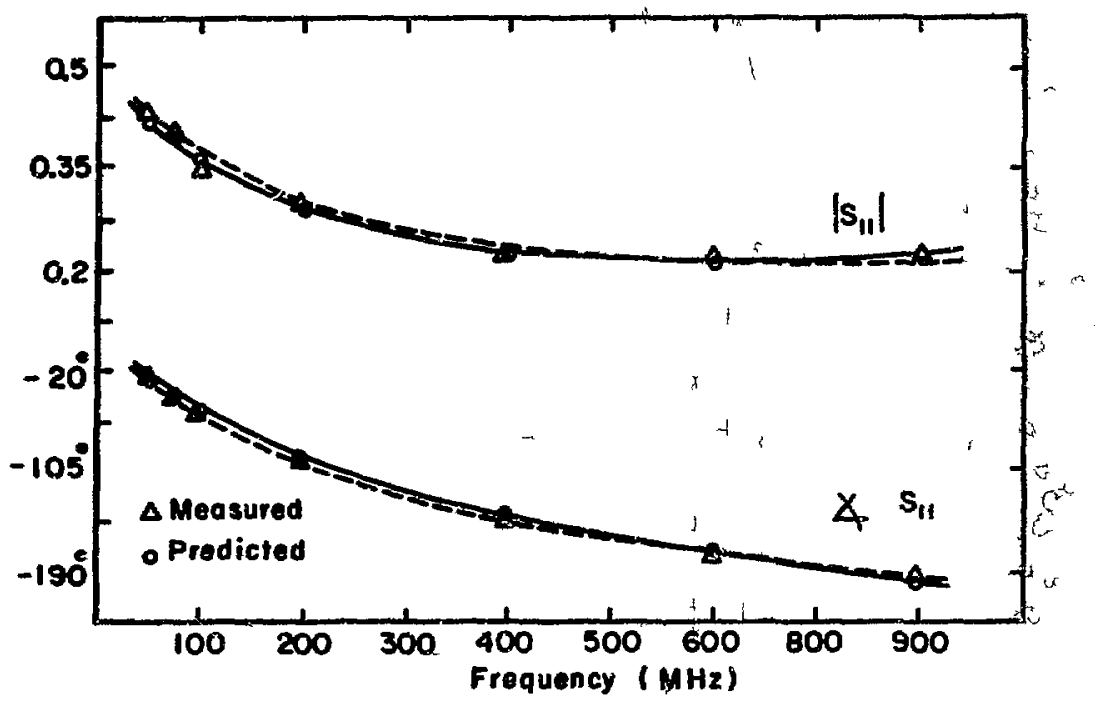

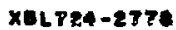

Fig. 4-2 


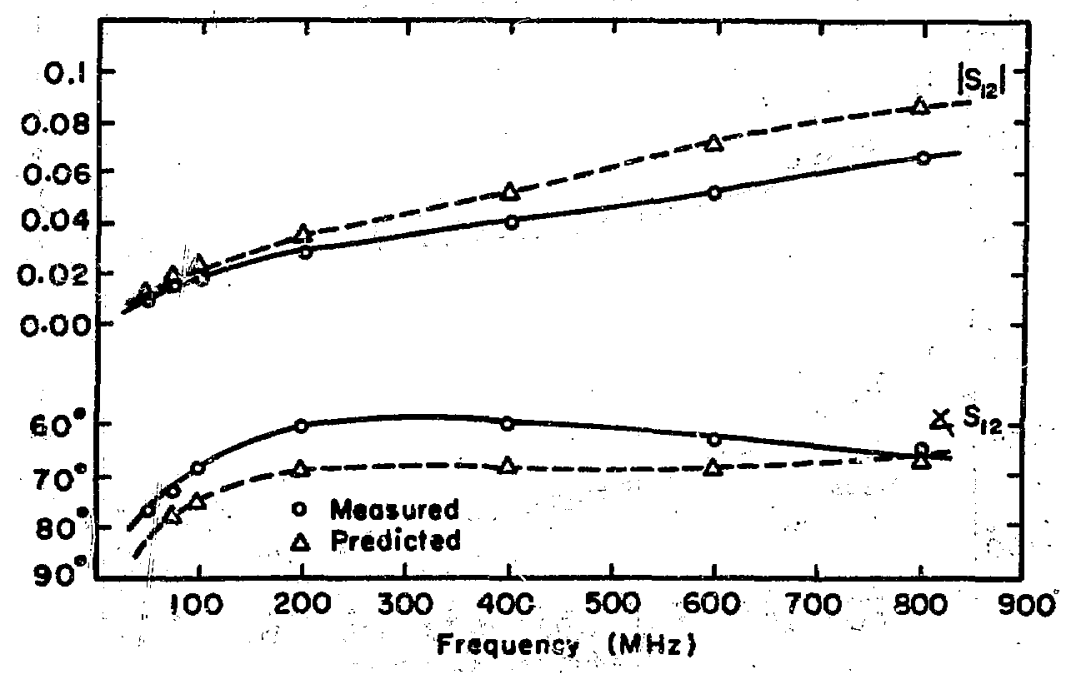

X ELT24-277T

Fig. 4-3 


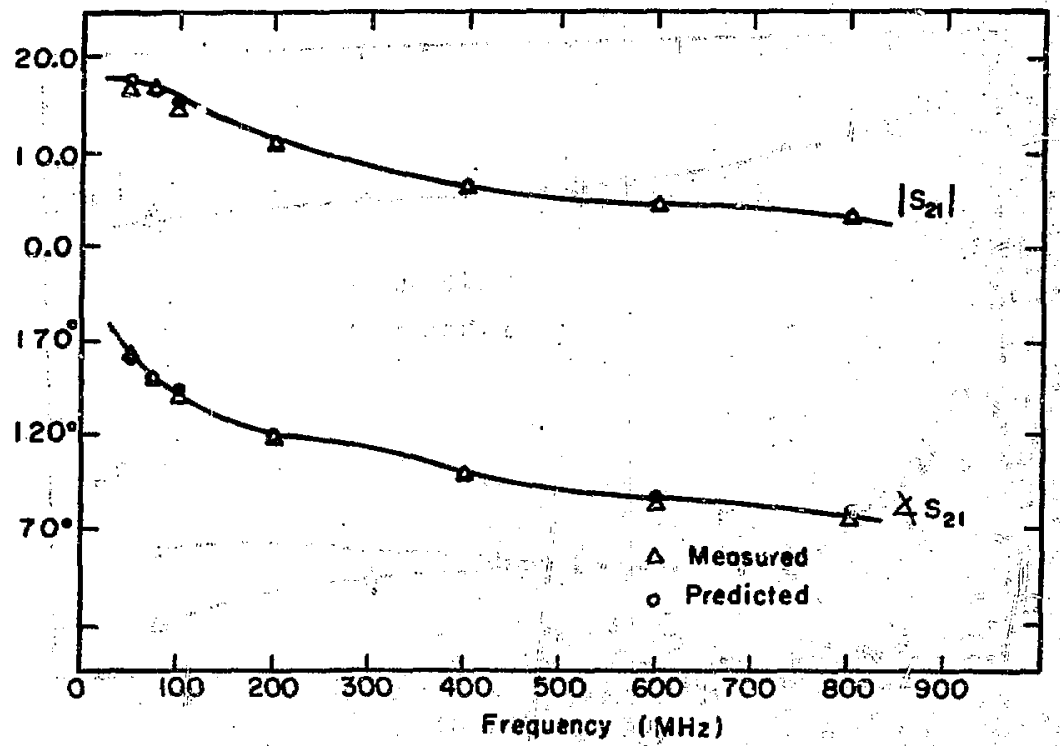

xEL724-2776

Fig. 4-4 
$-44=$

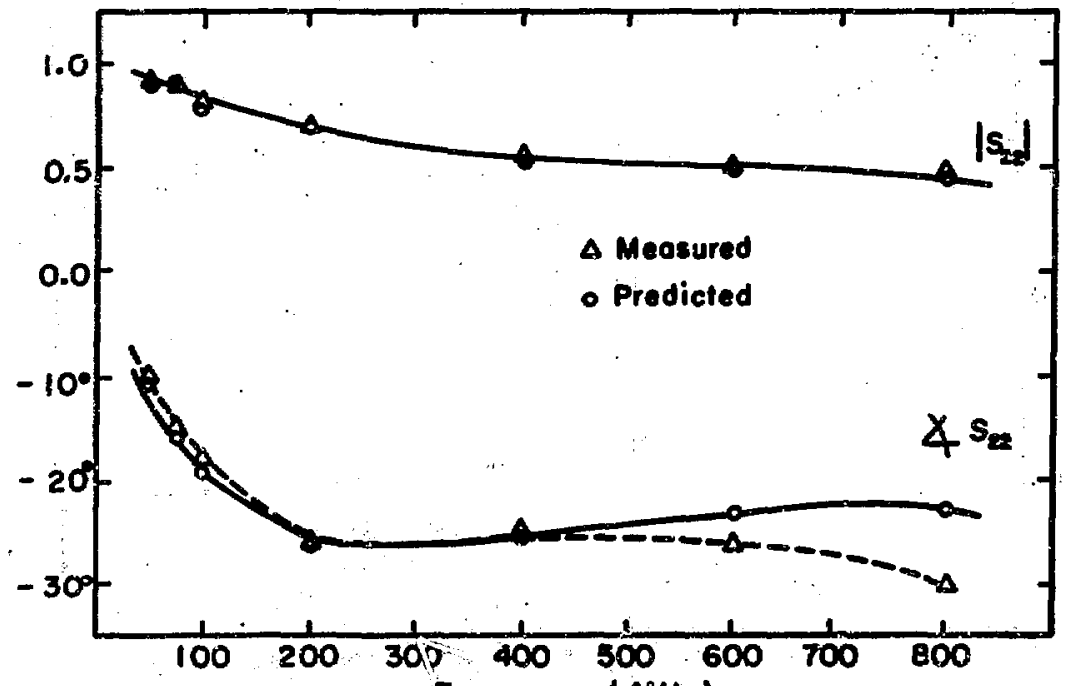

Frequency ( $\mathrm{MHz})$.

xOL7e4-2701

Fig. 4-5 
The actual modoling of the chip was accouplished by entering the topology of the complete cirait of Fig. (4-1) into the modelling program. Also included were the estinates already given for the values of the elements in the hybrid-pi model and the valus calculated previously by the progren for $L_{E}$ and $L_{B}$. The optinization was done simultaneously os the parcieters $r_{b}, r_{\pi}, c_{\pi}, c_{p}, g$, and $t$. Since $s_{11}$ and $s_{21}$ are most important in untaned wideband aplifier work, weight factors of $15,10,1$, and 4 were chosen for $s_{11}, s_{12}, s_{21}$, ind $s_{22}$, respectively. The parasoter values in the hybrid-pi wodel resulting from use of the progran are plotted in Figs. (4-6) through (4-11) for the device operating point $I_{C}=10 \mathrm{wA}$ and $v_{C C}=3,5$, and $8 \mathrm{~V}$.

Two tests were done on the nodol detemined in this way for the 35820-A transistor chip in a effort to check its validity. The first was to see if certain trends, predictoble on the basis of qualitative physical reasoning, could bo discernod in the model paraneters. of expeciul interest in this respect are the plots of $r_{b}{ }^{\prime}$ and $C_{\mu}$ versus $V_{C E}$ given in Figs. (4-6) and (4-9). Bvident in the latter plot is the decrease of $\mathrm{C}_{\boldsymbol{u}}$ with incressing collector-base vitage, in effect predicted by the thind-pown 1aw relating eradad function dapletion-1ayer crpecitince to juction, averse bias. Apparent ulso in the plot of $\mathbf{r}_{b}^{\prime}$ versis $v_{C E}$ is the 1,ise of $r_{b}^{\prime}$ with increasing $v_{C E}$ de to the fact

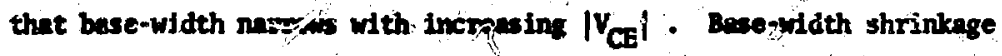
caves the rise in $x_{b}{ }^{\prime}$ oring to the consequent langthening of the path from the base contect pad to the sctive reign of the base: 
$-46-$

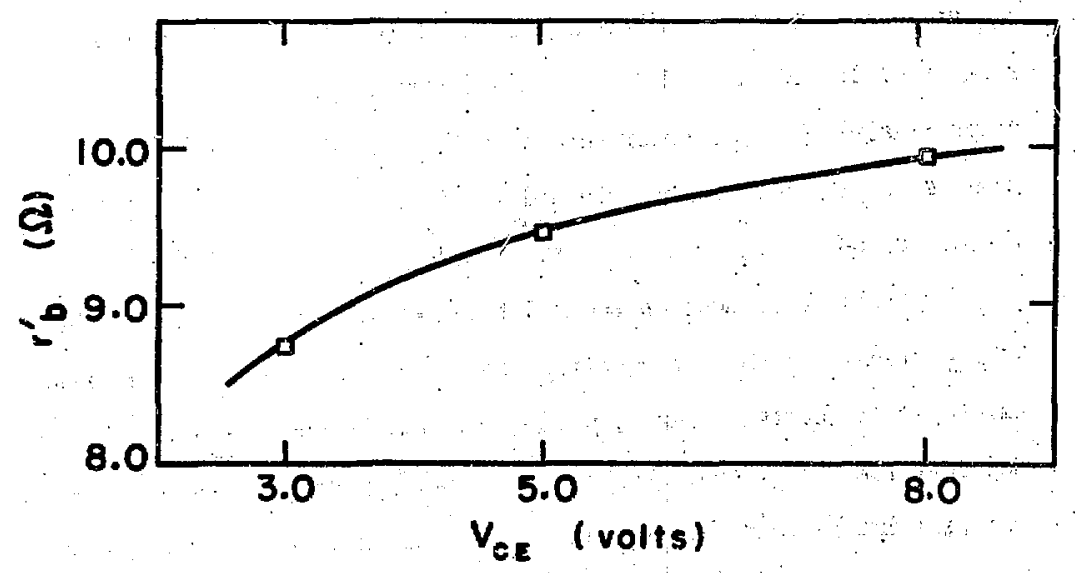

xอL724-2792

Fig. $1-6$ 


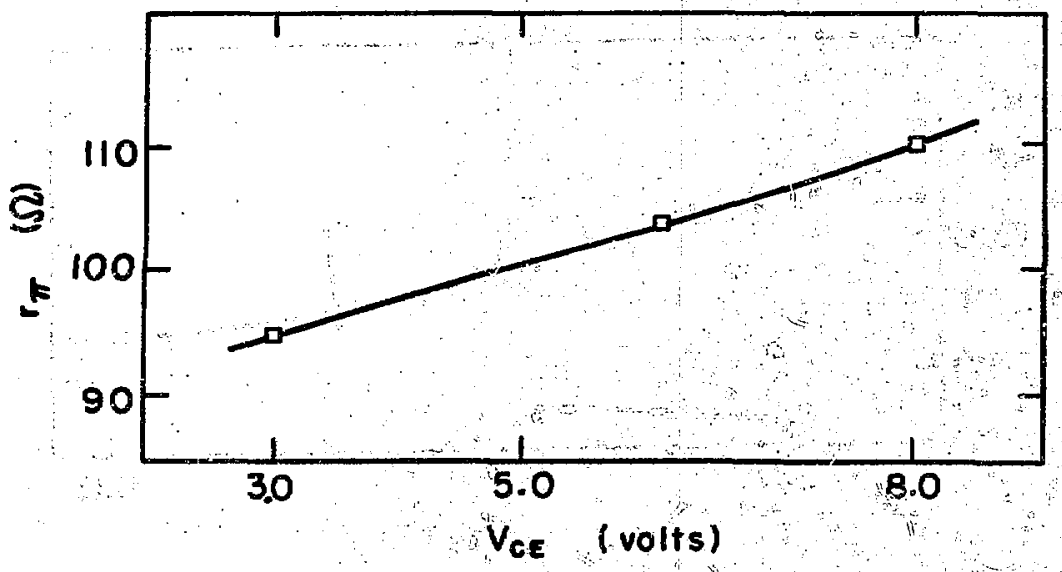

\section{$x B L 724-2783$}

Fig. 4-7

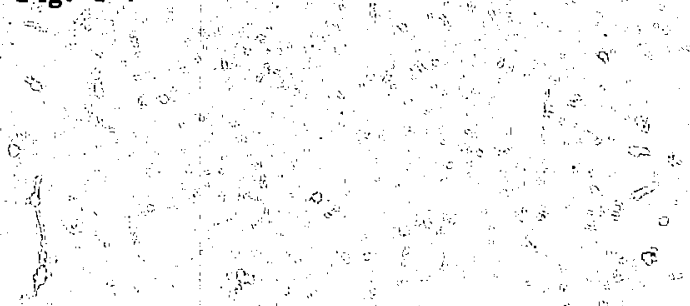


$-48-$

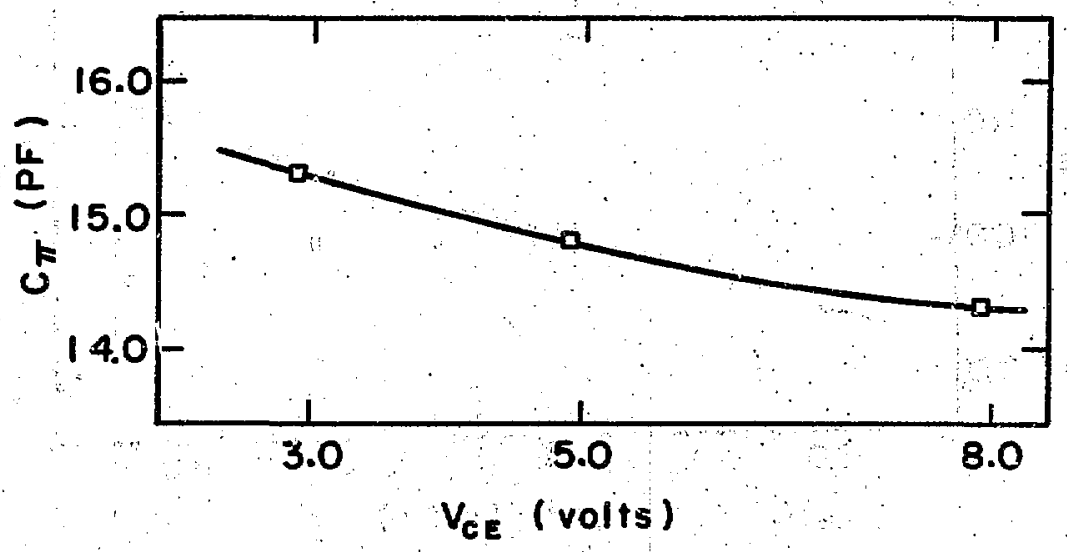

XBLT24-2784

Fig. 4-8 


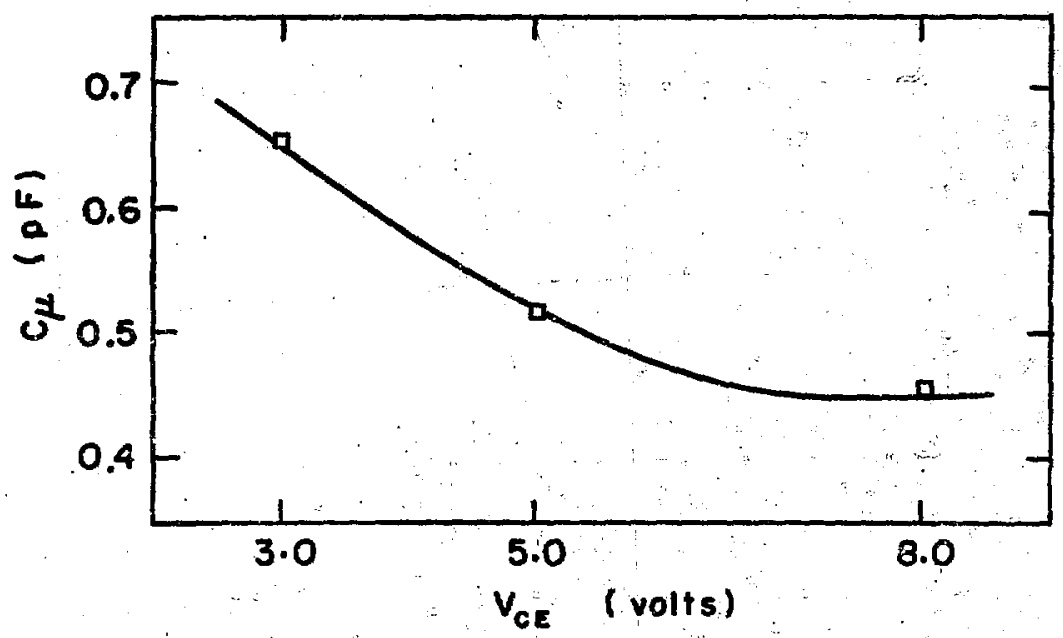

KDL724-2795

Fig. 4-9 
$-50-$

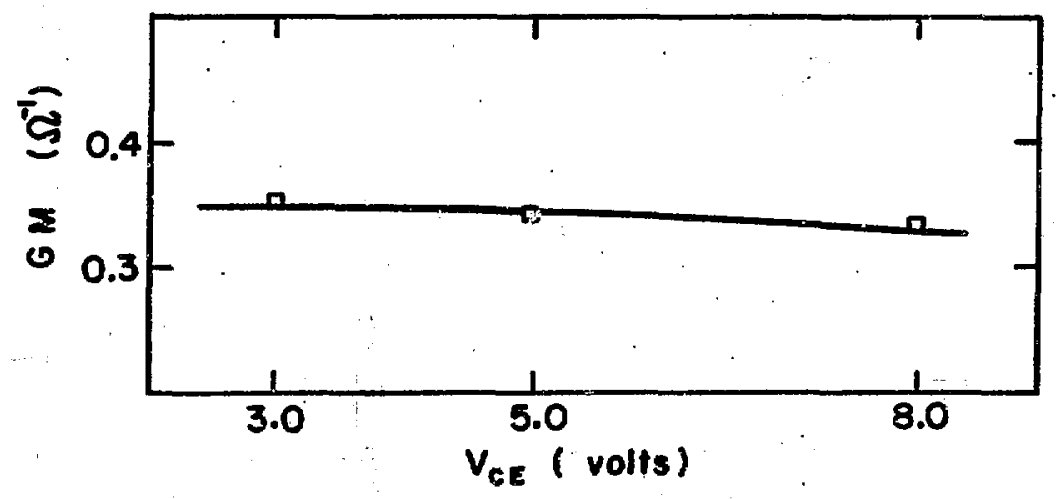

XEL724-2706

Fig. 4-10 
$-51$

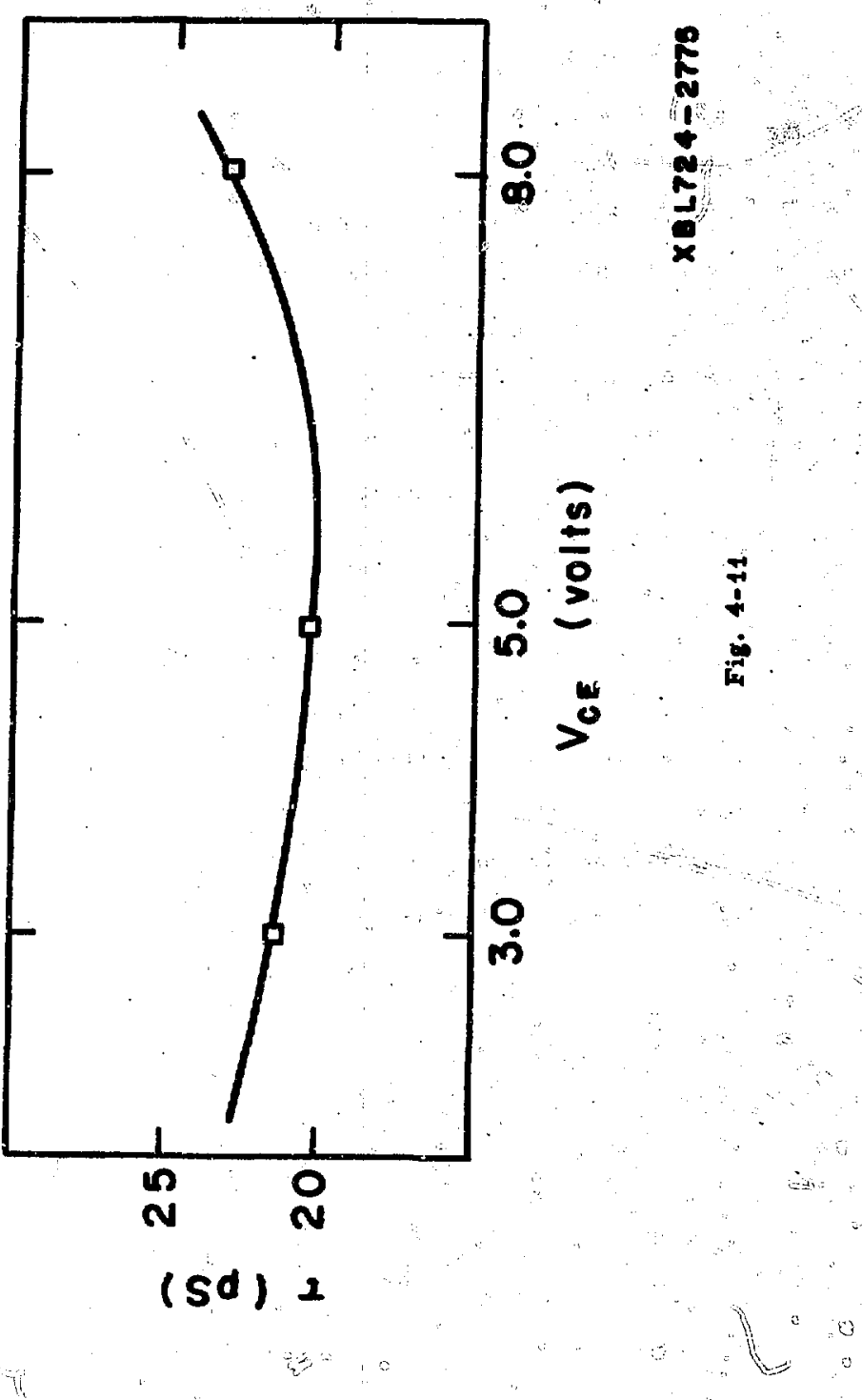


The second, and by far the wore drantic, verification wide of the efficacy of the model, was to work backwinds end calculate the scattorine peraupters of tho equivalent circuit of Fig. (4-1) and congre these with those moasured on the actual dovice. This was done for all three values of $V_{C E}$ used in biasing the transistor, and the rosults in the three cases wre rouhly equivalent; those for the case of $Y_{C E}=5 Y$ are plotted in Figs . (4-2) through (4-5). along with the experimentally determined data, and it will be seen that the fit is axcellewt. The effect of the prodominont weighting accorded to $s_{21}$ and $s_{21}$ is aparent in the virtanily parfect fit of these two parameters at the exponse of slight ingccuracies in the fits of $s_{12}$ and $s_{22}$.

It seces likely that with fyprovents in experiwental procedure the fit of the model could be inproved, since undor measurenent techniques wore refined then those ued here, the effects of spurious reactmees could be groatly reduced. In any esent, all the benefits hoped for in eutomed modalling heve been realized, and it should be cbrias that the techniques used here can be readily axtended to the characterization of other linear alencats on the basis of scattering dite. 


\section{CHAPTER 5. DESIGN CF A FAST-RISE SERIES-SHNII PAIR}

The series-shumt feedback pair to be dealt with jn this chapter has been designed with a view towards satisfying the risetime ( $\$ 500$ ps) and gain (20 dB) requirements set dan in Gopter 1 . Additionally, it is desirable that the aplifier possess the ability to operate within the context of a $50 \mathrm{i}$ systea, and to this, end a receiving and termination of appropriate value has been incorporated into the design. The circuit of the aplifier is the subject of Fig. 5,1

Hewlett-Packand Type HPA 35820-A NPN transisciors were chosen for this design because they possess a unique compination of several highly

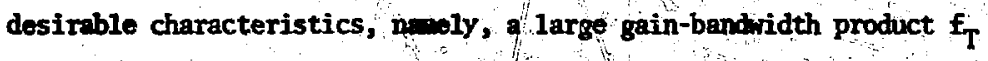
of 4 atz, the capability of handiing substantial collector current of up to $45 \mathrm{~mA}$, and an extrenely low base spreading resistance of appooxinately 10 8. Annther transistor, the Hotorola iN-4049, was investigated as a possible candidate for a PNP complewent to the HPA $35820-\mathrm{A}$, but it was found to suffer the severe disadventage of having a bese spreading resistence in excess of $80 \mathrm{\Omega}$. The gain-bandwidth product is optim in the HPA 35820-A for collector currents of 10-20, $\mathrm{m}$, hence the biassing arrangement enployed in the aplifier is designed to insure standing currents in both transistors of $10 \mathrm{AA}$. In the case of the output trensistor, since the mlifier works into $50 \Omega$ cable, a maxima per-

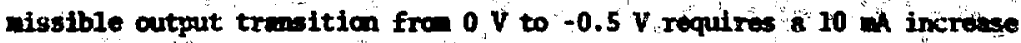
In collector curnat, and it is pparant that provified this linit on cutpirt swing is not exceedod, the second transistor operntes in a 
state guaranteeing maximum $f_{T^{*}}$ Small-signal fluctuations in collector current of the first transistor are considerably less than those in the output stage, so that the first stage is a.so optimally biassed with a $10 \mathrm{~mA}$ collector current. A quiescent value of about $5 \mathrm{~V}$ was arbitrarily set for the $\mathrm{V}_{\mathrm{CE}}$ of both transistors in order to effect a compromise between power dissipation on the one hand, and the desirability of minimizing the $V_{C B}$-dependent collector-base depletion layer capacitance, on the other.

Under these operating conditions, the small-signal medel of the transisturs is that found by the method of Chapter 4, and use of this equivalent circuit in the appropriate locations in Fig. (5-1) enables the entire amplifier to be characterized for small-signal operation as shown in Fig. (5-2). Analysis of the resulting amplifier model is best undertaken with the aid of a digital computer; use thereof enables many of the approximations essential to manual analysis to be dispensed with, giving a consequent increase of accuracy. Since the ulinate criteria of amplifier performance are to be assessed in the time-domain, the pole-zero approach was adopted for the analysis owing to the intimate relation existing beiween complex-plane singularities and transient behaviour. Initially, the pole-zero computation program, "Frank"(26) was used for these calculations, and no account was taken of parasitic elements or of the excess-phase of transistors. Therefore, these elements are not shown in Fig. (5-2), but they will be re-introduced later in the design procese, so that the final circuit simulations are an accurate reflection of trie circuit performance. 
$-55-$

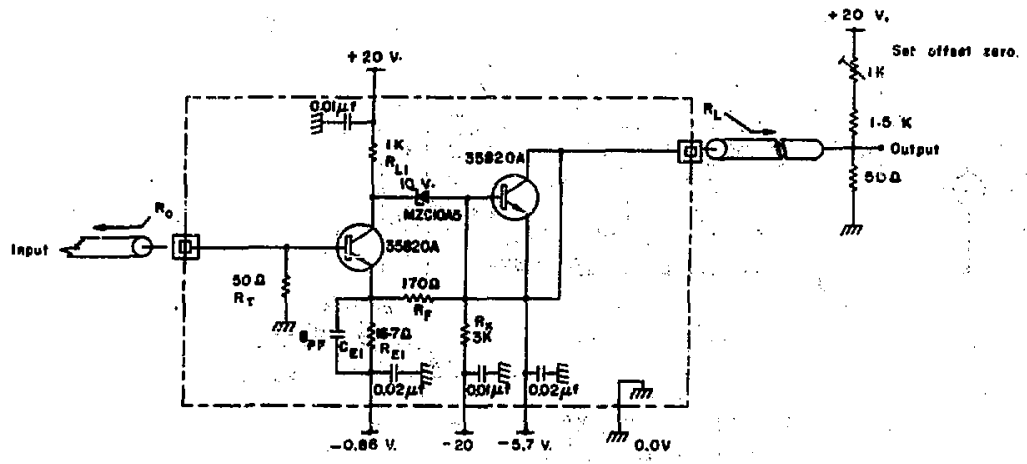

XOL 724-2004

Fig. 5-1 
$-56-$

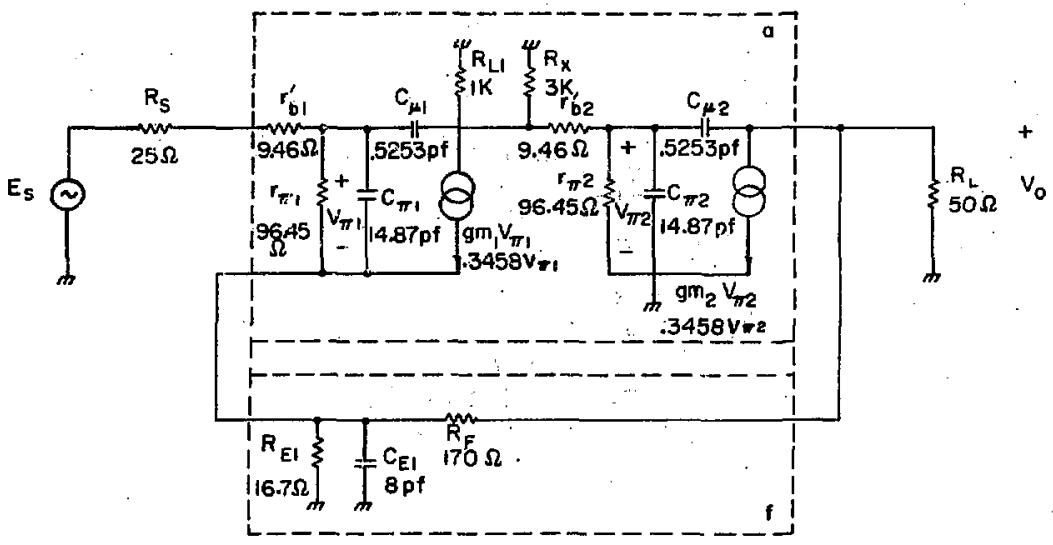

X日L 724-2802

Fig. 5-2 
The resistor $R_{S}$ of Fig. (5-2) replaces the transmission-1ine characteristic impedance and the line terminating resistor of Fig. (5-1) in accordance with the relation,

$$
R_{S}=R_{0} R_{T} /\left(R_{0}+R_{T}\right)
$$

Capacitor $C_{E 1}$ is incorporated into the circuit for reasons of frequencyresponse compensation, and a discussion will be given later regarding the deternination of an appropriate value for it.

The series-shunt feedback configuration may be regarded as an interconnection of two two-port networks; the partition of the overall circuit into a forward gain path $a_{v}(s)$ and a feedback network $f(s)$ is show symbolically in the Fig. (5-2). It should be apparent that the hybrid-basis two-port matrices are the ppropriate ones to use in this situation. Identification of $a(s)$ and $f(s)$ is therefore easily made, and the circuits pertinent to the computation of these transfer functions are given as Fig. $(5-3 a)$ and $(5-3 b)$, respectively.

Using the pole-zero analysis program "Frank", the open-loop gain transfer function $a_{v}(s)$ of the amplifier was found to be,

$$
a_{v}(s)=\frac{v_{0}(s)}{E_{s}(s)}=\frac{\prod_{k=1}^{4}\left(1-s / z_{a k}\right)}{\prod_{i=1}^{6}\left(1-s / P_{a i}\right)} \cdot a_{v}(0)
$$




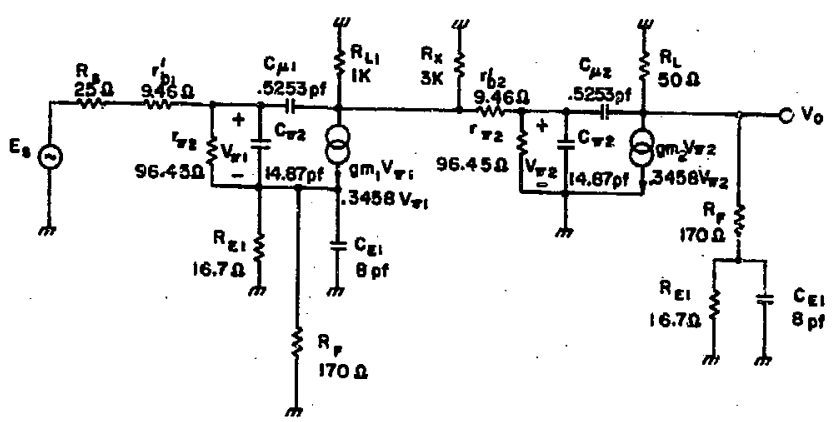

(a)

Circuit for open-loop goin calculations

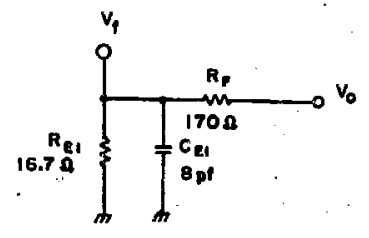

(b)

\section{Circuit for feedback network transfer function}

$\times 8 L 724-2810$

Fig. 5-3 
where,

$$
\begin{array}{ll}
P_{a_{1}}=-43 \times 10^{7}, & z_{a 1}=-82.2 \times 10^{8}, \\
P_{a 2}=-73.76 \times 10^{8}-562.2 \times 10^{8}, & z_{a 2}=-85.88 \times 10^{8}, \\
P_{a 3}=-73.76 \times 10^{8}+j 62.2 \times 10^{8}, & z_{a 3}=22.0 \times 10^{10}, \\
P_{a_{4}}=-80.9 \times 10^{8}, & z_{a_{4}}=65.83 \times 10^{10}, \\
P_{a 5}=-73.95 \times 10^{9}, & \text { and, } \\
P_{a 6}=-25.24 \times 10^{10}, & a_{v}(0)=67.1
\end{array}
$$

For practical purposes, since the response of the amplifier is of interest only for frequencies below about two gigahertz, or 12.56 $x 10^{9} \mathrm{rad} / \mathrm{sec}$, a simplification of Eq. $(5-2)$ can be made oil the basis of retaining only those singularities dominant in their influence upon $a_{v}(s)$ in that band. Therefore, to good approximation, Bq. (5-2) can be recast as,

$$
a_{v}(s)=\frac{\prod_{k=1}^{2}\left(1-s / z_{a_{k}}\right)}{\prod_{i=1}^{4}\left(1-s / p_{a i}\right)} \cdot a_{v}(0)
$$

The poles and zeroes in this equation are identical to their correspondants in Eq. (5-2).

The transfer finction of the feedback network is easily calculable analytically through consideration of the circiit of Fig. $(5-3 b)$, whence it is seen to be a single pole function of foim,

$$
f(s)=\frac{v_{f}(s)}{V_{0}(s)}=\frac{f(o)}{1-s / P_{f}}
$$


where $f(0)=-R_{E 1} /\left(R_{E 1}+R_{F}\right)$ and $P_{f}=-\left(R_{E 1}+R_{F}\right) /\left(C_{E 1} R_{E 1} R_{F}\right)$. For the values of $R_{E 1}, R_{P}$ and $C_{E 1}$ used here, $P_{f}=82.6 \times 10^{8}$. The standard feedback formula, namely.

$$
A_{v}(s)=\frac{a_{v}(s)}{1-a_{v}(s) f(s)},
$$

can now be applied to relate closed-loop gain $A_{y}(s)$ to the amplifier and feechack network transfer fumctions.

Proceeding first in the low-frequency case in the limit as $s+0$, substitution into Eq. (5-5) of the 10w-frequency analogues of Eqs. (5-3) and (5-4) and solution of the resulting formula for $R_{F}$ enables Eq. (5-6) to be deduced.

$$
R_{F}=R_{E 1} \cdot \frac{a_{V}(0)-A_{V}(0)-a_{V}(0) A_{V}(0)}{A_{V}(0)-a_{V}(0)}
$$

Through the intermediary of this relation, a value of $\mathrm{R}_{\mathrm{F}}$ can be calculated appropriate to give the $20 \mathrm{~dB}$ gain figure $A_{V}(0)=10$. Note thiat this calculation must be done iteratuely, for in fact $a_{V}(0)$ is depentent upon the value of $R_{1}$ as is evident from corsideration of Fig. (5-3a). The iterative cycle comenced with an estinate for $R_{F}$ of $150 \Omega$, whereupon convergence of the process led to value tor $R_{F}$ of $170 \Omega$

Analytic determination of a suitable value for $C_{g 1}$ would conmence with maliiplication of Eq. (5-5) by the Laplace transfoun of the Heaviside unit step function, followed by expansion of the resultant product 
into partial fractions and the application of the laplace inversion integral to effect a transformation of the response into the timedomain. From the expression obtained in this way, formula can be deduced relating $C_{E 1}$ to rise-time and overshoot. The ultimate objective is minimization of rise-time to a degree commensurate with the restriction that overshoot not exceed ten per cent.

The algebra involved in these computations is exceptionally lengthy and irvolves in several instances the solution of conplicated transcendental equations, a task most efficiently done iteratively using a conputer. For these reasons, it was decided to use the computer from the start and to adopt the rather empiricai approach of variation of $C_{E 1}$ followed by pole-zero, analysis of the closed-loop model of Fig. (5-2).

Direct substitution into Eq. (5-5) of Eqs. (5-3) and (5-4) and algebraic rearrangement yields,

$$
\begin{aligned}
& a_{V}(0) \prod_{k=1}^{2}\left(1-\frac{1}{1} / a_{k}\right)
\end{aligned}
$$

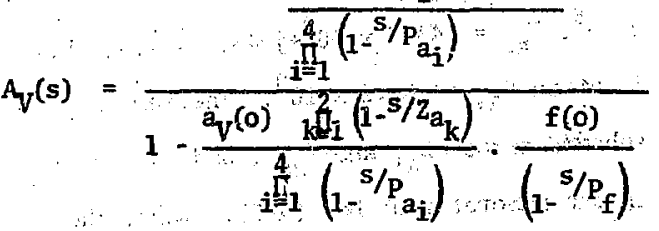

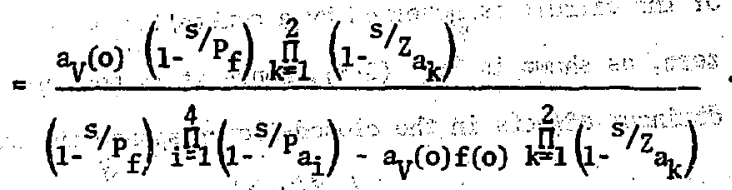


Equation $(5-7)$ indicates the fact that by variaton of $\mathrm{C}_{\mathrm{E} 1}$, and hence of $F_{f}$, the position of the closed-loop poles of the amplifier can be altered. It is notable that besides appearing in both numerator and denominator of $\mathrm{Eq}$. (5-7) through $\mathrm{P}_{\mathrm{f}}$, capacitor $\mathrm{C}_{\mathrm{E} 1}$ also gives rise to zero $z_{a 1}$ in the open-10op amplifier response $a_{v}(s)$ because of its interaction with the equivalent enitter resistance $R_{E 1} R_{F} /\left(R_{E 1}+R_{F}\right)$ of the inpur transistor. This is an elementary consequence of the fact that a comnon-enitter stage with a simple parallel R-C network in its emitter lead has a zero lying at 1/RC.

A plot of the trajectory of the roots of the denominator of Eq. $(5-7)$ as $a v(0) f(0)$ is varied ${ }^{(27)}$ is the subject of Fig. $(5-4)$. The circles and $x$ 's represent zeroes and poles, respectively, of the quantity $a_{v}(s) f(s)$, whereas the boxes denote the location of the closed-1oop zeroes of $1+a_{v}(s) f(s)$; which are hence the poles of $A_{v}(s)$.

Under influence of the quantity $a_{v}(0) f(0)$, the camplex pair of poles of $a_{y}(s), P_{a 2}$ and $p_{23}$, is disp aced to the location $P_{A 1}=-43.3 x$ $10^{8}-\mathrm{j} 48.2 \times 10^{8}, \mathrm{P}_{\mathrm{A} 2}=-43.3^{4} \times 10^{8}+\mathrm{j} 48.2 \times 10^{8}$, whereas $\mathrm{P}_{\mathrm{al}}$ is forced out to the location $P_{A 9}=-662 \times 10^{8}$. The remiaing foles $P_{a 4}$ and $P_{f}$ completely subsume zeroes $Z_{a 1}$ and $Z_{a 2}$ ? and so cancel these same quantities in the numerator of Eq. $(5-7)$. Thus, the closed-10op response of the circuit is governed by a constellation of three poles and one zero, as shown in Pig. (5-5), hence it is possible to write for the dominant effects in the closed loop response the expression,

$$
A_{V}(s)=\frac{A_{V}(0)\left(i^{s / P_{A}}\right)}{\prod_{k=1}^{3}\left(1^{s / P_{A K}}\right)}
$$




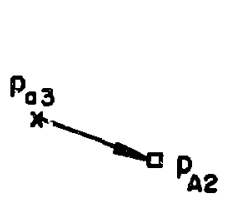

jw
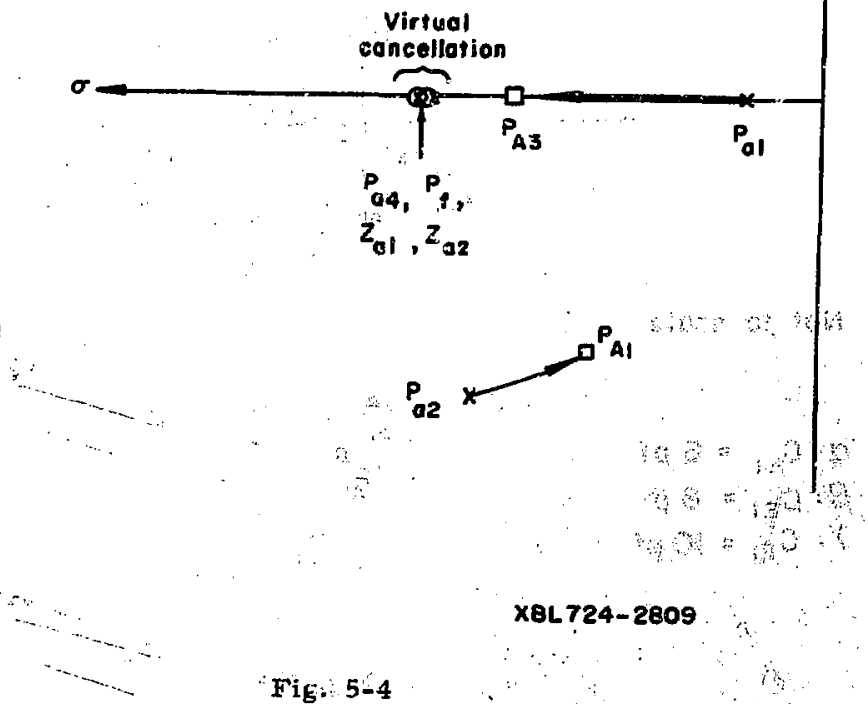

XEL724-2809

Fig: 5-4 


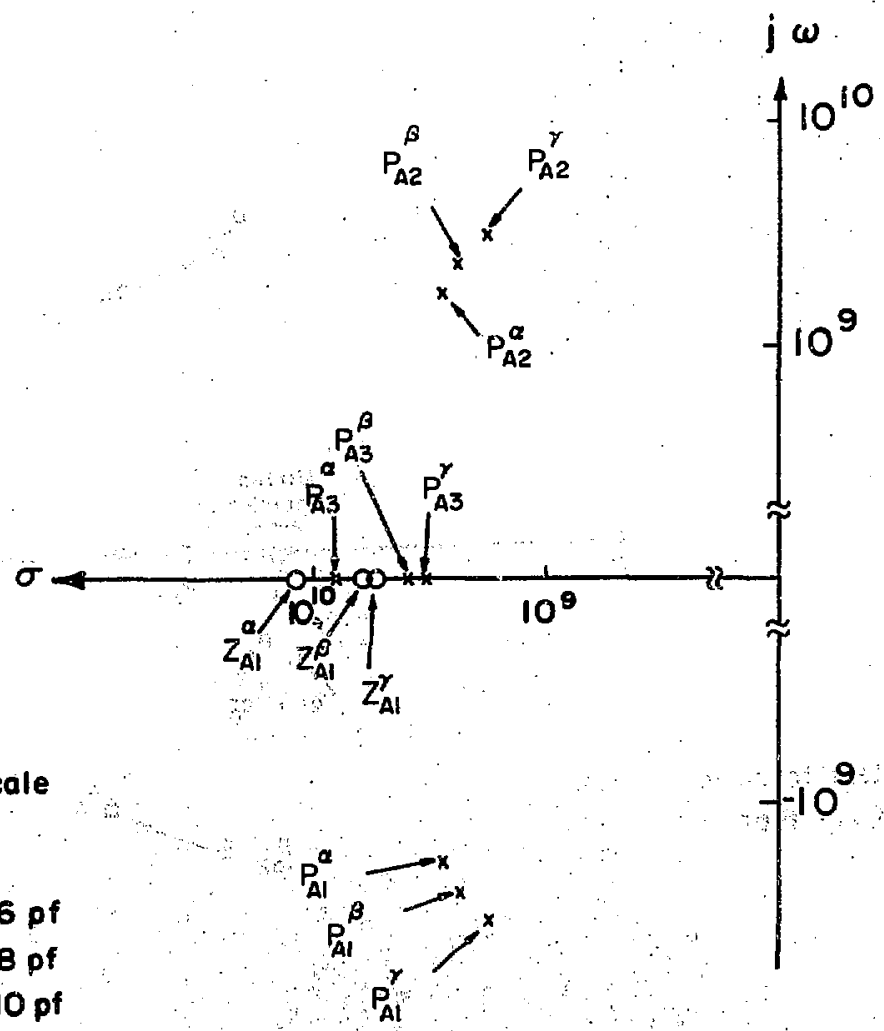

$\alpha: C_{E !}=6 p f$ $\beta: c_{E I}=B$ pf $\gamma: C_{E I}=10$ pf

Fig, $5-5$ 
The value of $\mathrm{C}_{\mathrm{El}}$ adopted in the design of $\mathrm{C}_{\mathrm{El}}=8 \mathrm{pF}$ is that required to pleco the closed loop complex poles of $A_{f}(s)$ on nearly the $45^{\circ}$ radials; this positioning yields optimal transient response. (28) Larger values of $\mathrm{C}_{\mathrm{E} 1}$ cause undesirable post- and pre-transition oscillation in the transient response, whereas smaller values leave opportunity for risetime improvenent through the introduction of a tólerable amount of overshoot in the response:

Show also in Fig. (5-5) are the closed-10op singularity locations for values of $C_{E 1}=6 \mathrm{pF}$ and $\mathrm{C}_{\mathrm{El}}=10 \mathrm{pF}$, the coordinates of these singularities are given explicitly in Table $(5-1)$.

\begin{tabular}{|c|c|c|c|c|c|}
\hline$C_{E I}$ & $A_{y}(0)$ & $P_{A 1}$ & $P_{A 2}$ & $P_{A 3}$ & $z_{A 1}$ \\
\hline $6 \mathrm{pF}$ & 9.8 & $-48.9 \times 10^{8}-j 39.4 \times 10^{8}$ & $-48.9 \times 10^{8}+j 39.4 \times 10^{8}$ & $-92.5 \times 10^{8}$ & $-11.3 \times 10^{9}$ \\
$8 \mathrm{pF}$ & 9.8 & $-43.3 \times 10^{8}-j 48.2 \times 10^{8}$ & $-43.3 \times 10^{8}+\mathrm{j} 48.2 \times 10^{8}$ & $-66.2 \times 10^{8}$ & $-84.2 \times 10^{8}$ \\
$10 \mathrm{pF}$ & 9.8 & $-35.9 \times 10^{8}-\mathrm{j} 51.0 \times 10^{8}$ & $-35.9 \times 10^{8}+\mathrm{j} 51.0 \times 10^{8}$ & $-57.7 \times 10^{8}$ & $-67.2 \times 10^{8}$ \\
\hline
\end{tabular}

TABLE 5-1. Doninant Closed-Loop Series-Shunt Pair Singularities.

The onset of ringing in the transient response for $\mathrm{C}_{\mathrm{SI}}>8 \mathrm{pF}$ is reflected in the entires of Table (5-1) by the jncreasing radial angle of the complex pole pair $p_{A 1}, P_{A 2}$ for increasing $C_{E 1}$; the angle exceeds $45^{\circ}$ for $\mathrm{C}_{\mathrm{EI}}>8 \mathrm{pF}$.

In order to predict in more refined fashion the actual transient response of the amplifier, account must be taken of the physical realizatian of the circuit. This requires estimates to be obtained for 
parasitic effects, so that the final simulation of amplifier performance more closely conforms to physical reality than the idealized analyses just made.

The need for extreme miniaturization of a feedback amplifier possessing subnanosecond risetime is manifest from consideration of the fact that the velocity of propagation of electronagnetic waves in free space is $3 \times 10^{20} \mathrm{~cm} / \mathrm{s}$; at this velocity, a path length of 36 cm would contribute a $360^{\circ}$ phase shift a 1 GHz. This is a liberal figure, for in most media, the propagation velocity is somewhat Iesis than that in free space. It should be apparenc from these figures that at microwave frequencies, the propagation delay of signals around its feedback loop can render an amplifier unstable. For this reason, it is essential that the physical length of the loop be maintained at an absolute minimum;

Parasitic reactances also pose a problen at frequencies in the gigahertz region, and these can be dealt with in either of two ways. A common approach is the incorporation of the parasitics into transmission lines. An altemative to this technique, and one more suited to the demands of feedback circuitry, where size is of paramount importance, is the mistimization of spuricus reactances through reduction of circuit size.

Fortinately, both these problems can be abated simuit meousiy through application to circuit construction of hybrid thin-film technology. Tiarefore, the anplifier described herein was fabricated upon a 
low-1oss sapphire substrate 1.0 inch square by 0.025 inch thick. Resistors were tormed from a nichrome film deposited to a thickness giving $50 \mathrm{~s} / \mathrm{square}$ resistivity, and a pattern of pure gold was used to provide conductive interconnections berween elements.

Microstrip transmission lines of $50 \Omega$ characteristic impedance provide the input and output signal feeds, and in this way irregurarities in the signal path are kept to an absolute minimm. The requisite conductor width required to realize this value of inpedance was cetermined to be 0.025 inch using data published elsewhere, ${ }^{(29)}$ in conjunction with the fact that for the sapphire substrate, $\varepsilon_{r} \approx 9.8$.

Shom in Fig. (5-6) is a diagran of the layout adopted for the amplifier. Connections to the microsicrip lines were made using stripline lamchers which provide a smooth transition from coarial cable to microstrip. All supply rails are bypassed to the extensive ground-plane using ceramic chip capacitors; in this way, 1ow impedance levels are maintained on the supply rails from dc to well into the microwave regior. A large-area contact is provided by the test fixture to the grourdplane, and fine wires were used to convey supply potentiais to the pads provided on the substrate for that purpose.

In spite of the reduction of parasitics afforded by hybrid construction: spurious reactances' still exist, and in an accurate simulation of the ampilifier, they must be taken into accomt. 


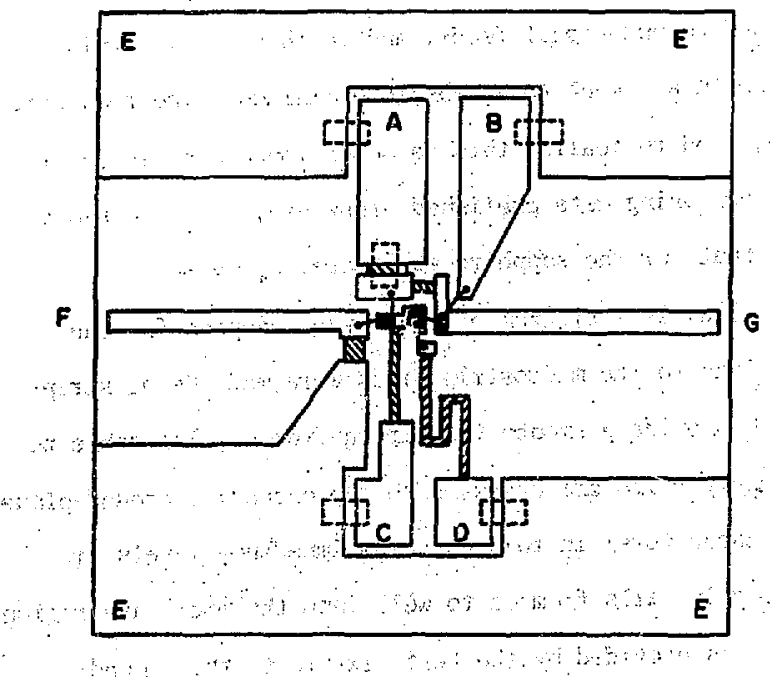

Connexion schedule
A $-0.86 \mathrm{~V}$
B $-5.7 \mathrm{~V}$.
c $+20 v$ :
D $-20 \mathrm{~V}$.
E Ground (OV.)
F input
$G$ Output

Not to scale

$\square$ Gold.

D Nichrome

XEL 72S-2807

Fig. 5-6 
Parasitic capacitance is not, as might pertiaps first be expected, solely a function of resistor and pad area and substrate thickess. Rather, it is a complox function of resistor pattern and material properties of the metal out of which the resistances are fâbricated. For the amplifier described here, estimation of these capacitances was made on the basis of earlier work. ( 30$)$

Device bonding wires contribute parasitic inductance, and appropriate estimates of values can be done in a straightforward fashion using the fact that the leads are an average 0.03 inch long and 0.0007 inch in diameter. These parasitics manifest thenselves in actuality as distributed effects, and the lumped-element approximations used here are only adopted out of the necessity of maintaining a tractable model.

The level-shifting zener diode of Fig. (5-1) can be modelled by the paraliel combination of its $18 \Omega$ dynanic resistance shunted by a 300 pF capacitor.

A difficulty in using existing transient analysis programs in the simulation of high-frequency circuits arises from their inability to accept delay operators directly. Consequently, it becomes necessary to formulate an adequate approximation to the delayed voltage-controiled current sources in the models of the transistors if account is to be taken of excess-phase effects.

A digression will therefore be made at this point to develop an adequate equivalent to the delayed voltage-controlled current source representing that element accurately over the spectrum of frequencies at wich the overall amplifier is expected to operate. 
Let the couplex exponential operator be expanded inter Hac Laurin's series, and retain only the first two terms of the expansion, whereupon

$$
e_{i}^{-j \omega t} \cong i-j \omega \tau
$$

The rational approximation of Eq (5) possesses a phase characteristic falling in asymptotic fashion from zene to $-\pi / 2$ at high frequencies, however, it possesses the disadvantage of having considerable magnitude error. For example, a single-pole R-C network having the phise response of the right-hand side of Eq. (5-9) for $\tau=20$ psec causes nearly a 108 magnitide error at $1 \mathrm{GHz}$, and for accurate sinulation, this is considered too high.

A superior candidate is a cascade of one or more lossless $\pi$-sections of the form of Fig. (5-7); the appropriate formulae for these sections can be deduced in terms of image parameters, and the characteristic impedance shown to be,

$$
\mathrm{z}_{0} \frac{\sqrt{\mathrm{L} / \mathrm{c}}}{\sqrt{1-\left(\frac{\omega}{\omega_{0}}\right)^{2}}}
$$

Where the parameter $\omega_{0}$ is given by,

$$
w_{0}=2 / \sqrt{\mathrm{LC}}
$$



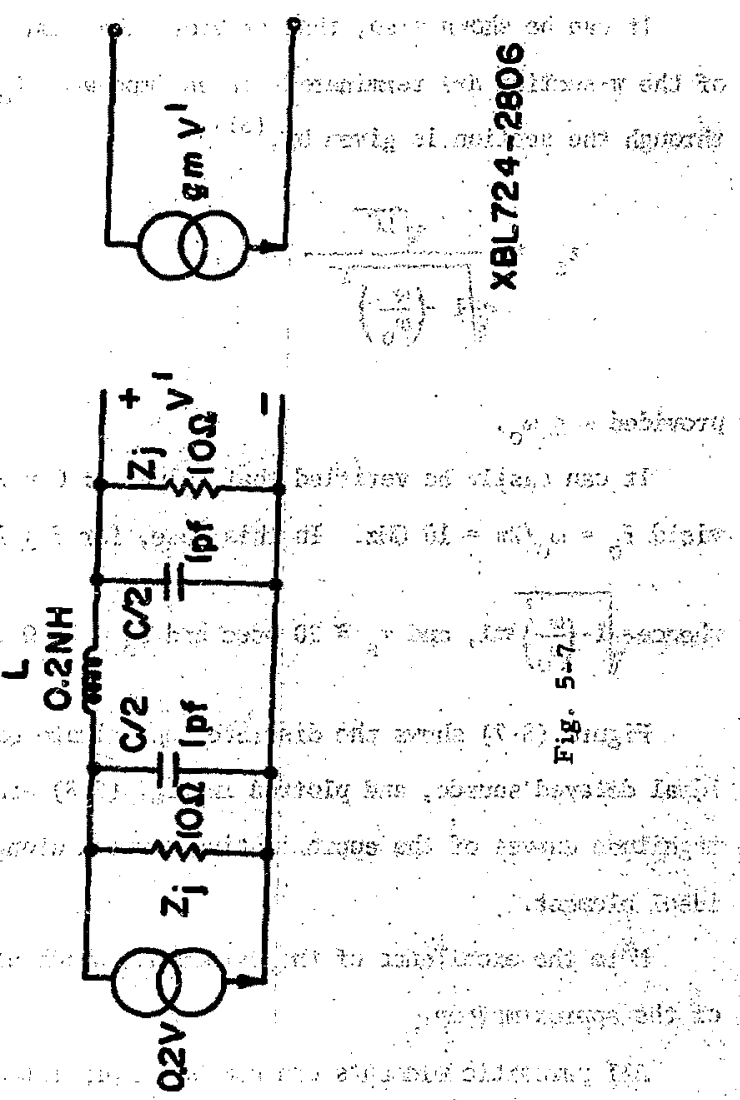

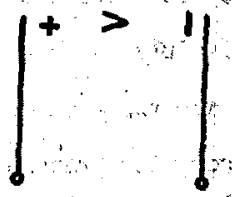


It can be shown also, that provided the input and output ports of the $\pi$-section are terminated in an impedance $z_{0}$, then the delay through the section is given by, (31)

$$
\tau_{s}=\frac{\sqrt{L C}}{\sqrt{1-\left(\frac{\omega}{\omega_{0}}\right)^{2}}}
$$

provided $\omega \leq \omega_{0}$.

It can easily be verified that values of $C=2 \mathrm{pF}$, and $\mathrm{L}=0.2 \mathrm{nH}$ yield $f_{0}=w_{o} / 2 \pi=16 \mathrm{GHz}$. In this case, for $f \leq 2 \mathrm{GHz}, \frac{\omega}{\omega_{0}} \leq 0.13$, whence $\sqrt{1-\left(\frac{\omega}{\omega_{0}}\right)^{2}} \approx 1$, and $\tau_{s} \approx 20 \mathrm{psec}$ and $z_{0}=10 \Omega$.

Figure (5-7) shows the discrete approximate equivalent of the ideal delayed source, and plotted in fig. $(5-8)$ are the phase and magnitude curves of the approximating network along with those of the ideal element.

Note the excellence of the agreenent, which attasts to the validity of the approximation.

All parasitic elements can now be incorporated into the basic equivalent circuit of Fig. (5-2) to yield the circuit given in Fig. (5-9). Although not shown (xplicitly in that illustration, all voltage-controlled current sources are replaced by the equivalent network of Fig. (5-7) for purposes of campiter transient-response similation using the "Cancer" Progran. 


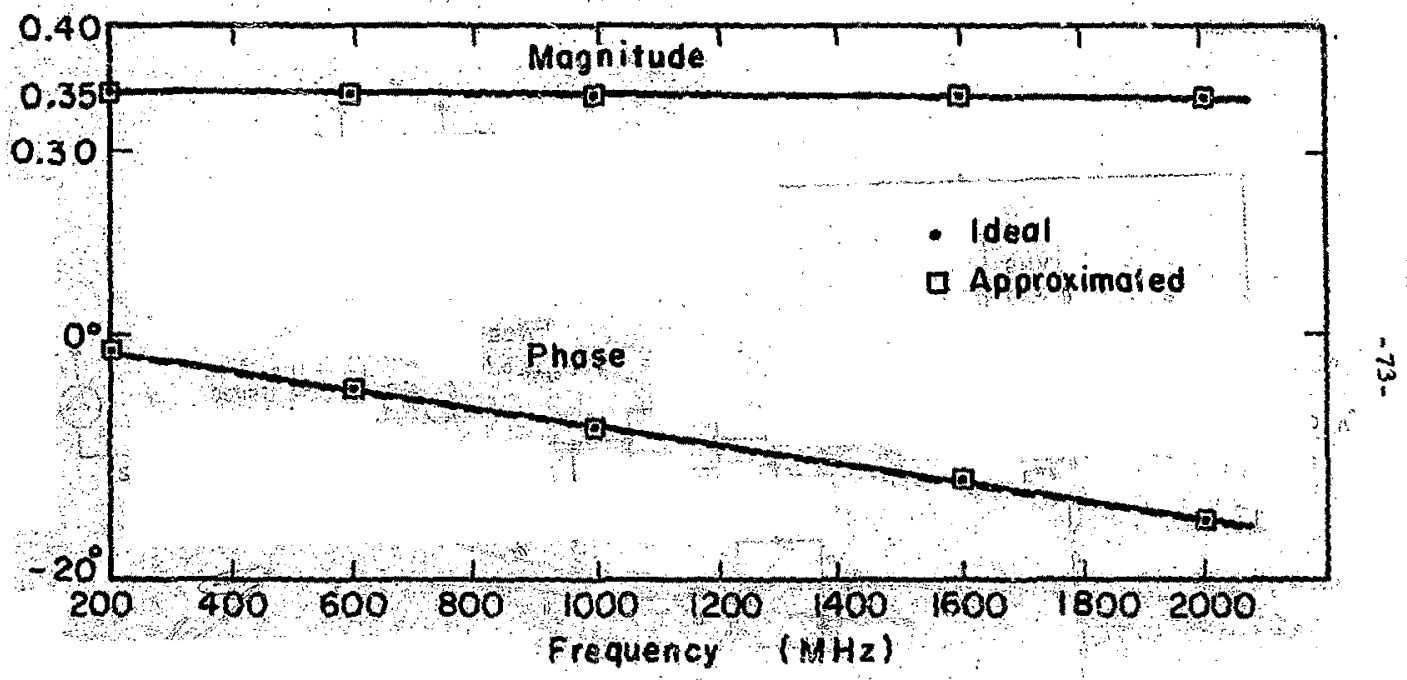

XEL724-2779

$$
2+5-8
$$




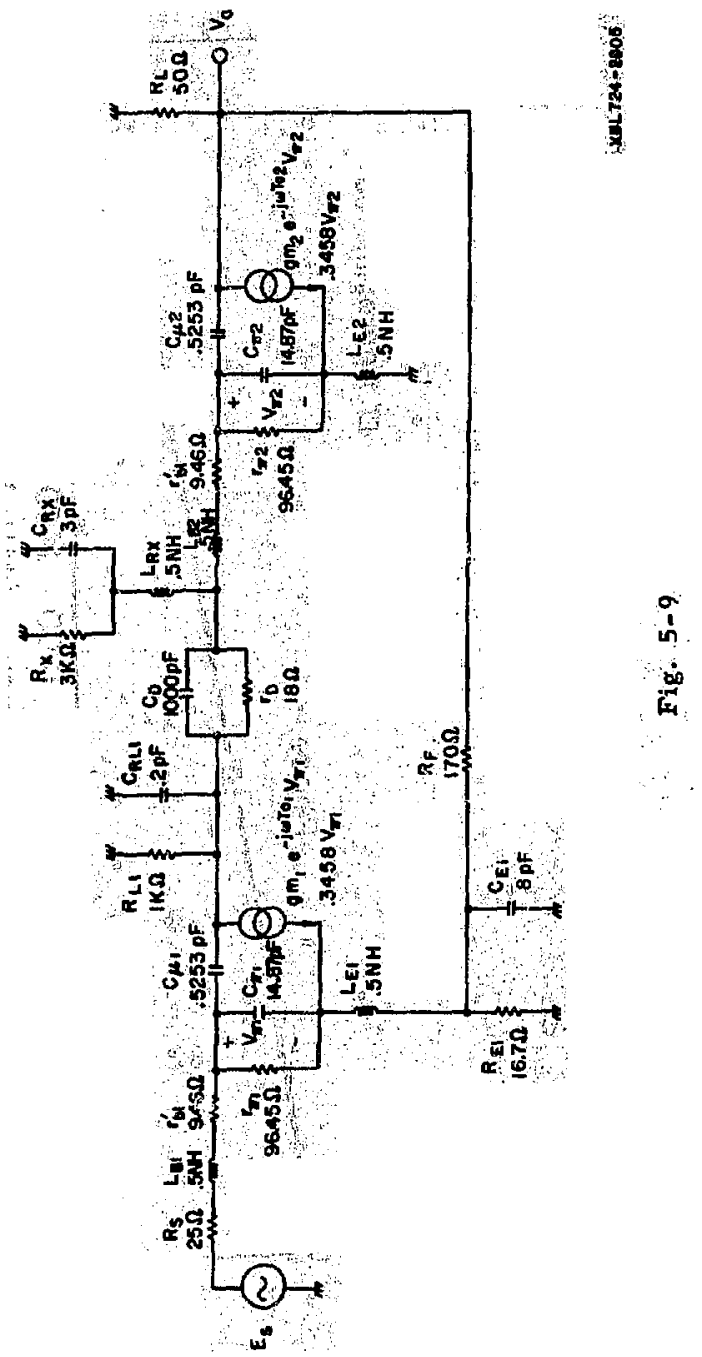


The results of that simuation, which was carried out with a stepfunction inpit to the amplifier equivalent circuit, are plotted in Fig. (5-10). From that graph, the $10 \%$ to 908 risetime on the output is seen to be $330 \mathrm{psec}$, and the overshoot is 98 . These figures are well within the design bounds stated at the outset of this chapter.

In order experimestally to assess the transient response of the actual amplifier a Hewlett-Packard Type $141 \mathrm{~A}$ oscilloscope equipped with the Type $1425 \mathrm{~A}$ sampling time base and Type 1411 sampling umplifier was enployed. The sampling head used is specified for a risetime $\leq 28$ psec, so that in the measurements to be described, the effects of oscilioscope response can essentially be neglected.

A step transition input to the amplifier was generated by a HewlettPackard Type 1105A pulser operating into a Tpe $1106 \mathrm{~A}$ tumel-diode mount.

Illustrated in Fig. (5-11a) is a photograph of the output of the tumel-diode pulser after attenuation sufficien to reduce the pulse amplitude to a $10 \mathrm{my}$ transition. It is evident from that figure that the testing waveficm in fact possesses a finite risetime of about 60 psec, hence a small correction mast be made for this fact when evaluating the output of the anplifier in the calculation of anplifier risetime. Figurs (5-11b,c) show the anplifier output corresponding to the input of Fig. (5-11a). The risetime of the output is ahout 400 psec, with in overshoot of $10 \%$. Thes figures agree excellently with the values of risetime $3370 \mathrm{psec}$ and overshoot $\approx 10$ s as computed using program "Cancer". for the model of Fig. (5-9) driven with a pulse possessing a linear front edge of $60 \mathrm{psec}$ risetime. 


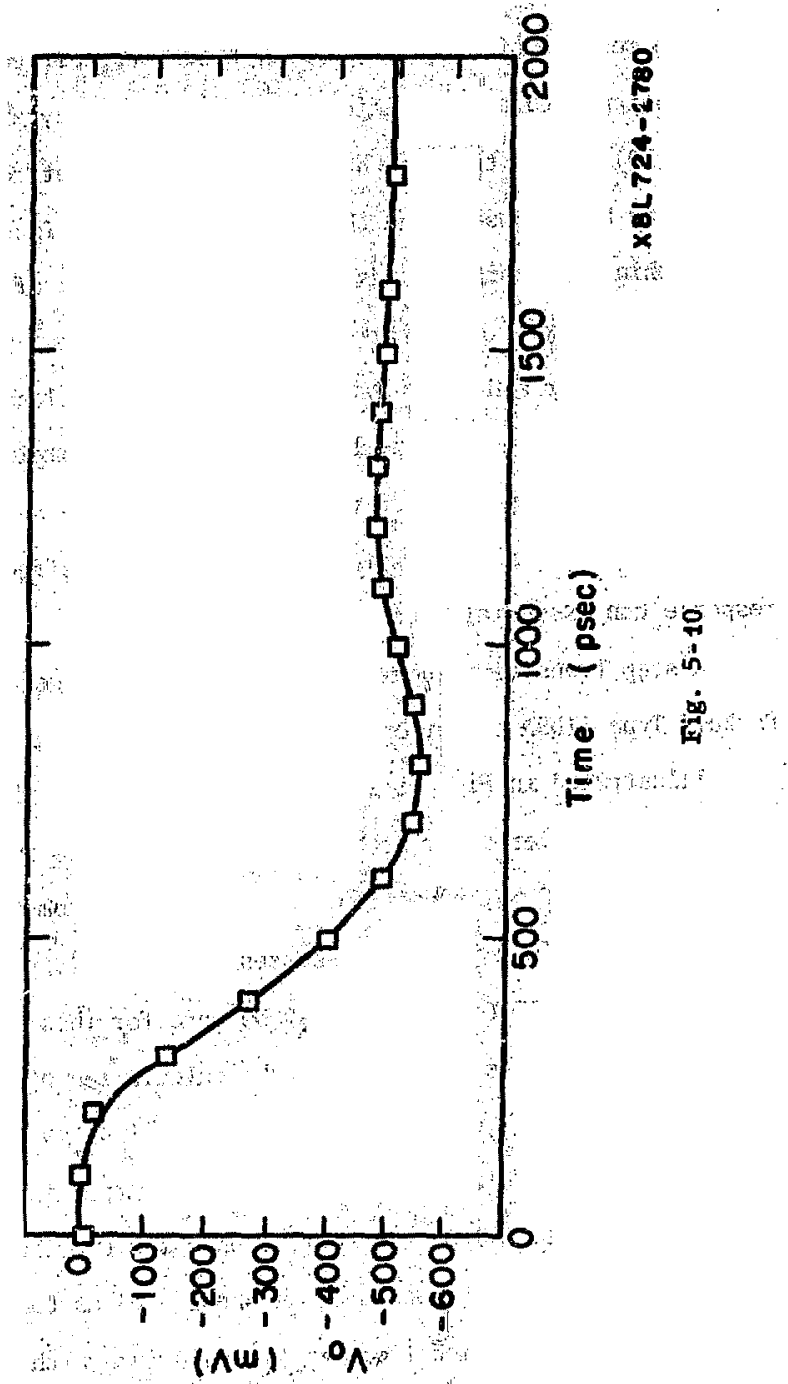




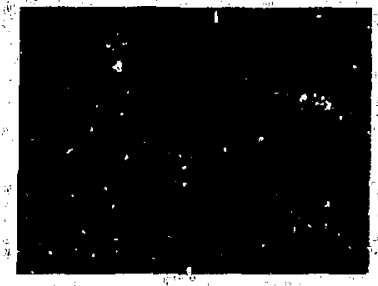

FIG. 5-11a

INPUT WAVEFORM

$50 \mathrm{ps} / \mathrm{div}$.

$2 \mathrm{mv} / \mathrm{div}$.

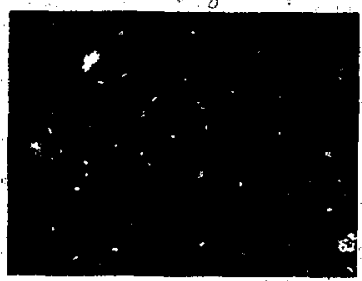

FIG. 5-11b

OUTPUT, WAVEFORM VIA

20 dB ATTEN.

$400 \mathrm{ps} /$ dive

$2 \mathrm{mV} / \mathrm{div}$.

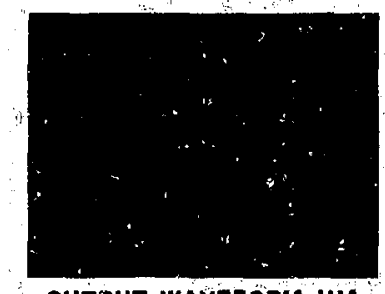

FIG. 5 -11c

CUTPUT WAVEFORM VIA

20 dB ATTEN.

$200 \mathrm{ps} / \mathrm{div}$.

$2 \mathrm{mv} / \mathrm{div}$ ?

XBB T21-397

FIG. 5-11 SMALI SIGNAL STEP RESPONSE

OF THE SERIES-SHUNT PAIR 
Although the amplifier was designed so as to pass negarive-going pulses, the use of the positive-going pulse employed in these tests was dictated by the unavailability of a negative-going pulse generator of adequately fast risetise.

To ensure a proper transient response of the amplifier, it is necessary properly to terminate the driving coaxial cable at the amplifier input for minimm reflections in the cable. This is especially inportant when the sending end is unterminated, as would be the case in a cascade of amplifiers of the type described bere.

The input impedance at low frequencies is virtually that of the $50 \Omega$ teminating resistor, since the series feedback at the inqut effectively increases the open-10op input impedanice by a factor of $1+a(0) f(0)$. The magnitude of this quantity decreases with incressing frequency, hence so also does the impedance looking into the first stige, and with it the imput impedance of the entire circuit.

The scattering parameter approach provides the most convenient vehicle of irput impedance measurenent, and from the discussion of Chapter 2, it follows that an ideal input termination corresponds, for identical system and normalizing impedances, to a value for $s_{12}$ of zero.

The magnitude and phase of $s_{13}$ were calculated for the model of Fig. (5-9) using the A-C analysis capability of the "Cancer" progran in conjunction with a small additional prugram designed to calculate the scattering parmeter $s_{21}$ from the impedance looking into the aplifier. 
Measurements were made in the laboratory on the actual circuit, and the data obtained are plotted alongside the analytically determined values of $s_{i 2}$ in Fig. (5-12).

The forward scattering parameter $s_{21}$ is also of interest, insofar as it gives a nsasure of the frequency response of the anjlifier, hence there are plotted in Fig. (5-13) both analytically detemined and experimentally measured values of this parametor. Once again, agreenent is excellent between theory and practice.

Hitherto, all neasurements done on the amplifier hare been of 'smallsignal' nature. Even the theoretical analysis has been carried out on the siball-signal basis, since linearization of the inherently non-linear phenonena responsible for transistor action demands that only small perturbations about a quiescent operating point be considered. Extension of the enalysis to the 1arge-signal case would require use of a fusi nonlinear model for the transistors.

The situation frequently arises, however, that in muclear pulse amplifiers high-amplitude pulses will be encountered that do not satisfy the small-signal assumption, and so it is instructive at least experimentally to exemire the resultant response of the amplifier. The experimental arrangement enployed for lack of better equipment a Hewlett-Packard pulse generator Type 215-A naving a risetime approximating to 1 nanosecond to generate a large-scale negative-going excursion at the amplifier inpact. Figure (5-14) shows some of the results of this test. A more detailed intepretation of large-signal response results requires a pulse generacior of faster risetime than that used to produce Fig. (5-14). 
Any amplifier other than the hypothetical idexl amplifier will. contribute noise to the signal passing through it in addition.to the intrinsic roise of the signal source. For signals of moderate to large anplitudes, the effect of amplifier noise may be negligible. However, noise performance of the amplifier may in same instances be of importance, for example, if it is to be used to premplify very low-level signals.

A common measure of the noise behaviour of an amplifier. is given by its noise figure $F$, which is defined as the quotient of input signal. to-noise ratio to output signal-to-noise ratio thus,

$$
F=\frac{\mathrm{P}_{\mathrm{si}} / \mathrm{P}_{\mathrm{ni}}}{\mathrm{P}_{\mathrm{so}} / \mathrm{P}_{\mathrm{no}}},
$$

where $P_{s i}$ and $P_{n i}$ are the input signal power and input signal noise power, respectively, and $P_{\text {so }}$ and $\mathrm{P}_{\text {no. }}$ are the corresponding quantities for the signals at the amplifier output. The noise figure is proportional to the decadic logarithm of according to the relation,

$$
N=10 \log _{10} F \mathrm{~dB} .
$$




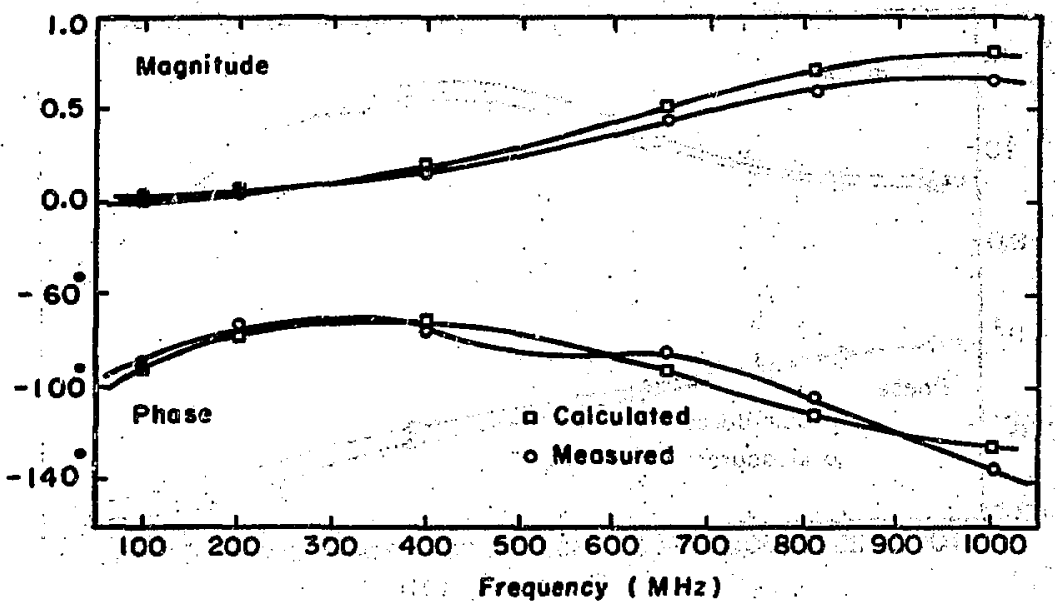

Fig. 5-12 


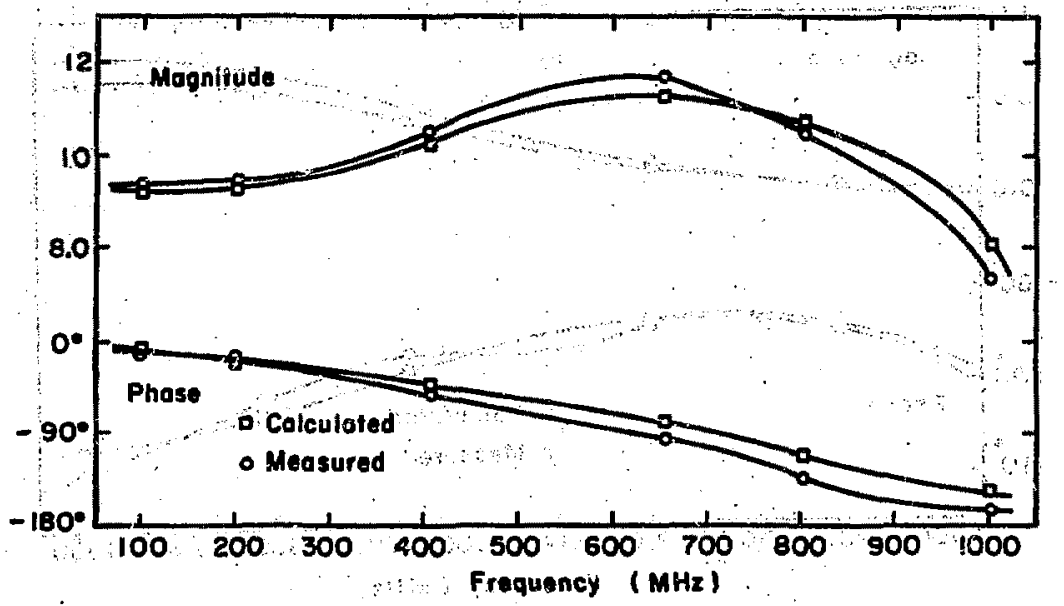

xaL724-2707

Fig. 5-13 


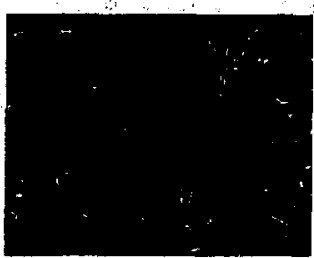

FIG. 5-14 a AMPLIFIER INPUT WAVEFORM $1 \mathrm{nsec} / \mathrm{div}$. $20 \mathrm{mV} / \mathrm{div}$.

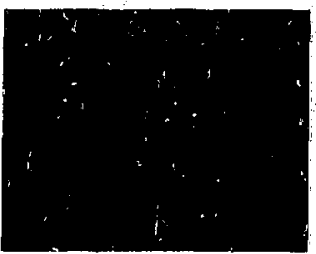

FIG. 5-14 b ARPLIFIER OUTPUT VIA 20 dB ATTENUATOR I nsec/div. $20 \mathrm{my} / \mathrm{div}$.

XIBB T22-817

FIG. 5 -34 
Spot-noise measurenents were taken for $N$ at selected points within the passband of the amplifier using a white noise generator and microwave receiver equipped with a $100 \mathrm{KHz}$ notch filter, and the data obtained thereby are plotted in Fig. (5-15).

As often useful alterrative index of amplifier noise behaviour is given by its input-referred noise, a quntity deducible from $k$ if Eq. (5-13) - is written in its equivalent form;

$$
F=\frac{\overline{e_{s i}^{2}} \overline{e^{2}}}{e_{n i}^{e_{\text {no }}^{2}}}
$$

there $F$ is now expressed in terns of mean-square noise vol tages. If $A_{1}$ denotes amplifier voltage gain, $\mathrm{Bq} .(5-15)$ becones, since

$$
\begin{aligned}
e_{s 0}^{2} & A_{V} e_{s i}^{\overline{2}}, \\
& F=\frac{1}{A_{v}} \frac{e_{n o}^{2}}{e_{n i}^{2}} .
\end{aligned}
$$

Let a new variable $\overline{e_{a i}}$ be cefined to represent the noise generated in the anplifier itself and referenced to the input, so that,

$$
\overline{e_{n o}^{2}}=\overline{e_{n i}^{2}} A_{v}+\overline{e_{a i}^{2}} A_{y}
$$




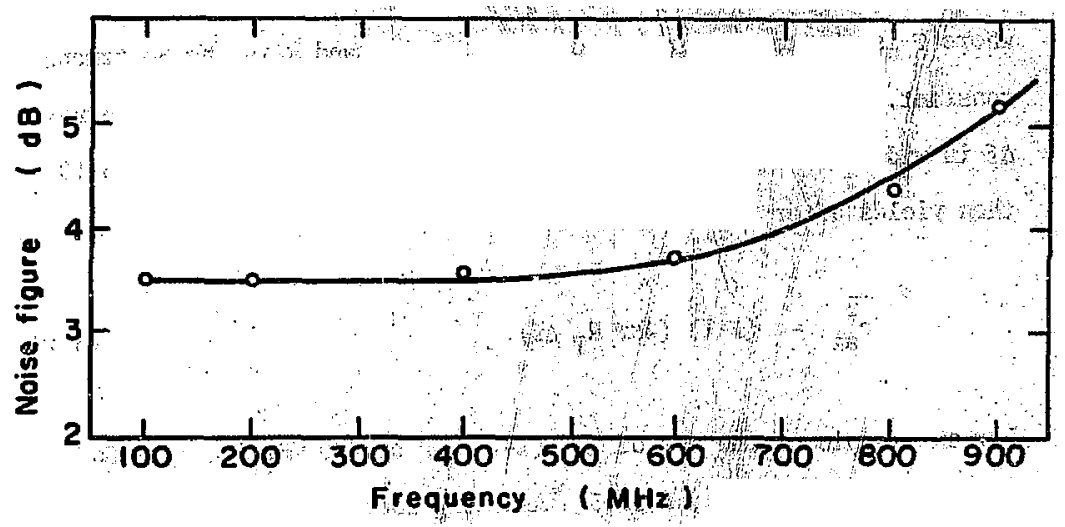

xot724 - 2700

Fig. $5-25^{2}$ 
Since the anplifier input is assimed to be terminated properly by the resistance $R_{T}$ of $50 \Omega$, the mal noise generated within $R_{T} c 0 n-$ prises $\overline{\mathrm{e}}_{\mathrm{ni}}$ according to the Nquist formula,

$$
\overline{\mathbf{e}^{2}}=4 \mathbf{k T} \cdot \mathbf{R}_{\mathbf{T}} \Delta \mathbf{f}
$$

where $I$ is the temperature in degrees Kelvin, and $k$ is the Boltzmam constunt. The thermal noise is considered over a frequency interval $\Delta f$ in width. Substitution into Eq. $(5-16)$ of Eqs. $(5-17)$ and $(5-18)$ then yields after rearrangement;

$$
\overline{e_{a i}^{2}}=(F-1) \cdot\left(4 k T R_{T} \Delta f\right)
$$

For an exaple of the use of $\mathrm{Fq},(514)$, $F$ at $400 \mathrm{Mz} \mathrm{is,} \mathrm{from} \mathrm{Eq.}$ (5-19) and Fig. (5-15), 7 a1.5. Assuming room temperature operation of the plifier input terninating resistor Eq. (5-19) works out to a value of $\overline{\mathrm{e}_{\mathrm{zi}}^{2}} \approx 40 \times 10^{-20} \mathrm{v}^{2} / \mathrm{Hz}$

The noise figures found for this amplifier at midband are about 3.5 dB. This value could be inproved upon by selecting a lower collector current for the transistors, since under the asstieption of constant $\beta_{d c}$ versus $I_{c}$ in the cortemplated range of $I_{c}$, the high-frequency shot noise ferierated in the collector and base regionis is proportional to $I_{c^{*}}$ (34) Noise figuxe will increase over the midhand value at the low and of the anplifier passband dye to the onset there of the effects of colored flicker noise. 
CHAPTER 6. DESIGN OF A FAST RISE SERIES-SERIES TRIPLE

The sezues-series triple feedback configuration offers the very substantial advantage over the series-shunt pair just treated of a much higher potentially available loop gain. This in turn leads to a superior gain stability than that possible with the feedback pair. This advantage is not obtained without penalty, however, for owing to the more complex singularity pattern of the triple, it is correspondingly more difficult to compensate for a given transient behaviour than the smies-shunt pair. Another difficulty with the feedback triple manifest at high frequencies, is that its increased circuit complexity leads to increased parasitic effects when campared with the simpler series-shunt feedback pair. These factors, in addition to the excess phase delay contributed by the additional transistor of the triple, tend to destabilize the ciranit.

Shown in Fig. (6-1) is the furl electrical diagram of a seriesseries tripie designed with a view towards meeting the elenentary specification set down in Chapter $i$; it can easily be verified fron the figure that each of the three transistors passes a standing current of $10 \mathrm{~mA}$ and sustains $\mathrm{V}_{C E} \times 5 \mathrm{~V}$. In order that the output transistor operate at all times at the 10 to $20 \mathrm{~mA}$ level of $\mathrm{I}_{\mathrm{C}}$ necessary for optimal $f_{T}$; the output of the amplifier is constrained to be in the range 0 to $-0.5 \mathrm{~V}$. 


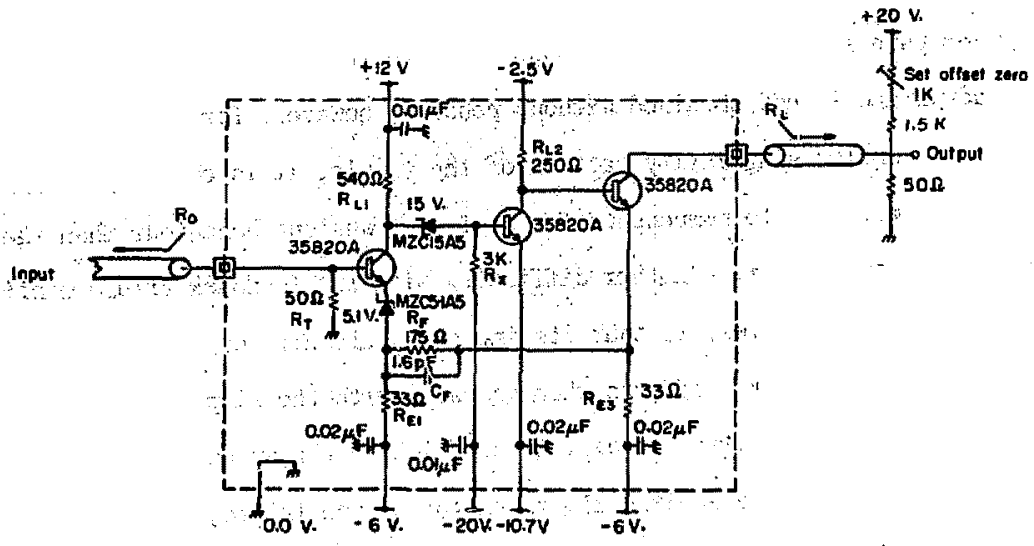

KEL720-2803

Fig. 6-1 
A drawing of the physical layout adopted for the circuit is iliustrated in Fig, (6-2). Figure (6-3) shows the full small-signal equivalent circuit, using the hybrid pi model deduced in Chapter 4 for the HPA $35820-A$, and including all the attendant parasitic effects. The resistor $R_{S}$ in series with the imput voltage source $E_{S}$ is defined identically to its counterpart of the preceding chapter.

As in the analysis done for the series-shunt pair, the low-frequency amplifier characteristics are first determined. For the low-frequency case, the series-series triple can be partitioned into its forward gain path and feedback network by opening all capacitors and short-circuiting all inductors of Fig. $(6-3)$, and by noting that the open-circuit impedance matrix is the appropriate two-port formulation for the case of series-series feedback. The result of this operation is shown in Fig. (6-4), whence it is apparent that provided the forward alpha of the output transistor is near unity, the feedback function at d-c:can be written as,

$$
f(0)-\frac{R_{E 1} P_{E 3}}{R_{1}\left(R_{E 1}+R_{E 3}+R_{F}\right)}
$$

This formula relates the voltage fed back to the aplifier input, to the voltage deyeloped at the aplifier output node. Now, the amplifier closed-loop d-c gain $A_{y}(0)$ is related to the d-c open-10op gain ay $(0)$ and to $f(0)$ by the equation,

$$
A_{v}(0)=\frac{a_{v}(0)}{1-a_{v}(0) f(0)}
$$




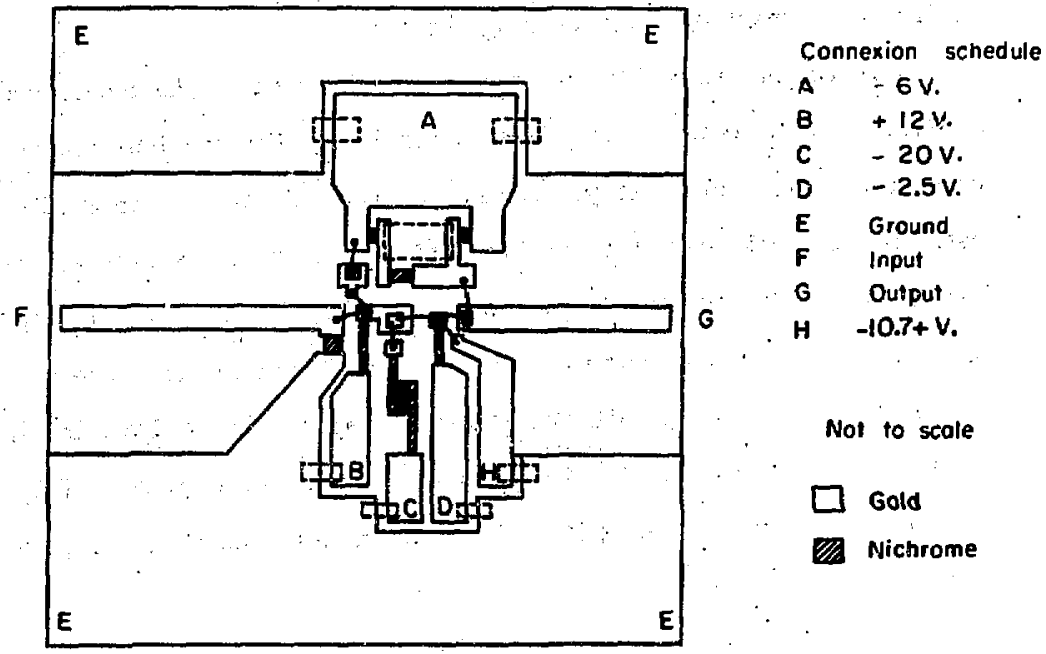

XEL 724 - 2001

Fig. 6-2 


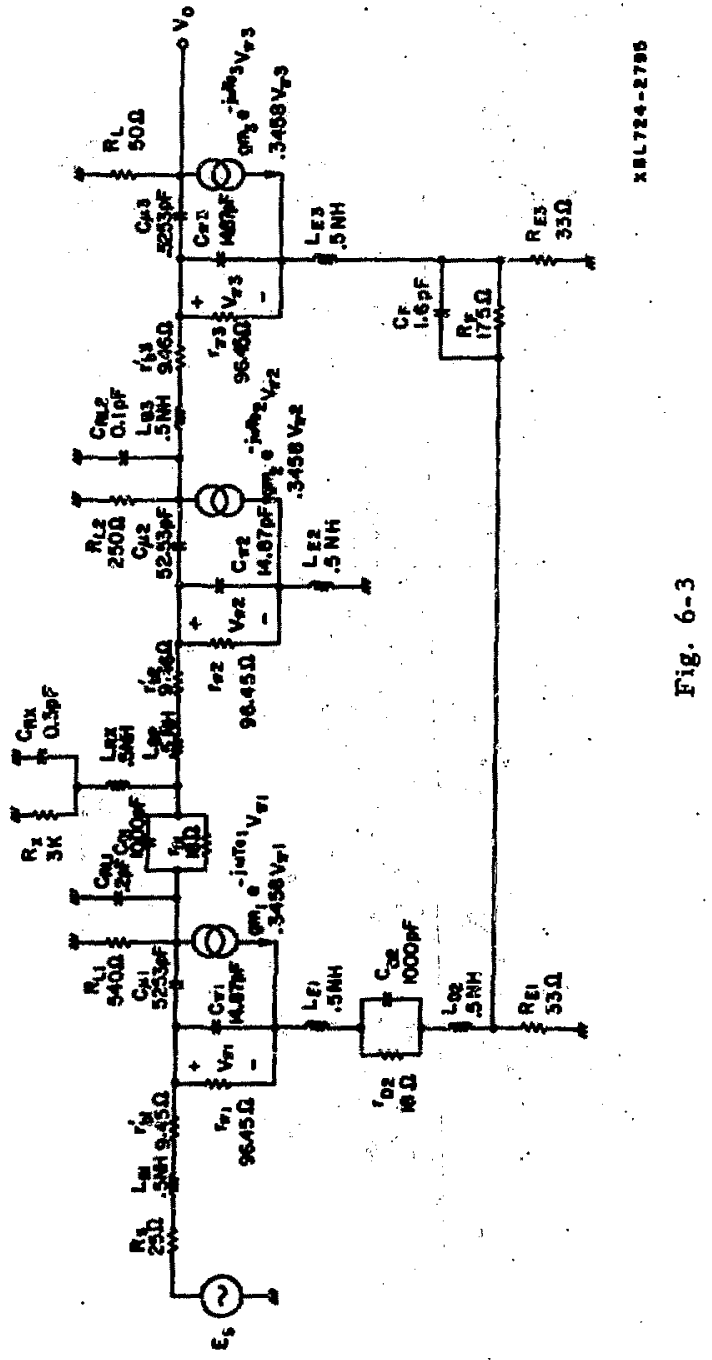



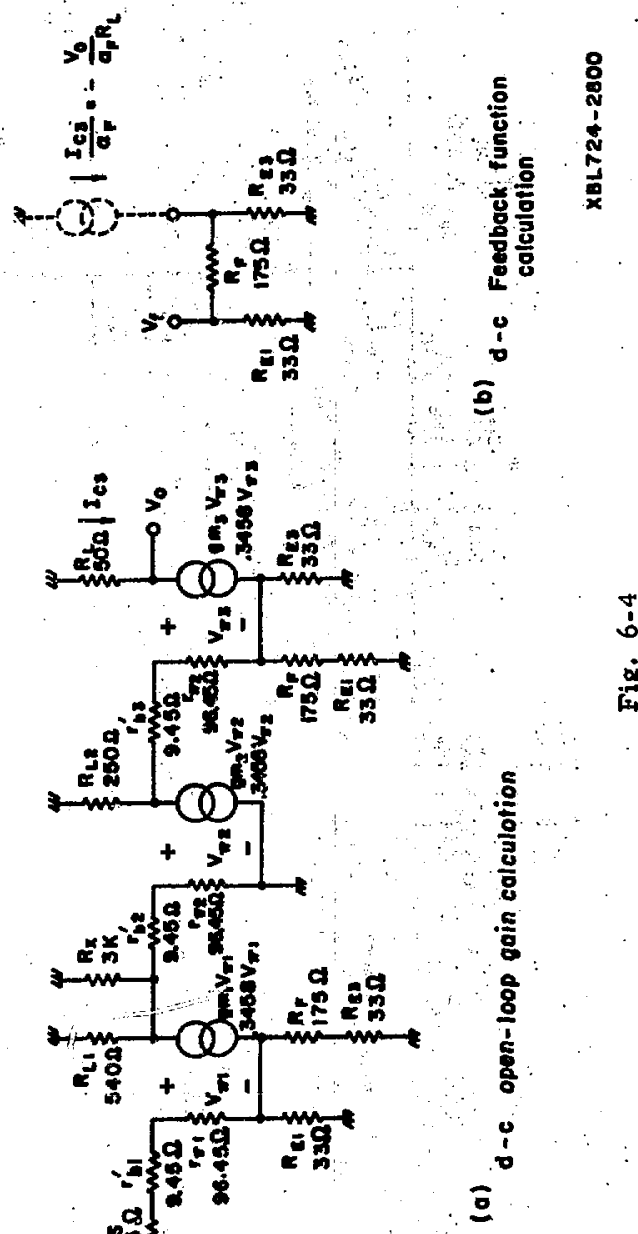
Substitution into $\mathrm{Bq}$. (6-2) of $\mathrm{Bq}$. (6-1) followed by algebraic rearrangement yields an expression for the value of feedback resistor $R_{\mathrm{F}}$ in termis of other circuit paraneters, as follows,

$$
R_{F}=\frac{\left.R_{L} \mid a_{v}(0)-A_{v}(0)\right]\left[R_{E 1}+R_{E 3}\right]-A_{v}(0) a_{v}(0) R_{E 1} R_{E 3}}{R_{L}\left[A_{v}(0)-\alpha_{v}(0)\right]}
$$

Several principal factors enter into the choice of values for the emitter resistances $\mathrm{R}_{\mathrm{E} 1}$ and $\mathrm{R}_{\mathrm{E} 3}$. In order to secure a large closed100p bandwidth in the triple, it is desirable to locate the second and thind dominant poles as far from the origin of the complex phase as possible. This requires broadbanding of the first and third stages of the explifier, a condition achieved by using large values for $R_{E 1}$ and $R_{\text {E3 }}$ On the other hand, high d-c loop gain in the triple, with the consequent advantage of increased desensitivity, demands low values for the two emitter resistances. An additional factor favouring choice of 10w values for $R_{E 1}$ and $R_{E 3}$ arises out of the practical consideration that any compensating capacitor used across $\mathrm{R}_{\mathrm{F}}$ mist have a reasonably large value in order to be physically realizable. Arguing on a first-order basis, it is therefore desirable that $R_{F}$, hence also $R_{E 1}$ and $R_{E 2}$, be of low value.

These several conflicting requirements are resolved in the particular selection made for the emitter rosistors of $R_{E 1}=R_{E 2}=33 \Omega$. Once this choice has been taken, Eq. (6-3) mest be solvad itoratively for the requisite $A_{v}(0)$ of -10 since $a_{v}(0)$ depends upan the value of $R_{F}$ as is apparent from cansideration of Fig. (6-3a). Commencenent of the itoration 
with a value of $R_{F}=150 \Omega$ led after two cycles to a value of $R_{F}=175 \Omega$, at which a $(0)$ was calculated to be -158 .

with the d-c characteristics of the amplifier thus determined in closed-1oop, it renairs to take up the more difficult topic of the arrangenent of suitable compensation to provide the fastest risetime on the output waveform, for a step-franction input to the aplifier, consistent with an overshoot not arceeding ten per cent.

Although in the design of the series-shunt pair considered in Chipter 5, a pole-zers analysis was used owing to the intimate connection exlsting betwen this representation and time-domain behaviour, it was decided here to use optinization techniques to compensate the circuit. This aproach enables direct use to be iade of scattexing parameters, and provides a link between the wethods used for transistor charactiorization, wid the design of the final plifier. The disadvantage of the wothod is, of course, that an inmediate and readily apparent correlation does not exist between transient response and the scattering parameter repreecentation. Consequently, it was souplit only to ensure sall peaking and mine brank frequency for $\left|s_{2}\right|$ in the hope that this would yield adequate step response.

The progran discussed in Chepter $3 \mathrm{mas}$ used as the whicle for optinization; a nodification was incorporated into the progren to enable the optinization to be cerried out with respect only to the nigitude of the formand scatterine parmoter $s_{21}$. 
In particular, the error function of Eq. (3-1) was reformulated as,

$$
e(x)=\sum_{i}\left\{\left|s_{21}^{A}\left(j \omega_{1}, x\right)\right|-\left|s_{21}^{G}\left(j \omega_{1}\right)\right|\right\}^{2}
$$

where,

$$
\left|s_{21}^{A}\left(j \omega_{i}^{*}, x\right)\right|=\sqrt{[R e}\left\{s_{21}^{A}\left(j \omega_{i}, x\right)\right]^{2}+\left[I m\left\{s_{21}^{A}\left(j \omega_{i}, x\right)\right\}\right\}^{2}
$$

The superscript $G$ signifies a given paraneter to which fit is sought, and supexscript $A$ denotes a quantity calculated from the alifier circuit of Fig. (6-3). The gradient vector corresponding to the error function of $\mathrm{Eq}$. (5-4) can be conputed in tenis of $\partial s_{21}^{A}\left(j w_{i}, x\right) / \partial x$ as,

$$
\begin{aligned}
\frac{\partial \dot{\varepsilon}(\underline{x})}{\partial \underline{\underline{x}}} & =\sum_{i}\left[\left|s_{22}^{A}\left(j \omega_{i}, x\right)\right|-\left|s_{21}^{G}\left(j \omega_{i}\right)\right|\right] \frac{1}{\left|s_{21}^{A}\left(j \omega_{1}, x\right)\right|} \cdot \operatorname{Re}\left\{s_{21}^{A}\left(j \omega_{i}, x\right)\right\} \\
& \left.R=\left\{\frac{\partial s_{21}^{A}\left(j \omega_{i}, x\right)}{\partial \underline{x}}\right\}+\operatorname{In}\left\{s_{21}^{A}\left(j \omega_{1}, x\right)\right\} \cdot \operatorname{Ix}\left\{\frac{\partial s_{21}^{A}\left(j \omega_{i}, x\right)}{\partial x}\right\}\right](6-5)
\end{aligned}
$$

The cepacitor $C_{F}$; located across the fecubick resistor $R_{R}$, was selected as the sols comensatine element, ind the opticization routine.

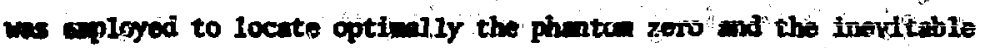
Higher-order yole introduced by $C_{F}$. to aplication was of ipolesuifeting' techiques (35) within the eplifier forwand gain path, since these would require the we of apecter of inprectically simil valus. 
The form chosen for the $\left|s_{21}^{G}\right|$ was that of a constant 20 dB out to $1.2 \mathrm{GH} 2$, after which a fixed $60 \mathrm{~dB} /$ decade rolloff was followed. The slope used for the rollofi of $60 \mathrm{~dB} / \mathrm{dec} a d e$ was chosen on the basis of a three pole transfer function for $a_{v}(s)$. Thus, with the mode of compensation used here, the closed loop gain $A_{V}(s)$ will also possess three poles, which in the limit yields an asymptotic approach of $\left|A_{y}(j \omega)\right|$ to the $-60 \mathrm{~dB} /$ decade 1 ine. The optinization was done on the fuil inodel of Fig. (o-3), thus all parasitics are accounted for from the outset.

Figure (6-5) shows the form of $\left|s_{21}\right|$ calculated from the optimized circuit for the optimal value of $C_{F}=1.6 \mathrm{pF}$. Shown also in Fig. (6-5) is a plot of the phase characteristics of $s_{21}$ of the optimized anplifier. Figure (6-6) shows the irput reflection parameter $s_{i 1}$ in both phase and magnitude, as computed from the optimized circuit. The absence of serere peaking in the plot of $\left|s_{21}\right|$ implies a transient response having tolerable overshoot, whilst the plot of $s_{11}$ shows that the imput impedance of the applifier is maintained reasonsbly constant at $50 \Omega$ up to noarly 1 Giz.

In order to assess the transient response of the amplifier, the wadel of Fig. (6-3) was entered into the "Cancer" program along with the eproximation developed in the proceding chapter for the dolsyed valteg-controlled current sources. The results of this siallation are plotted in Fig. (6-7), whence the figures of risetim $\approx 270$ psec and overahoot ost are calculable. 


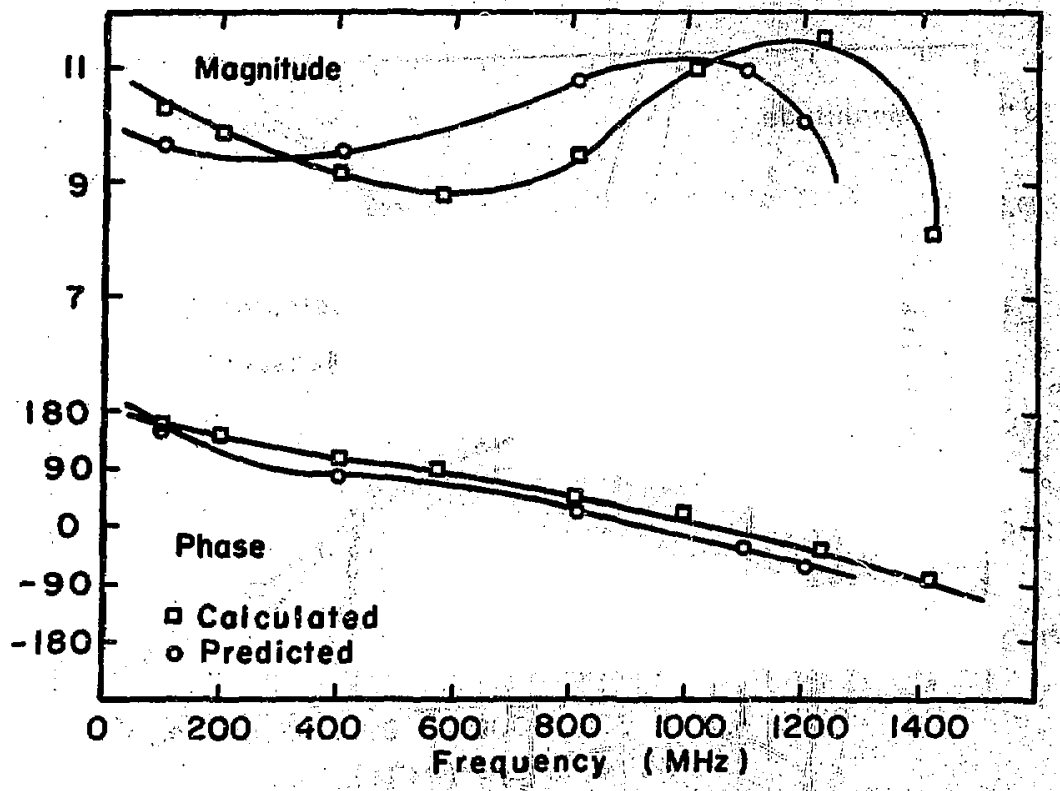

xBL724-2700

Fig. 6-5 


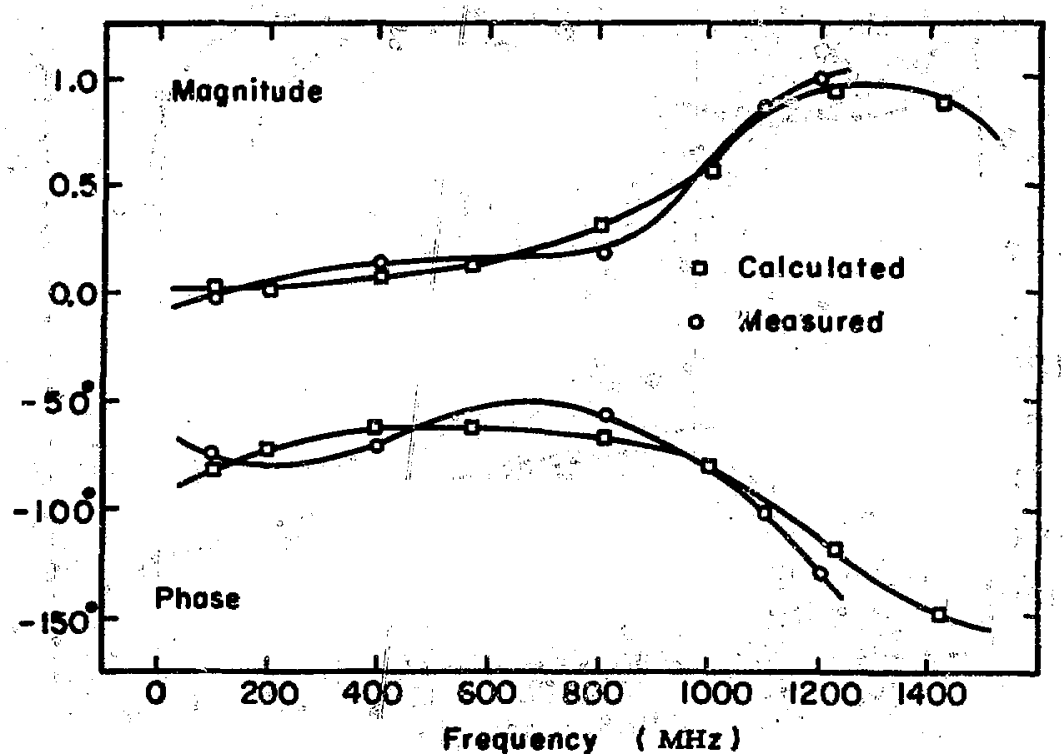

X8L724-2791

Fig. 6-6 


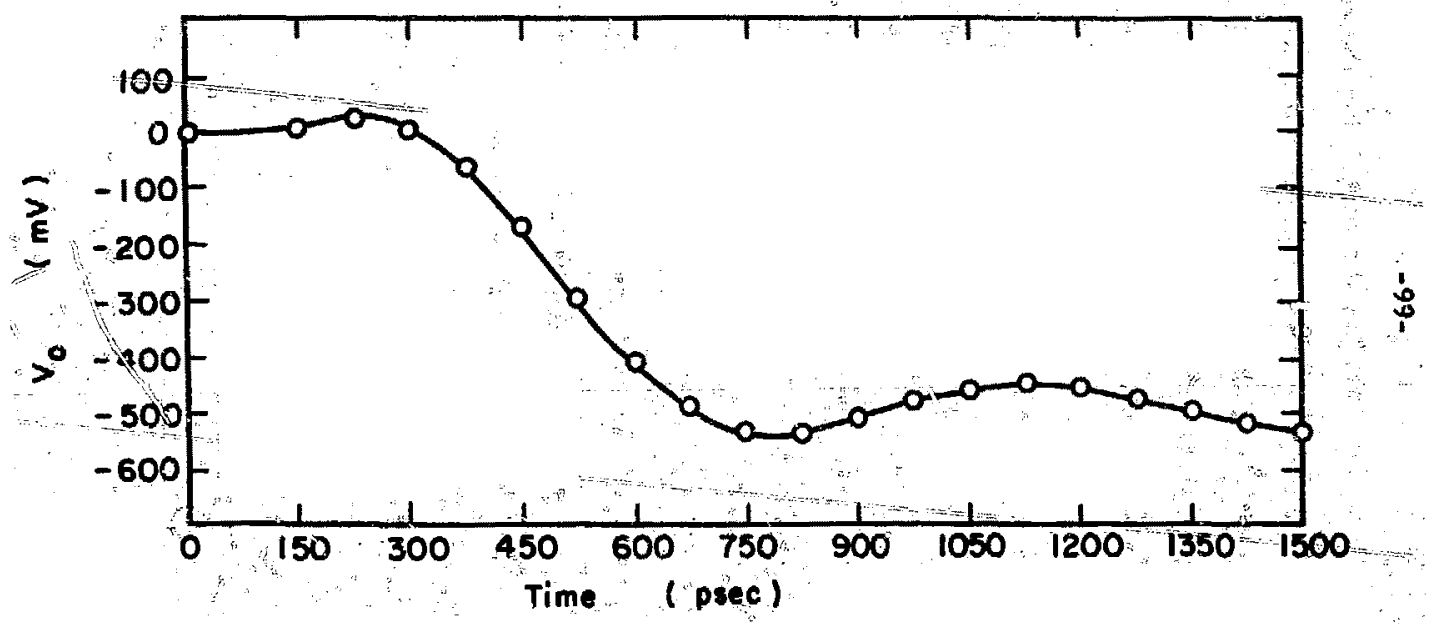

xघL724-2792

Fig. 6-7 
Actual test of the aplifier was wade using tine equipwent eiployed for eval ation of the series-shent pair described in Chapter 5. Figure (6-a) shows the aplifier driving wareform used in the test, and shown in the Figs. $(6-8 b, c)$ is the resulting output. The output waveform posesses a risetive of epproximately 320 psec with maxim overshoot of about 134.

The risetime of the experimental device is about $16 t$ slowgr then the predicted risetine, and the overshoot is about 5 hipher. These discrepancies are certainly within the range of acceptability, since estination of all circuit parasitics was mede on a silple first-order basis, and since the passive compononts are not at their exact values due to fabrication tolerances.

The errors notwithstanding, the response of the plifier meets for all prectical purposes the specification laid down for it in Chapter 1. The overshoot can easily be brount down to less than $10 \mathrm{~s}$ sively by increasing slightly the value of $\mathrm{C}_{\mathrm{F}}$. This procedure would, of course, increase the risetime, but an adequate safety margin of $180 \mathrm{psec}$ exists before the limiting value quoted in the spectfication of 500 psec is resched.

Scattering parmater evaluations wore also made on the eplifier for the irput scattering quantity $s_{1,1}$, and the forward scattering parameter $\mathbf{s}_{21}$. The resuits of those measurenents are plotted in Fig. (6-6) and (6-5), respectivaly, alongside the anelytically deternined paraneters. Agreenent is good, and the slightly laver frequency rolloff of $s_{21}$ in the experimantal case may be taken as indication of the observed fact that the step response of the actual aplifier is a little slower than predicted. 


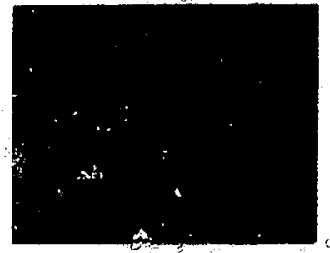

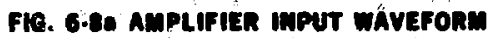
$2 m$ wdiv.

30 peec/div.

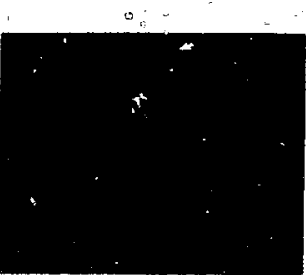

FIB. 6-8b aispLafien outrut mavifonm VIA 200D ATTEWUATOR 2mv/div. Inewe/div.

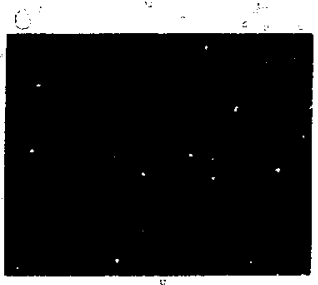

Fig. orge Amplifien OUTPUT mavefoñm VIA 20 d ATtenustor zinV/div. 400psec/div.

FIG. 6.8 SMALL-SIGNAL RESPONSE OF THE SERIES-SERIES TRIPLE. 
As was done in Cheter 5 for the series-shunt pair, it is of interest to wake on exporivontal ascestumat of the largo-signel behaviour of the series-series triple. To this ad, the aplifier was driven with a varibble aplitude vorsion of the pulse uned to evaluate its smallsignal response, and risetif moasurements were ande on the cutput. Figure (6-9) gives a pictorial exple of the large-signal response of the inlifier; the upper photogeph shows the input wareform, and shown in the laiver photograph is the eseociated aplifier cutput. It is apperent that oven with on 800 if filtud on the output waveforn, the rise-

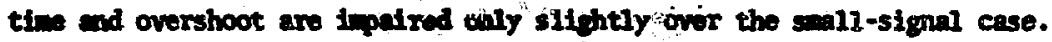
A exphical presentation of the Imge-siping trisient-response moasurewate is the subject of PIg. $(6-10)$, and it will be noted that in all cases, the risotive at the cutput is bold aprecibly below the design Iixit of 500 psoc. This very high slew rate is a consequence of the fact that the design of the aplifier incorporates no lange cepacitors wich have to be charged throuph hish ipadmce sources, and which would honce linit the speed of the cutput. Slew rate can be calculatod diroctly fron Fig. (6-10) for any value of output lovel by taking the ratio of output risotino, to 80 of the total output voltage excursion. A typical value for slew rate is that for in output transition aplitude of $500 \mathrm{mV}$, at wich in elementary calculation shows that $t_{\text {slow }} \mathbf{1} \mathrm{V} / \mathrm{ns}$. The mechmism responsible for risetive degradation in the large signal case is yost probebly the effect of transistor nonlinearities, especially those in the output device, which in large signal casos is required to operate over a noarly $3: 1$ variation in $I_{c}$, with 
- rather lesser change in $V_{C E}$. Quntitative ovaluation of these effects requires malysis of the eplifier to be done using the full nonlinear nodel of the constitument transistors.

Spot measurements were takin of the nolse figure $N$ of the seriesseries triple, and the redults plotted in Fig. (6-11) where it is seen that a niband noise-figure of boit $4 \mathrm{~dB}$ is attained. Corresponding to this, from Eq. (5-19), is an input-referred noise voltage of $\overline{0}_{\mathrm{i}}^{2}=47 \times 10^{-20} \mathrm{v}^{2} \mathrm{Mz}$. As wes the case with the series-shunt pair noise figure, $\boldsymbol{\|} \mathrm{cm}$ be expectod to incresse for low frequencies due to the effects of flicker noise in the trinsistors. Sinilerly, noise figure incresses at the high-frequency and of the aplifier passband due to rolloff of aplifier gain, and the incroese of transistor $1 / f^{2}$ noise. 


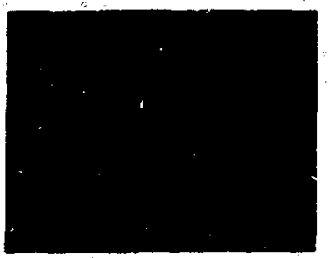

FIG. 6-9. AMPLIFIER IMPUT WAVEFORM $20 \mathrm{mV} / \mathrm{div}$. 50 proce/div.

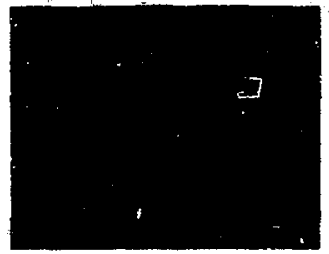

FIG. 6.9b AMPLIFIER OUTPUT WAVEFORM VIA 20 dB ATTENUATOR $20 \mathrm{mV} / \mathrm{div}$. 1 mese/div.

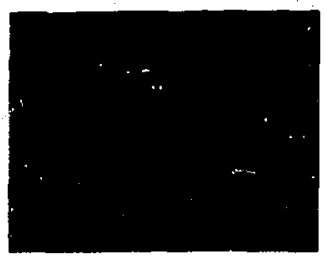

FIG. 6.96 AMPLIFIEA OUTPUT WAVEFOAM VIA 20 dD ATTERUATOR $20 \mathrm{mv} / \mathrm{div}$. 400 psoc/div. XBB T22-815

FIO. 5.9 LARGE-SIGNAL RESPONSE OF THE SERIES-SERIES TRIPLE. 
$-105-$

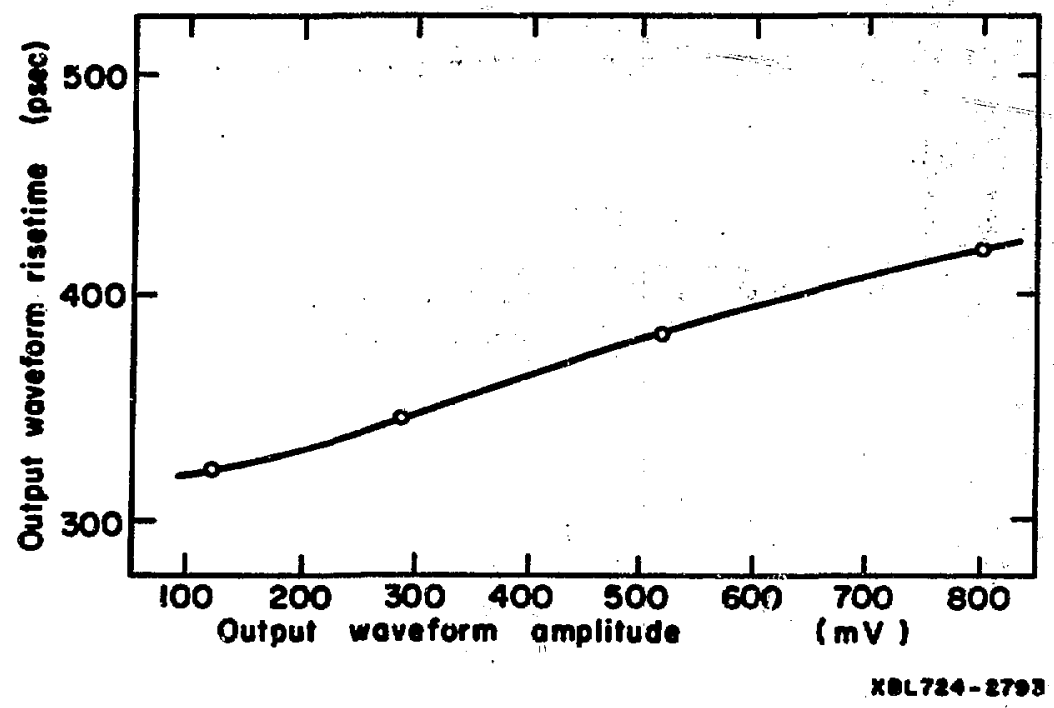

Fig. 6-10 


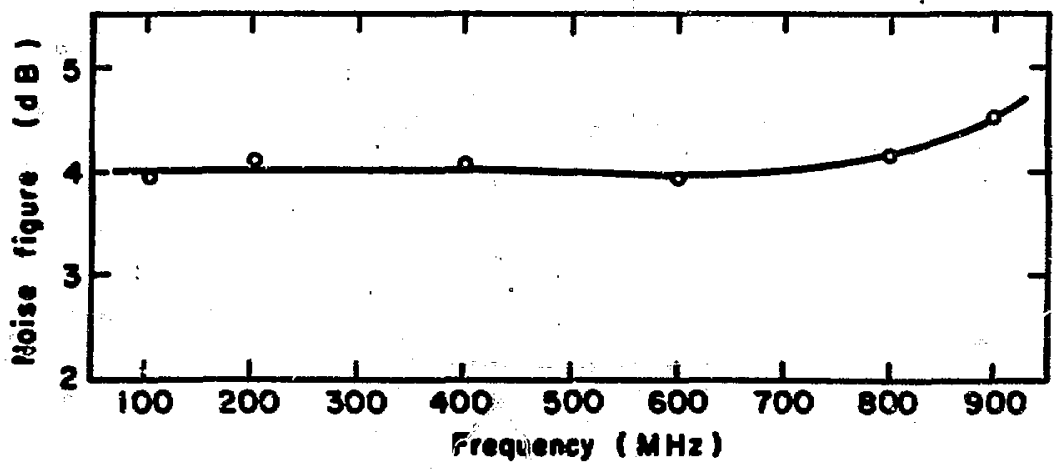

Nith 75-1055

Fis. 6-11 


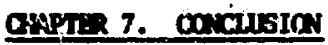

The efficient design and sccurats prediction of perfotmeze of Inoar yulse apliftere of submenosecond risetive requires, in idditicn

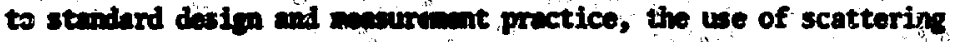
perraneters and of the coiputer.

The use of scattorine parwieters is apeciaily nocessery in the gin-signel characterizitiod of hiph-frequency trinsistot owing to

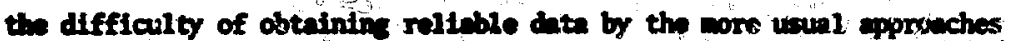
of $y$ - or 2-intrix monourmant, or thrount the aplication to the device of a series of masurements deftend to single out for valuntion a particular elewent of the anl-signe bolil. The accurate interpretation of scatterine anta for a purtianar dorice is greatly hided by the

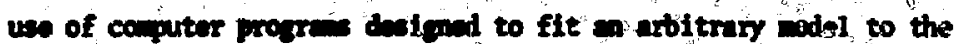
manared date. That this operation cm be done efficienty can be verified by notine that an coplete characterlizntion of the type discussed In Chepter 4 took 2.07 seconds of central processere tim on a (XX) 6600 mohine.

In the ectur seigh of aplifier circuits intended tor high-frequacy oporation, the we of the computer is esselitisl, for 1t enables full eccount to be tabon of all spurious roactences consequent to the physival realization of alroult. Computor alded malysis is further comended if hrbild or integrated circuit method of circuit construction are contemplated dis to the difficulties attendant upon prototype alteration. 
Ipon conclusion of the eplifier desipo and construction, scattering parmeters provide cominient vehicle of performence evaluation in the fropuncy domin, and wo useful dinactly if it is dosirod that the ipltfier be desterad to net a freviency-dojain respense specification. The excellent agrecibent observed in this work between theoretical and experisontal date confin thint the epproaches described herein are valid, and pives confidence that thoy can be applied in futire work in 1ivenr wdiberd circuit daston and yield accurate results.

Of the 2wo feedbeck configurations treated in this paper, the seriesstries triple eppeare theorveteally to hwre a definite superiority over. theres-shat pair. This is a consequence of the improved risetime of the triple, a prodiction thich wa also borne out experimentally. In andilimy bactit of the triple lies in its possession of a potentintly hichor loop gain than that of the pair; this leads to an increased Laneitivity of the triple to parmoter variations in caparisan with thite of the fomibeck pair.

In reopet of noise performenco, both the series-shemt pair and scries-sertis triple appier from exporimental stindpoint to be about 4pin. The cocurrey of the noise mosurements ande on the aplifiers winted by that of the tost equipunt used; find a nore detailed comprison of plifier naise figure anits moguremonts of higher cocursey and greater frepuncy rainge then those indo horo. 
The performance of these amplifiers is to an extent limited by the capabilities of the apparatus and techinology used in their fabrication, and also by the fact that the designs were carried out as an investigation into the feasibility of attaining subnanosecond risetime feedback amplifiers rather than with the intention of designing a circuit for general use. Suggestions ror a mmber of improvenents in, and additions to, the original designs can therefore be nade.

In regard to device fabrication, there appears to be no bar to recucing by a factor of, say, two, the size of the active area of the circu't. Such a retuction would yield further decreases in magnitude of the parasitic elements. The effects of a large enitter inductance can be serious, for it leads to degenerative $10 \mathrm{~cd}$ i series feedback which iricreases with frequency, this causes the stage gain to fall off at a faster rate then would be the case were the enitter inductance absent. It has been found, however, by means of repeated computer aided analysis, that only a small $(\because 20 \mathrm{psec}$ in the series-series triple) thoorotical improvement in circuit risetime is possible tr reducing to zero the enitter inductance parasitics in the circuits described here. This degree of improvenent is not significant for the order of magnitixdo of risetim posessed by these circuits, however, as risetimes are iproved, the effects of lead inductance may increase in dominance. 
As a safety precuution in a user-oriented design, it would seem advisable to incorporate into the output stage som sort of output current lijiting in onder to svoid catastrophic failure of the output stag due to excessive current drain. For the hA 35820-A transistor used in the aplifiers described herein, $45 \mathrm{AA}$ is quoted as the maxima sfe onlector current. Hence, output stage arrent liniting could rumsonably be set to linit at somithat above $30 \mathrm{~mA}$, a value corresponding to wope than one voit output into 50 ohs, assuming a quiescent citter current of $10 \mathrm{~mA}$.

As afinal madification, it would be of utility to incorporate d-c besaline stabilization into the aplifier. Especially at low pulse duty-cycle ratios, an efficient wry to accomplish this is through the we of m ancillary circuit which integrates the irput and output of the wideband aplifler and fumfshes a d-c error voltage to the widebend yplifier of such polarity as to couse the aplifier output to track the input ac lovel. Hist loop gain in the correction circuit can be attained by using a standard integrated operational aplifier.

Fiture work aicang the lines of circuit redization to provide extropely high-speed eplififation will most probably nocessitate the

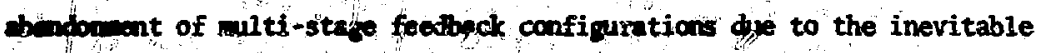
problins in then occesiond by loop lenth and the consequent destabilizIng foffect of the transversal deliny introduced thereby. Moreover, the parpsitics in the circuit tem $\rho$ introduce additional ligs over and above these due to doninant singularities; these additional phase shifts roluce the loop phase targin, therevy increasing the difficulty of applying overall feetuack around several stages. 
A more profitable approach for aplifiers intended to have risetime of the order of say 100 psec, would be the use of a cascade of single stages, perhaps with local fsedback. The use of impedance level mismatching betwreen adjacent stages has the additional virtue of pernitting an overall anplifier pole-zero pattern to be synthesized by appealing to each stage in turn sincs, at least to first order, miswatching would ensure response independence of an intennediate stage fran its predecessor and successor.

Transistors are now available with $f_{T}$ figures of the order of $6 \mathrm{GHz}$, and altrough these devices presently suffer the limitation of a restricted range of operating conditions, this disadvantage may be remedied in future. (36) An alternate route to the direct use of high $f_{T}$ devices might be the application of novel circuit techniques; for example, the ' $f_{T}$-doubler' circuit proposed recently ${ }^{(37)}$ by workers at the Toktronix Company is capable of a theoretical doubling of the $f_{T}$ of the constituent transistors.

The development of higher speod amplifiers will also necessitate the tighter control over parasitic elewents, and the nore universal application of transmission-line technique than has been used in the circuits described in this paper. 


\section{ACANOILEDGENS}

Although I had helpful discussions with mamy perscons regarding the work described herein, I an particularly indebted to Professor H. G. Jackson for undertaking to supervise this research and for guidence during all phases of the work. I should like aiso to thank Mrs. Dorothy McDaniel of the Integrated Circuit Laboratory of The thiversity of California for her assistance in the fabrication of the experimental devices. Finally, I wish to thenk Mrs. Vicky Donelson for typing the ranuscript and preparing certain of the figures.

\section{REFERPACES}

1. J. Harms, "Coupensation of Enitter-Base Voltage Variations with Operational Amplifiers", Muc1. Inst, and Methods, Vol. 77, 173 (1969).

2. B. A. Wooley, Ph.D. Thesis, thiversity of Califomia, Berkeley, 1970, "Design Optinization of Integrated Broadband Arifiers".

3. E. S. Kuh, R. A. Bohrer, "Theory of Linear Active Networks", HoldenDay Comany, 1967 Sen Francisco.

4. Fritz Weinert, "Scattering Parameters Speed Dosign of High-Frentency Transistor Circuits", Electronics, Sept. 5, 1966. Reprinted in H.P. Application Nore 95, p. 2-1).

5. S. W. Director and R. A. Rohrer, 'The Ceneralized Adjolnt Netiork and Hetwork Sensitivities", IEEE Trans. on Circuit Theory, Vo1. GT-16, No. 3 (1969). 


\section{References (Continued)}

6. S. W. Director and R. A. Aohrer, 'On the Efficient Conputation of First-Oxder Network Sersitivitios (For Prequency-Domein Studies of Lupod, Linear, Timo-Imvarient Notworks)", Umpublishod Nonograph.

7. R. A. Pohrer, "Automated Network Dosign--The Froquency-Domain Case", IEEE Trans, on Circuit Theory, Vol. CT-16, No. 3, pg. 330 (1969).

8. C. A. Dosoor and E. S. Kuh, "Elenentary Circuit Theory", MeGrawHi11 Coupany, New York, pg. 392 (1969).

9. R. Fletcher, "A new Approach to Variable Motric Algorithes" The Computer Journal, Vol. 13, No. 3, pg. 317 (1970).

10. R. Flotcher and M.J.D. Powoll, "A Rapidly Convergent Descent Method for Minimization", The Computer Joumal, Vol. 6, No.13 pg. 163 (1963).

11. I.B.M. Company, "Systea/360 Scientific Subroutine Package" (Publication 360A-O4-03X Vor. III) Program FaP, Extroma of Functions.

12. R. E. Willianson, R. H. Crowell, and H. F. Thottor, Jalculus of Vestor Punctions", Prentice-Hall Compeny, New Jorsey, pg. 251 (1968).

13. E. Polak, "Couputational Methods in Optinization", Academic Press How York, pg. 38 (1971).

14. W. C. Davidon, "Variable Moteric Mothod for Minimization", Argenne National Lab. Report NL-5990 (1959). 


\section{Roforences (Continued)}

15. R. Fletcher and M.J.D. Powe1l, "A Rapidly Convergent Descent Method for Minimization", The Computer Jcurnal, Vol. 6, No. 13, P8. 164 (1963).

16. R. Fletcher, "A new Approech to Variable Metric Algorithms", The Computer Joumal, Vol. 13, No. 3, pg. 322 (1970).

17. 1bid, pg. 319.

18. R. D. Berry, "An Optimal Ordering of Eleccronic Circuit Equations for a Sparse Matrix Solution", IEEE Trans. Circuit Theory Vo1. CT-1a, No. 1 , pg. 40 (1971).

19. K. Hoffman and R. Kumze, "Linear Algebra", Prentice-Hall Company New Jersey; (1961).

20. A. Ralston, "A First Course in Nemerical Analysis", McGraw-Hill Compeny, New York (1965).

21. S. W. Director, 'LU Factorization end Network Sensitivity Computations", IEEE Trans. Circuit Theo1y, Vol. CT-18, No. 1 (1971).

22. Conputer Program "RoHRER-X" Written in Fortran IV for general circuit analysis in dc and ac stearly-state conditions.

23. P. E. Gray, D. Delìte, A. R. Boothroyd, and J. F. Gibbons, 'Physical Electronics and Circuit Models of Transistors", John Wiley and Sons, New York, (1965). 
Poferences (Continued)

24. Hewlett-Packard Company,HPA 35820-A Transistor Specifications: Microwave Division.)

25. Howlett-Packand Conpany, Instruction Hendbooks for the following instruments:

(i) Type 8405A - Vector Voltmeter

(ii) Type 8745A - Scattering Paraneter Test Set

(iii) Type 11600B - Transistor Test Fixture

26. "Frank!": Linear Pole-Zero Analysis Progran written by I.C. Group, university of California, Berkeley.

27. R. Saucedo and E. B. Schiring, "Introduction to Contirnous and Digital Control Systems", The Machillan Company, New York (1968).

28. B. M. Cherry, and D. E. Hooper, "Anplifying Devices and Low-Pass Arplifier Design", Inhn Wiley and Sons, New York (1968).

39. S. V. Judd, I. Whitely, R. J. Clowes, and D. C. Rickard, IAn Analytical Nethod for Calculating Microstrip Transmission Line Paraneters", IEEE Trans, on Vicrowave Theory and Techniques, Vol. MT-18, №. 2 (1970).

30. H. G. Jackson, and J: A. Matitis, "A Direct-Coupled Hybrid I.C. Anplifier with 1-nsec Risetime", UCRL Report 18367 (1958).

31. M. S. Ghausi, "Principles and Design of Linear Active Circuits", McGraw-Hill Coxpany, New York, (1965). 
Peferences (Continued)

32. "Cancer", General-purpose Circuit Analysis Progran written by the I.C. Group at the University of California, Bericeley. See also, L. Nagel and R. Rohrer, 'Computer Anglysis of Nonlinear Circuits, Excluding Radiation (Cancer)", IEkE J. Solid State Circaits, Vol: SC-6, No. 4 (1971).

33. B. P. Lathi, "Comamication Systems", John Wiley and Sons, New York (1968).

34. M. Schwartz, "Information Transmission, Modulation and Noise", McGraw-Hill Company, New Yơrk (1970).

35. D. O. Pederson, "Electronic Circuits", McGraw-Hi11 anpany, New York (1965) preliminary edition.

36. See for example, Avantek Ccomany, Type AT-240-B. Avantek Company, 2981 Copper Road, Santa Clara, Califormia 95051.

37. V. Garuts, and T. Hallen, "A Subnancsecond Realtime Oscilloscope" Tektronix Caryany, Tekscope, July 1971 . 
AP PENDICES 


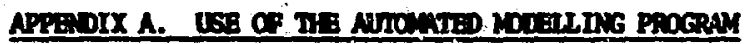

Date input to the progrem is via punched cards; in order to facilitato the task of entering data, the cands are resd by the progran under a 'free" format whorein flelds on a card are separated by a deliniter 'd' which wy be a caim or one or wore speces. Mrerical information wy be given in fixed-point, floating, or exponential form, and any card nay be continued in pbitrary nuber of times by punching as the first charactor on each continuation card on asterisk. Batch-processing is ued, so that any nuber of duta decks nay be processed consecutively by the program.

What follows is a doscription of the various cards required by the progrem.

\section{[A] TITLE CARD}

The title card ast be the first card in each date deck, and it may contain arbitrary alphamueric information descriptive of the problem being dors, for eximple, NODE OF HPA 35820-A TRUSISTOR AT IC = $10 \mathrm{MA}$, $v_{C E}=5$.

\section{[B] SCATTERING PARAVETER CARD}

Up to sixty scattering paranter cards my be used. These cards contein the scattering natrices to which the circuit undergoing optimization is to be fitted by the program. Their general form is: 


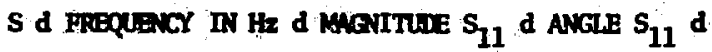

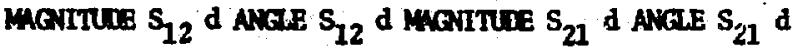
MANITUDE $s_{22}$ d ANGE $s_{22}$

\section{[C] MEICTT-FACIOR CARD}

Tinis card contains the wighting factors to be used in the error fuction and also the normalizing resistance under which the scattering parmeters of [B], bove, are taken. This card is of general form:

$$
\begin{aligned}
& \text { WEIGT d WEIGH } s_{11} \text { a WEIOH } s_{12} \text { a WEIGT' } s_{21} \text { ? } \\
& \text { WEIGT } \mathrm{S}_{22} \text { a NORMLIZING RESISTANCE }
\end{aligned}
$$

One wipht card must be included with each problen.

\section{[D] BLEVEN CARDS}

These cards describe the elements of the circuit in terms of their topolorical position and value. The nodes of the circuit are assumed to heve been assigned integer mubers with the sole restrictions that the dutu node aust be nubered zero, and that no nuber must be used wore then once. Element cards are of four classes, as follows:

\section{(i) Pesistors}

\section{S. $:$}

WWE OF UP 10 SEVEN CHARACTERS BEGINING WTH R d ESTIMATED OR TREE VALUE d + NODE d - NODE. 


\section{(ii) Canacitors}

NWE OF UP TO SEVEN CHRACTERS BEGLWING WTTH $C$ d BSTIMATED OR TREE VALE $d+$ NODE $d$ - NORE.

(iii) Induxtors

NAE OF $U$ TO SEVEN CHARACTERS BEGINING WITH $L$ d ESTRATED OR TRAE VALUE d + NODE d - NODE.

(iv) Voltagi-Controlled aurrent sources

NAEE OF UP TO SEVEN CHARACTERS BEGINIING VITH OU d ESTIMATED OR TPUS VALUE OF TRANSCONDUCTANCE d. NANE OF UP TO SEVEN CHARACTERS BEGTNING WITH TO d ESTTMATED OR TRIE

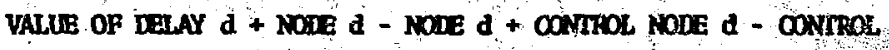
soDe.

\section{[E] PORT CARRS}

no port cards must accomany each problem; that for the inpurt port is as follows:

INPORT $d+$ nOCE $d$ - NoDE.

While that describing the output port hes the form: OUIPORT $d+$ MOEE d - NODE.

[F] OPTIMZE CNPD.

This card doscribes by neme the circuit paramters subject to variation by the progrm in the fitting process. This card is of the forlowing forn: 
.OPT a MAXIMM PEPMISSIELE NUBER OF ITERATIOAS IN THE OPTIMIZATION A PRTNT INTERVAL IN THE OPTIMIZATION A NAME OF FIRST PARAMETER TO BE OPTIMIZED d NME OF SECOND PARAMETER TO BE OPTIMIZED d - - - .

Up to 30 parameters may be optimized simultaneously.

[G] ERD CARD

This card must be the last card in each problem, and has the form: .END

An example circuit and data deck are illustrated in Fig. A-1. 


\section{(1) circuit}

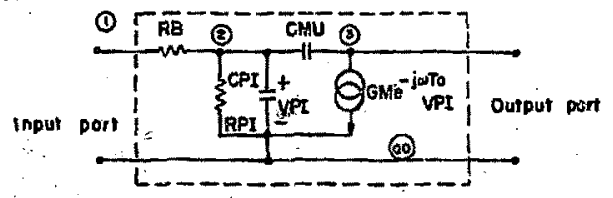

(2) ESTIMATED YALUES SCALED TO $\rightarrow$ IN OHMS,

$C$ IN $P F, T$ IN PS, AND $F$ IN $\times 10^{12} \mathrm{~Hz}$

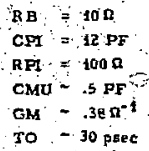

(3) MEASUTED BCATTERTIE MATRICES.

FRECUEXCY $s_{11} ! s_{11}\left|s_{32}+s_{12}\right| s_{21}\left|s_{24}\right| s_{22} \mid+s_{22}$ (x) $10^{12}$ HE⿰冫)

$\begin{array}{lllllllll}0.0002 & 0.5 & -95^{\circ} & 034 & 69^{\circ} & 11.2 & 123^{\circ} & .69 & -26^{\circ} \\ 0.0004 & 0.22 & +145^{\circ} & .052 & 68^{\circ} & 6.5 & 500^{\circ} & .55 & -25^{\circ} \\ 0.0006 & 0.22 & -176^{\circ} & .072 & 68^{\circ} & 4.4 & 87^{\circ} & .50 & -26^{\circ}\end{array}$

50 . SORMALHANT RESISTAVCE USED.
(4) Phoblem

CALCULATE CMU, GM, AND TO SO AS TO GIVE BEST AGREEMENI OF CTRCUIT SCATTERINT:

PIRAAMETERS AMD MEASCRED SCAT TERING MATRICES.

(5) PRogram infut dita.

\section{TEST EXAMPLE}

WEIGHT, 1, 1, 1, 1, 50

$R B, 10,01,02$

RPI, $100,02,00$

CPL, 12,0,02, 00

CMÚ, 0.50, 02, 03

LNPORT, 01, Uิt

GM, .38, TO, 30, 03, .10, 02,00

OUTPOFT, 03, 00

OPT, 300, 10, GM, CMJ, TO

S, $2 E-4,3,-95,034,7+9,14.2,123, .69,-26$

$S, 4, E=4, .22,-145,, 05: 68,6.5,100, .55,-25$

S, $.0006, .22,-176, .072,68,4,4,87, .50,-26$

END

NOTE THAT UP TO 300 TTERATIONS WHLL BE MAOE, THAT PRINT-OUTS OF DROGRAM STATUS WILL OF. TAKEN EVEF $Y$ 10 ITERATIONS, ANO THAT ALL SCATTERING PARAMETER WEIGHTS HAVE AEEN SET TO UNTY.

\section{XBL725-3057}

Fig. $A=1$ 
APPENDIX B.

Given in this appendix is a full fortran listing of the program 'MODEL". In its present form, it is suitable for use on any of the CDC 6400,6600 , or 7600 conputers; minor alterations may be necessary to suit the program for use on other machines. In particular, it may be found necessary on computers having smaller word sizes than the CDC machines to use double-precision in the matrix solution and decomposition routines, and in the optinization subprogram in order to avoid mmerical difficulties arising froil rounding errors. 
PROGRAM HMOOEL (INPUT, OJ̦TPUT, TAPESEINPU̦T)

R. WILSON. VERSION NITHJUT POST-OPTIMISATION SCATTERING sarameter calculation.

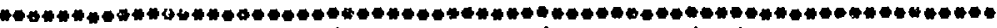
MMMOOEL IS A COMPUTER PROSRAY TO DETERMINE THE VALUES OF PRESERIJED ELEMENTS OF AN. R=L-C=GM-TO (DELAY) NETWOAK REOUIZEJ TO REALISE THE BEST FIT OF THE NETWORK TO A GIVEN SET. OF TWOAPORT RESPOUSES. JHE JESIREO RESPONSE IS FUNNISHED TO THE PHOGHAN IN FOAM OF A SERIES JF UP TO SIXTY SETS OF TWO-PORT SCATTENING PARAMETERS TAKEN I ARBITRARY FREQUENCIES UVEA. THE SPEETHUH IN WHICH BEST. FIT OF IME VETWORK TO THE GIVEN DATA IS SOUGHT. THE IVCORPORATION INTO THIS PROGRAYY OF PROVISION FÜH SIMULATINS DELAY TIME AVD FOR ACEEPTING ŚCATTERING PARAMETERS MÄKES IT PAHTICULARLY USEFUL TH THE MOJELLING Jo miCROHAVE DEVICES IN THS SMALL-SIGNAL REgIOÑ OF OPERATION.

PROGRAM CAPACITY IS AS FOLLOHS.

36 NOUES, NOT INCLUSING DATUM: 1 IO ELEMENTS. R. LO C. AND GM/TO ARE aCCEPTEO AS ELEMENTS. 30 OPTIMISABLE PARAMETERS. zerozivalued Elements are not: PERmItTed.

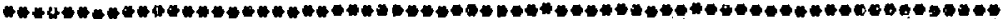

THIS IS THE CONTROLLING PROGRAM.

COMMON DECLARATIONS.

COMMON /KILL/ NOGO JEOFI

COHHON FOPTIKUM WEIGHT(S) JLOCX(30) IDOPT (30) NOPT NPRINI.

1 NITER X $(30)$. SCALEX(30)

COMPLEX YDA TUM YNL VOATUH, UN

COMMON FMATRIX, YOATUH YNL (300) VOATUH, VH (30) 4ATLOC (4BA)

COMPLEX PORT

COMMON, /PORTDAT/ PORT (60.4) -OMEGA (60) , NPOINTS PRNOAM LOCPAI I.

1 LOCPRT2

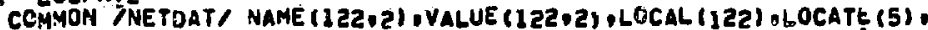

1 NODPLE IA84I. NUMNOD

COMHON FCARD/ FIELOIZZJ HUHFLD, IO, IHALT, ICAROI

DIHENSION TEYPOAT $(60,6)$

EQUTVALENCE (TEMPONT $(2,1)$ YNL (1))

OIHENSION ITITLE (B)

DIMENSION IONOPIZOI, JUNODE (30)

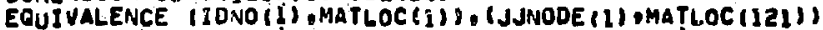

DATA ISHIFTILQ0000U000000B/

DATA ILETA/225/

DATA ILEFC/O3B/

DATA ZLETL/14B/

DATA TLETG/OTB/

DATA ILETT/ZGB/

C

C EAlsulate constants and gNitialise. 
PROGRAM MMODEL (JNPUT, ,OJTPUT, TAPESEJ HPUT,

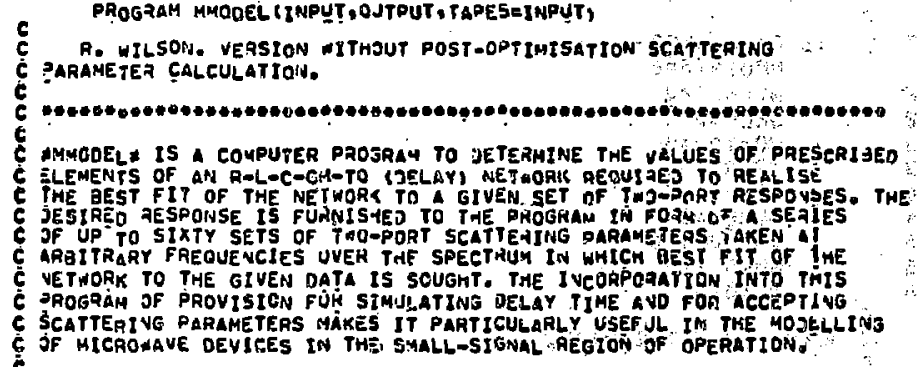

PRDGRAH CQAPACZTY IS aS FOLL,OAS.

30 NODES, HOT INCLUJIAG DATUMa

120 ELEHENTS.

R. Li C. ANO aH/TO ARE ACCEPPẸ AS ELENENTS.

TO OPTIMISAGLE PARAMETERS:

ZEROAVALUED ELERENTS ARE NOT PERMITTED.

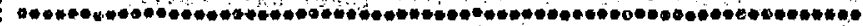

thIS IS tHE CONTAOLLING PRJgRAM.

8

COAMON DECLARATZONS.

COHHON AKILL/ NOGO.JEOF!

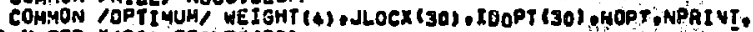

1 NITER, X (30) - SCALEX (30)

COMPLEX YOATJMHYNL VOATUY, VH

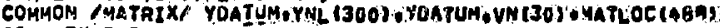

COMPLEX POAT

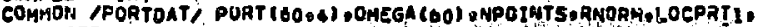

I LEPRT?

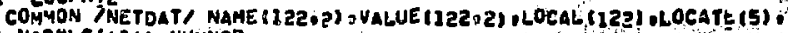

1 NODPLC (\$B \&) +NUMNOD

COMHION /CAAD/. FIELO(32),NIJHFLO IO.JHALT. JCAADI

DIMEVSTON TEYPOFT(G),

FouIVALENCE (TEMPONA(1,1), VNL (1)

OTMEVSION ITITLE (B)

OIMEYSION IDYO(IZO) JUNOTE T36)

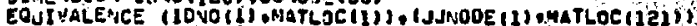

OATA ISHIFTHIO000060000UgaP

DATA ILETARZ2BR

QATA ILETC/OBOP

DATA LLETL/LE/

OATA ILETG/OTZA

c

OATA ILETT/ZSB

C Ealculate constavts and InItrelsse: 


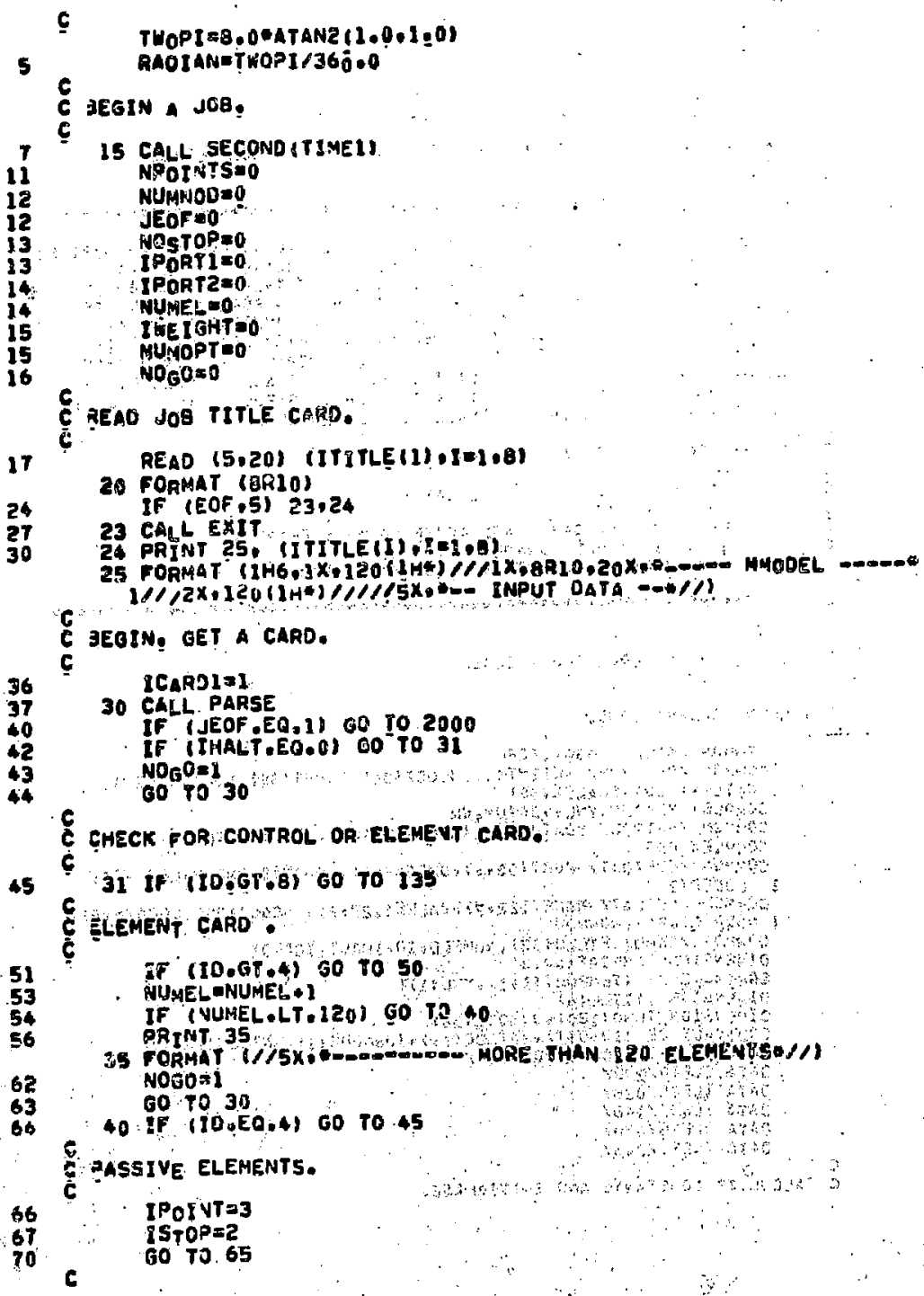




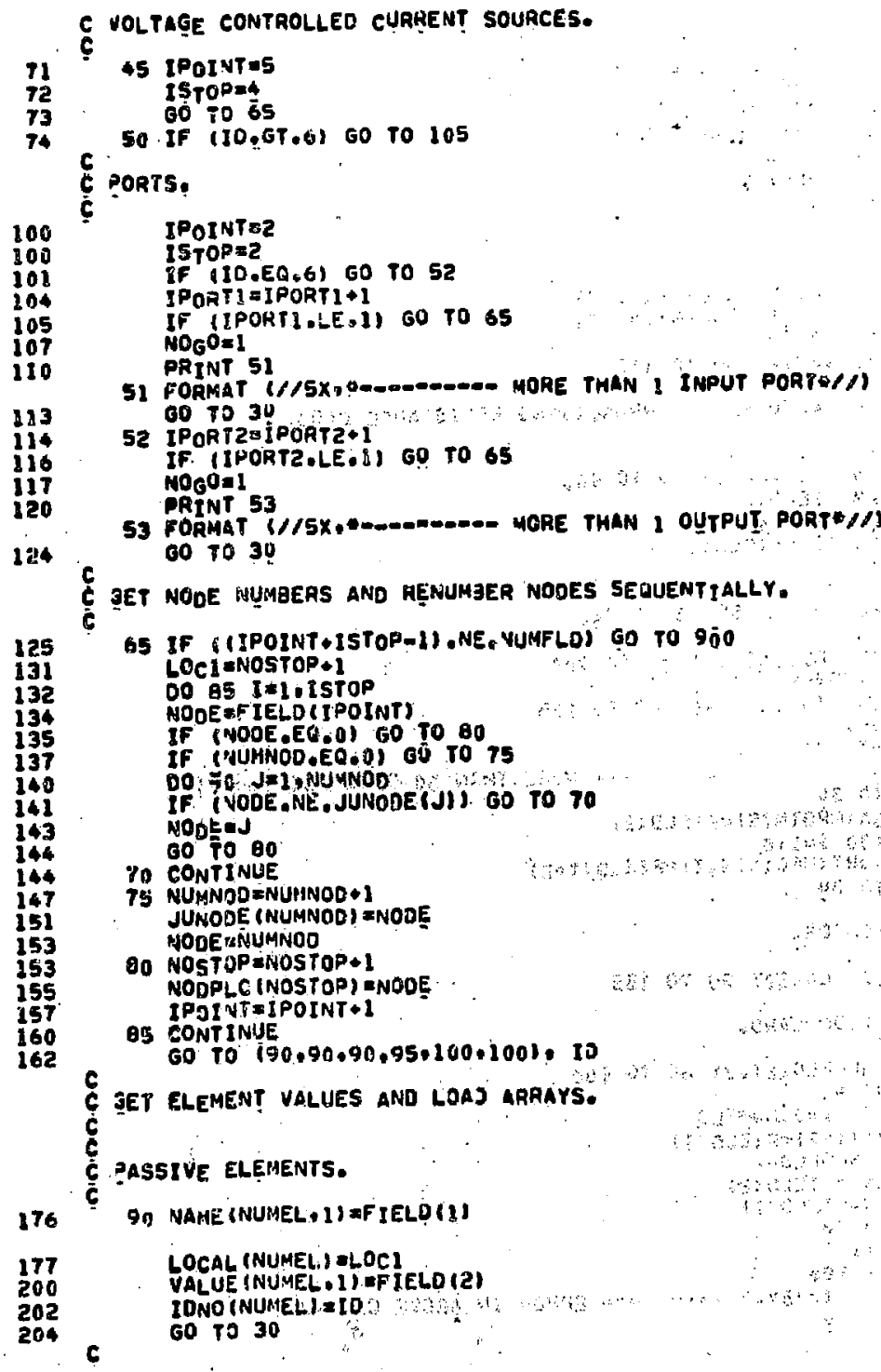


\& VOLTAGE CONTROLLED CUYRENT SOURCES.

$c$

95 MAME (NLMEL , ?) $=F$ IELD (1)

VALUE (NUMAEL D 1) =F IELD (2)

MAME (NUMEL , 2 ) $=F$ IELU (3)

YALÚ (NUMEL, 2 ) E FIELD (4)

LOCAL (NUMEL) $\approx L O C I$

IONO (NUMEL) $=$ ID

CORTS.

60 TO 30

100 IF (ID.EO.5) LOCPRT IELOCI

If $(10, E Q, 6\}$ LOCPRTZ-LDCI

60 ro 30

105 If $(10, G T \cdot 7)$ GO TO 115

C AEIGHTING FACTORS AND NORHALISING RESISTANCE CARD.

IWEJONTEI

IF (NUAFLD.NE.6) GO TO 900

QNNORM=FIELD (B)

00 i20: $1=1.4$

110 WEIGHT (I) =FIELD $(I$ \& I)

60 ro 30

C PORT FREOUENCY RESPONSE DATA.

C

115 IF (NUMFLO NE, 10) GO TO 900

MPOINTSENPOINTS 1

If (NPOINTS.LE.6O) GO TO 125

MOgOel

phint 120

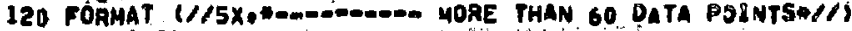
00 to 30

125 OMEGALPOINTSI $=F$ IELO (2)

$00130 I=1,8$

130 TEMPOAT INPOINTS,I) \#FIELO (I+Z)

$C$ control caros.

CONTHOL GAAOS.

I35 If (IO,EO.10) GO TO 155

$c$

DPTIMISATION CARD.

IF (NUMFLD.LT.3) 60 TO 900

NUMOPTAI

145 DO 1 SO $1=3$, NUMFL

ISO IODPT (I-Z) FFIELOII)

NOPT $=N U M F L D \rightarrow 2$

NPRI VTAF IELD (2)

NITEA $=$ IELO (1)

00 To 30

300 NOGOEl

PRINT 705

TOS FORHAT II/5X.0........... ERHOA IN ABOVE CARON/) Bo 10 34 
C

C ENTRY INTO THE FOLLOWING PART OF THE PAOGRAM IMPLIES THAT AV
C END CARD HAS BEEN ENCOUNTEREO.

ç

155 IF $($ NOGO.EQ.0) 60 TO 170

CERROR MESSAGES.

PRINT 165

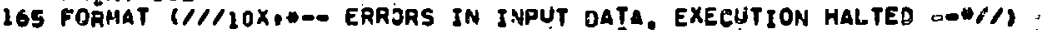
60 TO 2000

170 If (VUMEL:GT:O) GO TO 176 $\mathrm{NO}_{\mathrm{G}} \mathrm{O}=1$

\section{PAINT 175}

175 FORMAT $/ / / 10 X_{0}$ *- CIRCUIY HAS NO ELEMENTSE EXECUTION HALTEO 121

176 IF (NUMOPT.GT.O) GQ TO IBO $\mathrm{NOG}_{\mathrm{G}}=1$ PRgNT 177

177 FORMAT $/ / / / O X_{7} *-$ NO OPTIMISATION REQUESTS. EXECUTION HALTED $1 / 1$

160 . IF (IPORTI.EQ.1) GO TO 186

$\mathrm{NO}_{\mathrm{G}} \mathrm{O}=1$

PRINT 185

183 FORMAT (/H/10X, $1 / 3$

186 IF (NPOINTS,GT.0) GO TO 188 NOGOx1.

PRINT 187

I6T FORMAT (I//IOXOUL NO SCATTERING PARAMETER DATA. EXECUTION HALTEO $1=-\$ / 1 i$

188 IF (IPORT2.EQ.1) GQ TO 190 $\mathrm{NOGO}=1$

PRINT 189

189 FORMAT ///1OK, CIACUIT HAS NO OUTPUT PORT EXECUTION HALTEO -O $1 \%(1)$

190 IF (IWEIGHT.EQ.1) GO TO 200

NOGO=:

PRINT 191

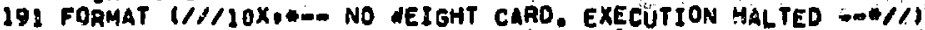

200 IF. (NOGO.EQ.1) GO TO 2000

DAOCESS TWO-POAT DATA:

JAINT OUT TWO-PORT DATA.

PRTNT 205

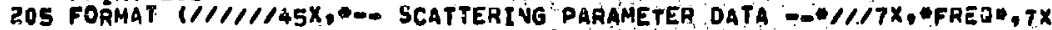

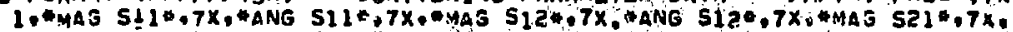

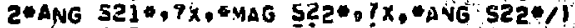

DO 215 IDI. NPDINTS

PRINT 2JO, OYEGAII) , (TEM.'ORT (I.J),J=l,B)

441 315 CONTINUE

C

c

CONVERT FORT DATA FAOM POLAR TO RECTANGULAR COMPLEX FORM. 
444

445

447

451

455

460

$+78$

502

SD6

507

511

512

513

514

515

526

527

531

332

532

534

535

545

553

561

566

570

570

57:

573

576

577

601

617 7

610

611

Q0 2दO ININAOINTS

OHEOA (LI THOPI OOHEG (1)

09216 Jal 24

ANG ARAD I ANETEIPORT (1.2\%J)

KMAG $=$ TEMPORT $(I, 2+J-1)$

c

216 PORT $(I-J)=C M P L X$ (XMAG COS (ANG) XMAG SINIANG)

220 CONTINUE

C PRINT PORTS AND AEIEHTLMO FRCTORS.

PRTNT 225

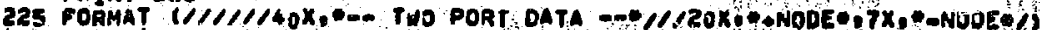
KPHODE NNOOPLC (LOCPATL)

KNANEDE $+N O S P L C(L D C P A T I+1)$

IF IKPNODE.EO.OD GO TO $<30$

KPNODE - JUNODE IKPNOOE

230 If IKNNODE EQ.0I GÚ TO 235

RNNSDE JJUNODE (KNNCDE)

235 PRINT 240.KPNDDE +KNNODE

240 FOAMAT ( $/ 5 x, 4$ INPUT POZT , 5X, I5,7X,IS)

KPNODE $=$ NODPLC (LOCPKTZ)

KAHODE =NODPLC (LOCPKT $2+1)$

IF (KPNNODE.EO.O) 60 TO 2\$5

KPNODE = JUNDDE (KPNODE)

245 IF (KNHODE,EO.0) 69 TO 250

KNNODE JUNOOE \& KNNODE)

250 PRTHT 251, KPNDDE, F.NNO2E

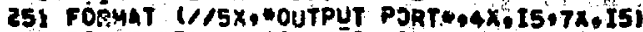

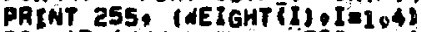

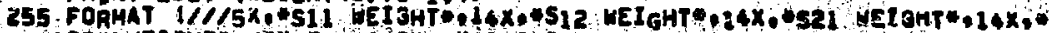

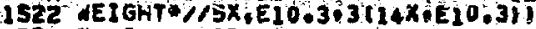

PAINT-256. RNORH

c

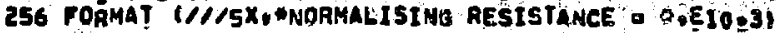

MROCESS MEIGHTING FACTORS.

s.

$00257 \mathrm{Ia1} 1.4$

257 WE GHT (I) EWE IGHT (I) *Z

c

DROCESS CLRCGIT ELEMENT DATAO

SORT ELEUENTS INTO THE OROEA A. Co LO BH/TO, ANO ESTAOLISH

tHE LOCATE ARRAY.

LOCATE (1)=1

NPLACE $=1$

$00266,1 \times 1.4$

IF (VILACE.GT.NUMELI 60 TO 265

00,260 JENPLACE NUMES

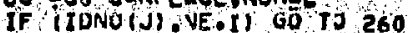

IF UEEG NPLACE, GO TO z59

EXCHANGE ELEMENTS:

NTEMPANAME $(J, 1)$

NAME (J.l) ENA YE (NPLACE, 1)

NANE INPLACE 1 I ENTEMP 
613

615

615

617

620

621

622

623

624

625

627

630

630

631

632

634

637

641

643

647

650

652

654

657

661

663

664

666

667

670

671.

672

710

713

714

7 is

721

724

726

NTEMPRNAME (J.Z)

NAME $(J-2)=N A Y E$ (NPLACE

NAME (NPLACE, 2) =NTEMP

NTEMP $\approx$ LOCAL $(J)$

LOCAL (J) =LOCAL (NPLACE)

LOCALINPLACES SENTEMP

NTEMPEIONO (J)

IONO (J) = JONO (NPLACE)

IONO (NPLACE) I NTEMP

TEMPEVALUE (J.1)

VALUE $(J, 1)=V A L U E$ (NPLACE 1 )

VALUE (NPLACE + 11 TERAP

TEMP $=V A L U E:(J, 2)$

VALUE ( $S, Z$ ) *VALUE (NPLACE, 2 )

VALUE (MPLACE VZ) = TEMP

259. NPLACE $=N P L A C E+1$

260 CONTINUE.

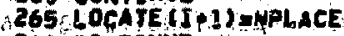

$c$

2GS CONTINUE

PRINT ELEMENT PABULATION.

6

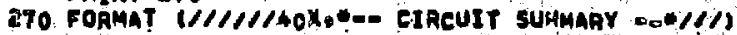

Casstve clements.

C

ISTARTEI

ISTOPALDCATE $(4)-1$

If (ISTUP.LT.ISTART) 60 TO 300

PAINT 275

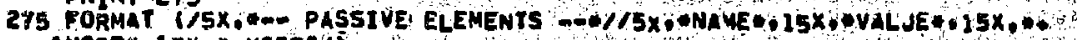
$1400 E * 15 x ; *-100 E * / 1$

DO 295 InISTART,ISTOP

LOCI:LOCALII)

KPNOOE =NODPLE (LOCL)

KNNODESNODPLC ILOCL \&I)

IF QKÖNOCE.EQOOI 00 TO 200

KPNODE = JUNOOE (KPNODE)

280 IF EKNNODE QEO 001 BÜ TO 295

KNNODEEJUNODE (KNNODE)

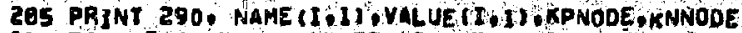

2QO FORMAT $1 \%, 6, R T, 11 X, E 10,3,12 X, 15,15 x, 151$

c

295 CONTINUE

VOLTAGE-CONTROLLEO CURRENT SOURCES

300 ISTART=LOCATE $(4)$

ISTOPECOCATE (5)-1

If IISTOPGLTISTAATS GJ TO 330

PRTNT 305

305 FCAMAT W////SA - VOLTAGE CONTROLLED CUARENT SOURCES - $-/ / 6$ W

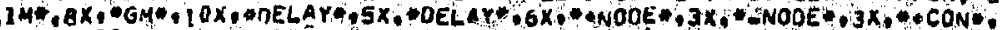

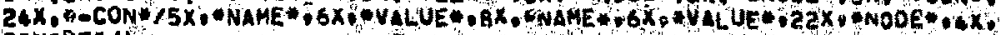
3PNODE:/1 D0 $335, I=$ ISTART, ISTOP LOCI LLOAL (T) 
730

731

733

734

736

737

740

141

742

743

746

745

746

776

1001

1002

1004

1007

1007.

1011

1025

1026

1027

1031

1035

1036

1037

1040

1045 lose

1056

1060

1061

1062

1063

1064

1067

2070

2072

1100

\$10C

KPNODE NODPLC (LOCL)

RNOODE SNOOPLC (LOC1-1)

KPCNODE $=$ NODPLC $(L O C l+2)$

KNCNOOE =NODPLC $(L O C I+3)$

IF (KPNODE, $F 2 \% 1$ ) 00 TO 310

KPNODE E JUNODE (KPNOOE)

320 TF IKNNODE,EO.01 GO TO 315

KNNODE S JUNOOE (KNNOOE)

$31 \mathrm{~s}$ If IRPCNOOE EQOOL 60 To 320

KP WNODE - JUNODE (KPCNODE)

320 IF (KNCNODE.EOIO) GO TO JeS

KNCNDOE $=J U N O D E$ (KNCNICOE)

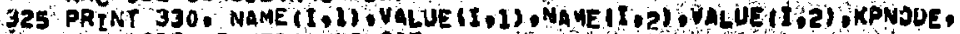
1 KN VOUE OKPCNOOE OKWCHOJE

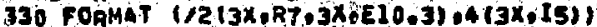

c

333 CONTINUE

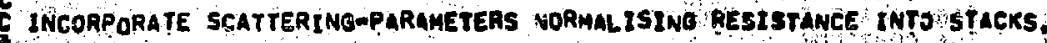

336. ISTAAT $=L O C A T E(2)$

ISTOPELUCATE (5) -1

If (ISTOP.LT.ISTART) 60 To 3005

keistop

jeIsTOP +2

DO 3000 I=ISTART ISTOP

G MOVE ELEHENTS DOWN BY TWO LOEATIONS IN sTAEK.

MAME $(J, 1)$ WNAYE $(K, 1)$

NAME $(J, Z)$ aNAME $(K, 2)$

LOCAL (J) ELOCAL (K)

YALUE (J, I) EVALUE (K, I)

YALUE (J,a) UVLUE (K.2)

$k=K-1$

Jojol

3000 CONTINUEE

C AMENO lOCATE ARRAY TO REFLECT NEW STATUS OF STACK

G.

$3005003020 \quad 1=2.5$

3020 LOCATE (I) LLOCATERII-Z

C INSERT ANOAM ACROSS INPUT MO OUTSUT POPTS:

c

I LOCATE(2)-1

VALUE (I.II ERNORH

LOCAL (I) LOCPATI

$I=I=1$

VAL UE $(I, I)=R$ NOAM

LOCALII I IOCPRT?

C InVERT Resistances ano tnd JCTANCES.

336 ISTARTEI

ISTOPELOCATE (2)-1

OO 337 IIISTART, ISTOO

$337 V f$ UE $(I, I)=1,0 / V A L U E(I, I)$

Q. KETTLDCATE (3) 
1117

1120

1122

1126

1136

1141

1142

1145

1153

1155

1150

iIs?

1161

1163

1164

1166

1167

1170

1172

i17s

1175

1177

1250

1201

1203

1206

3206

1210

1211

1212

1214

1217

1217

1221

1222

1223

1225

1230

1234

1235

ISTOPALOCATE (4) -1

IF IISTOP.LT.ISTARTI GP TO 340

DO 339 I ISTART, ISTOP

339 VALUE $(1,1)=1,0$ NVALUE $(I, 1)$

C ESTABLISH ADMITTANCE MATRIX SPAASE POINTER SYSTENo

340 CALL SETUP

IF NOGO.EO.11 GO TO 2000

C PROCESS OPTIMISATION REOUESTS.

Cognt 349

C ESTAELISH OPTIMISATION POIVTER SYSTEM.

344. FORMAT I///1/140X, OPTIMLOSATION SUMHARY - -OS

- PRTNT 345, NITEA, NAPAINT

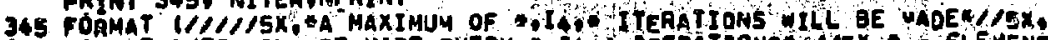

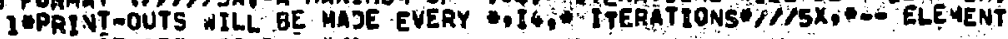
2S TO BE OPTIMISED - $-\star !)$

$00390^{\circ} I=1$.NOPY

NAMSTOOPT (I)

NAMLET TNAM/ISHIFT

Mathr 346. NAM

346 FÖRAT $\left\{/ 5 X_{0}\right.$ RT)

IF (VAMLET ONE. ILETR) GO TO 350

NPLACE $=2$

ISTART:I

ISTOPALOCATE (2) -3

IDOPT (I) al

60 To 370

350 If (NAMLET.TJE.LLETC) GO TO 355

NP $\triangle A C E=1$

ISTART=LOCATE (2)

ISTOPELOCATE (3)-1

IDOPT (I) $\times 2$

60 TO 370

355 IF (NAMLET,NE.ILETL) GO TO 360

MPL ACEE 1

ISTART L LOCATE(3)

ISTOPELOCATE (4) I

toppt (I) $=3$

60 TO 370

360 If (NAMLET .NE. ILETOS GO TO 365

MPLACE 1

ISTAATOLOCATE (4)

ISTOPxLOCATE (5)-1

TÓopt $\{1\}=4$

30 ro. 370

365 IF (YAMLET NE. ILET!) GO TO 380

NPLAGẼC

ISTART ILOCATE (4)

ISTOP $=L O C A T E(5),-1$

TDOPTILI 5

370 If (ISTAAT.GT.ISTOPI GS TO 380

DO J75 JaISTAAT, ISTUP

IF TMAM.NE.NAME (J.NPLACES) GO TO 375 


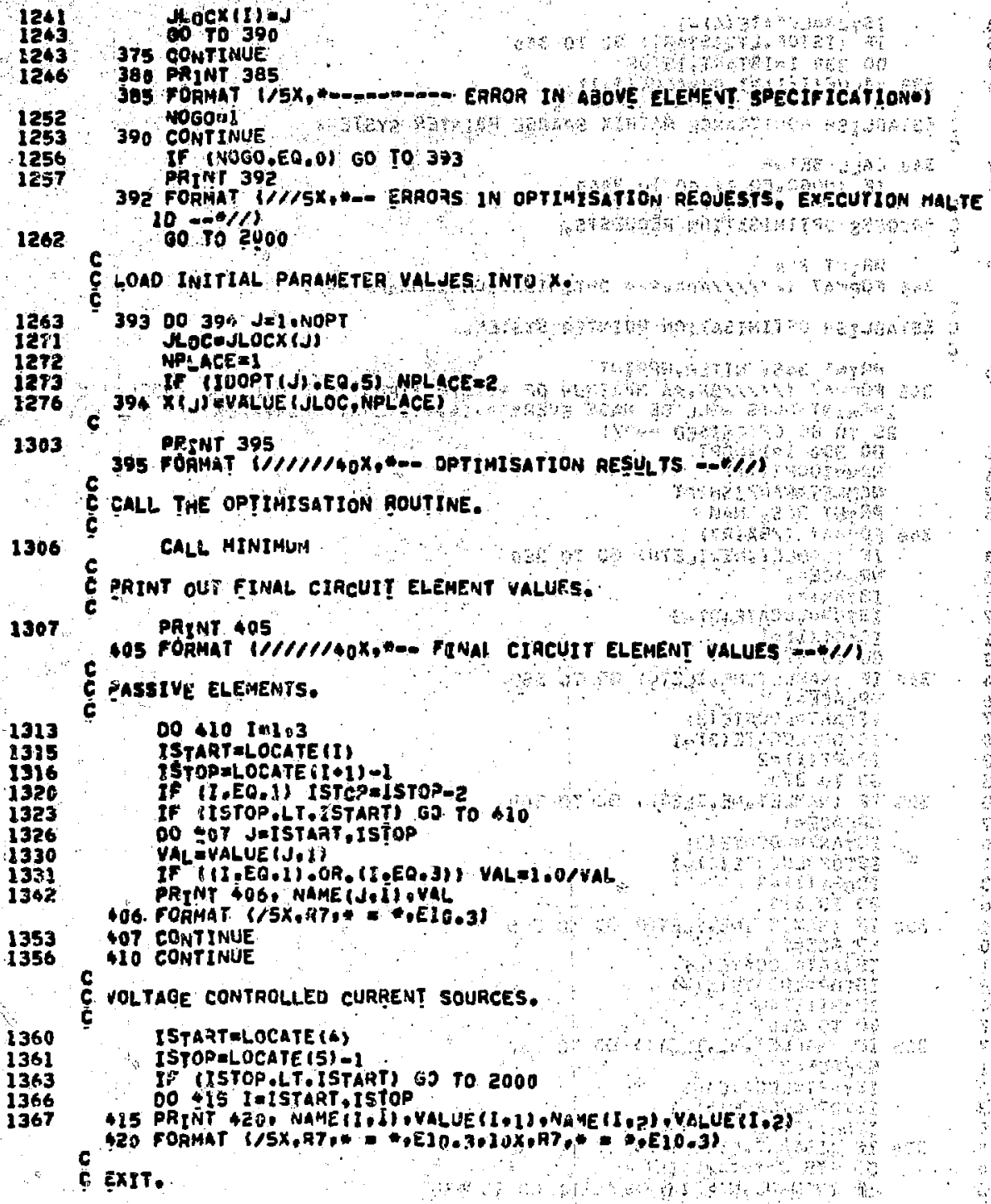


1411 2C0O CALL SECONOCTIMEZI

1413 ET =TIME2-TIME

2415

1423

1424

PRINT 2005 . ET

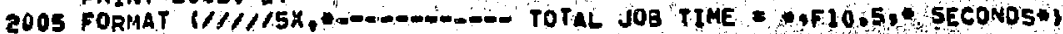
Go. TO 15

END

PROGRAN LENSTH INCLUDING I/O BUFFERS 003230

FUNCTION ASSIGNMENTS

STATEMENT ASSIGNMENTS

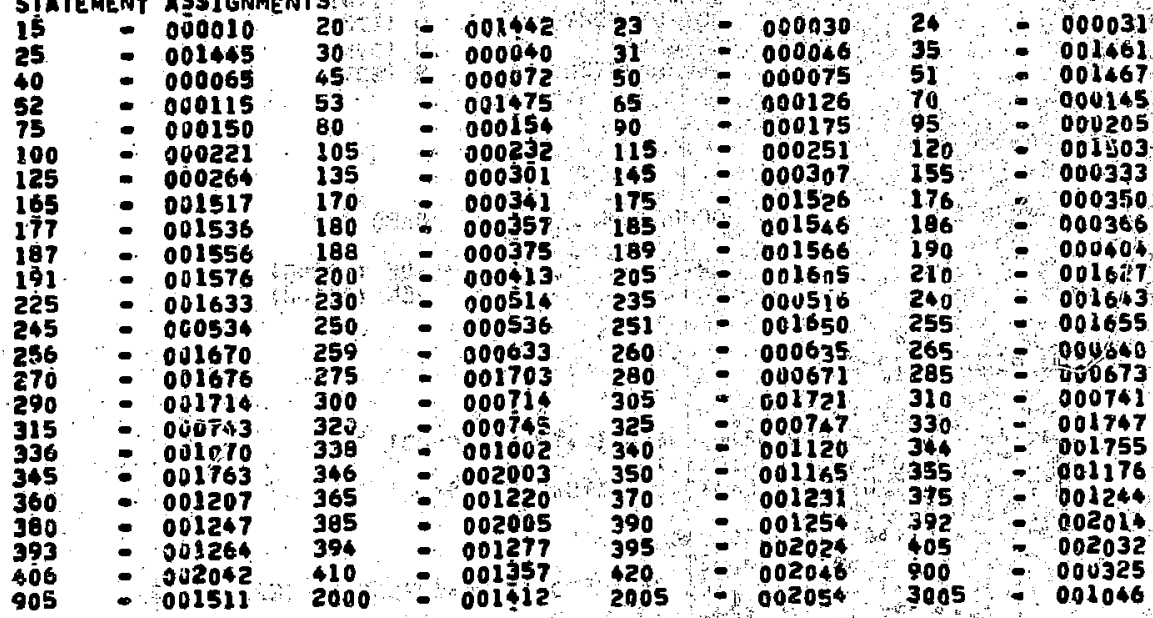

BLOCK NAMES AND LENGTHS

\begin{tabular}{|c|c|c|c|c|c|c|c|}
\hline ILL & $\begin{array}{l}000002 \\
-\quad 002114\end{array}$ & $\begin{array}{l}\text { OPT LMUH } \\
\text { CARD }\end{array}$ & $\begin{array}{l}10 \quad 000177 \\
=\quad 000044\end{array}$ & MATRIX & $\because 002200^{\circ}$ & PJATDAT- & $=001040$ \\
\hline $\begin{array}{l}\text { YARIABLE } \\
\text { ANG } \\
\text { 3CAROI } \\
\text { IHALT } \\
\text { ILETR } \\
\text { YPORTZ } \\
\text { ITITLE } \\
\text { JLOC } \\
\text { KNENOOE- } \\
\text { LOEAL } \\
\text { LOCI } \\
\text { NAMLET } \\
\text { NOGO }\end{array}$ & 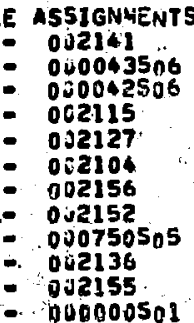 & $\begin{array}{l}\text { S ET } \\
\text { ID } \\
\text { ILETC } \\
\text { ILETT } \\
\text { ISHIFT } \\
\text { IWEIGNT } \\
\text { JLOCX } \\
\text { KNNODE } \\
\text { LOCATE } \\
\text { MATLOC } \\
\text { NITEP } \\
\text { NOPT }\end{array}$ & $\begin{array}{ll}= & 002161 \\
= & 000441506 \\
= & 002116 \\
= & 002121 \\
= & 002114 \\
= & 002131 \\
= & 000004502 \\
= & 002146 \\
= & 001142505 \\
= & 001230503 \\
= & 000102502 \\
- & 000100502\end{array}$ & $\begin{array}{l}\text { FIELD } \\
\text { TONU } \\
\text { ILETG } \\
\text { TPOINT } \\
\text { TSTAPT } \\
\text { JU } \\
\text { JUNOUE } \\
\text { KPCNUDE } \\
\text { LOCPRTI } \\
\text { VAM } \\
\text { NODE } \\
\text { VOSTOP }\end{array}$ & $\begin{array}{l}=000000506 \\
=\quad 001230503 \\
=002120 \\
=002136 \\
=\quad 002150 \\
=002140 \\
=002420503 \\
=002151 \\
001036504 \\
=002154 \\
=002137 \\
002125\end{array}$ & $\begin{array}{l}\text { I } \\
\text { IOOPT } \\
\text { ILFTL } \\
\text { IPARTI } \\
\text { ISTOP } \\
\text { JEDF } \\
\text { K } \\
\text { KPNONE } \\
\text { LOEPRT2- } \\
\text { NAHE } \\
\text { NODPLC - } \\
\text { NPLACE - }\end{array}$ & $\begin{array}{l}002133 \\
000042502 \\
002117 \\
002126 \\
002135 \\
000001501 \\
002153 \\
002143 \\
001037504 \\
000000505 \\
001147505\end{array}$ \\
\hline
\end{tabular}




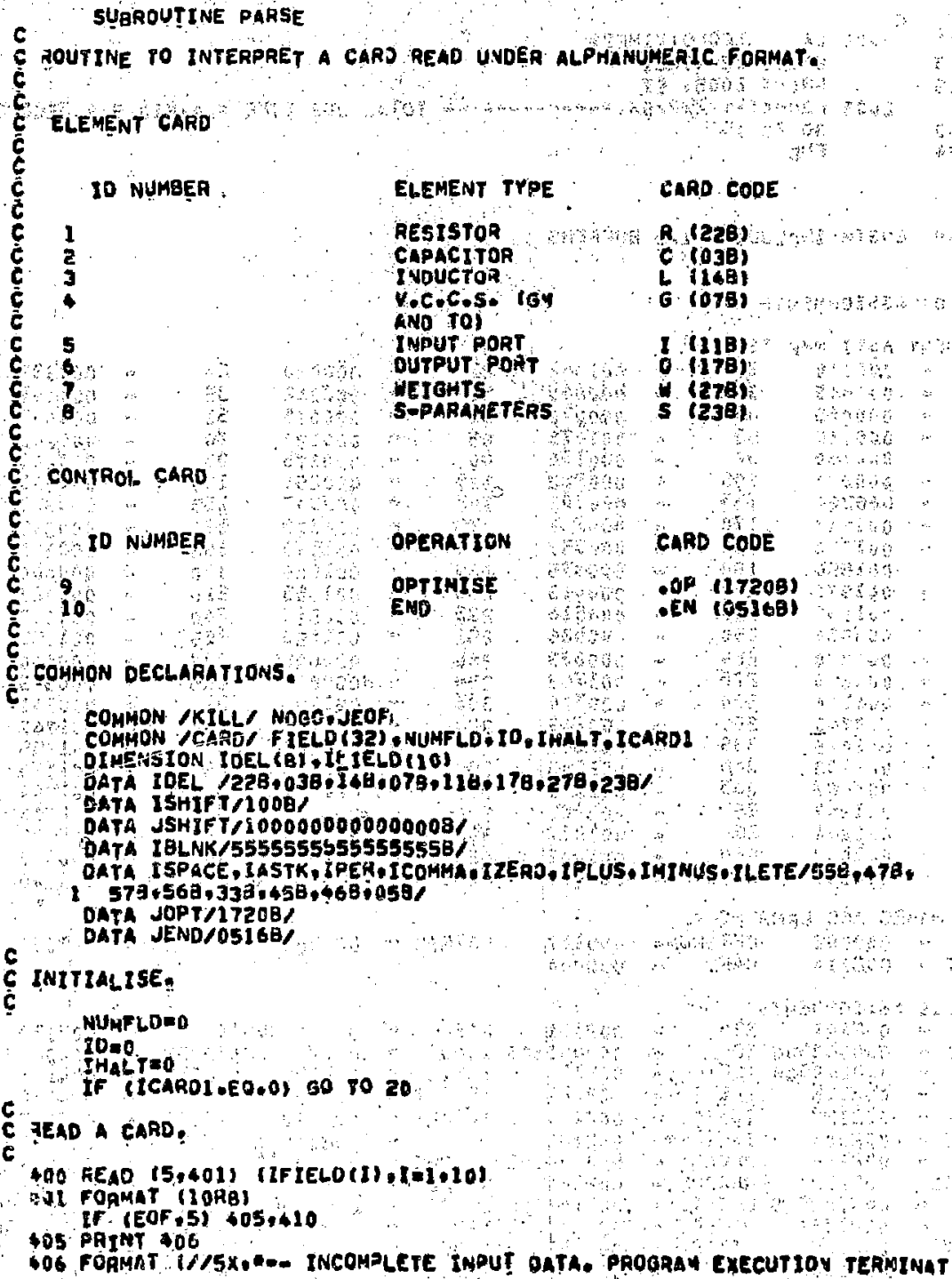




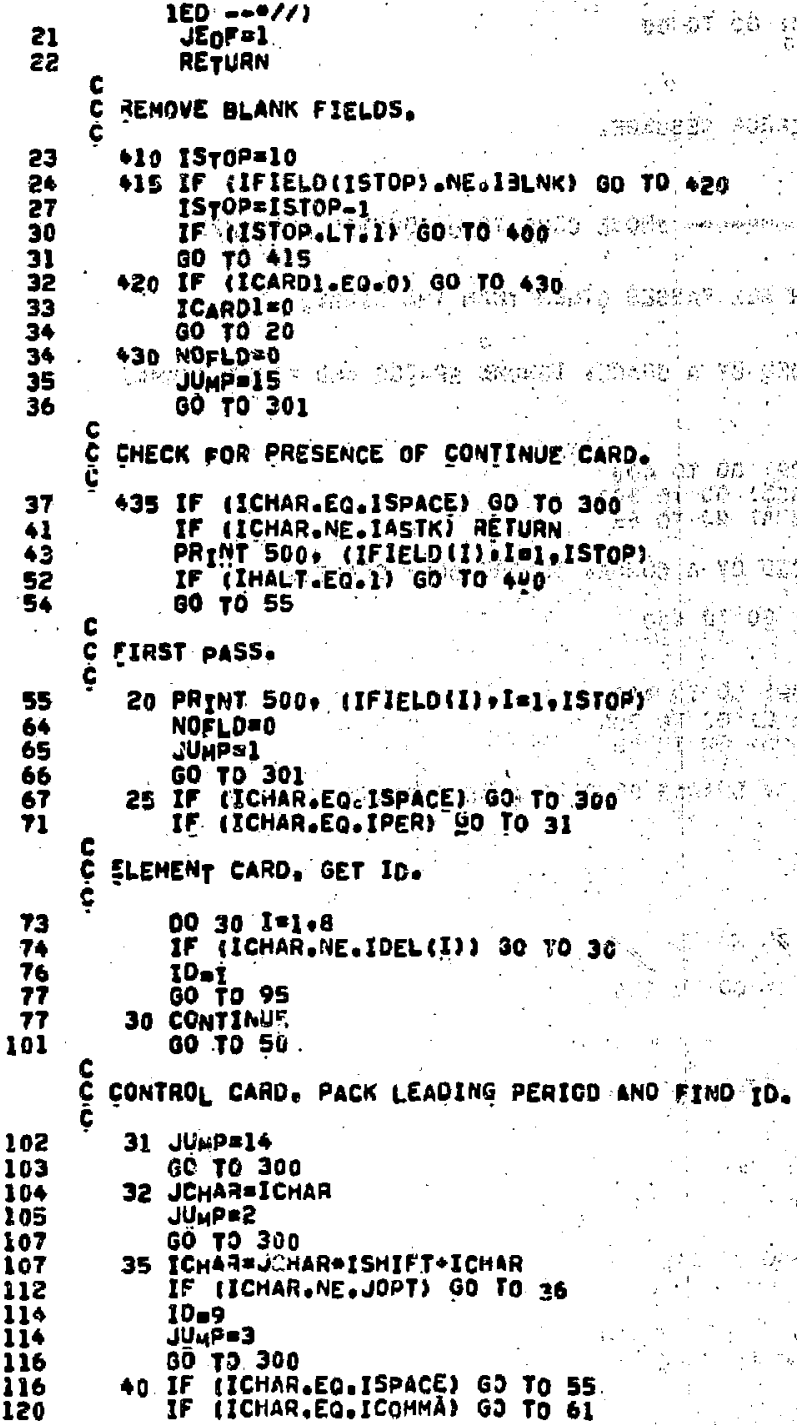


36 IF TICHAR.NE.JENDI GO TO 50 SD=10 RETURN

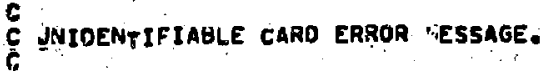

\section{IHALTEI}

\section{PRINT 51}

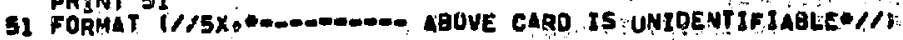

IHIS LOOP IS USED FOR ALL PASSES OTHESA THAN TKE FIAgY.

IF LAST FIELLO WAS ENDED BY A SPACE. IGNORE SPACES AND FIRST COYHA.

55 JU

60 IF TNOFLD.GT.ISTOP), 60 TO 100
IF TICHAR.EO.ISPACE, 60 TO 300

If (ICHAR,NE.JCOMMA) GO TO 65

C IF LAST FIELO WAS ENDEQ OY a cOMHA TONOAE ONLY SPACES.

61 If (NUMFLDiEO,32) go TO 400

JUMpas

60 To 300

62 IF. (NOFLD.GT.ISTOP) 00 io $\$ 00$

IF IICHAR.EO.ISPACE) GQ TO 300

C IF ICHAR, NE. ICOMMAI GS TO 65

C THO COMMAS SEPARATED BY SPACES DEMJTES A ZEAO-YALUED FIELD.

c
- NUMFLO =NUMFLD 1
EO TO 61

$\stackrel{c}{c}$

CHECK UHETHER NUMBER OQ NAYE.

G IF IJEHAR.GE.IZERO! 00 TO 125

C VARE FIELD,

95 IF (YUAFLO.EO-32) 90 10.212

NUMFLDEAUMFLO I

NAMEO

$I_{\mathrm{H}} \mathrm{KO0}$

ICouviet

100 NAHEVAREISHIFT + ICHAR

IEOUVTEI COUNT + 1

IF (ICOUNT.GT.7) GO TO 130

IU⿴囗十⺝木

GO TO 300

105 IF (ICHAR.EO.ISPACE) GP TA 118

IF IICHAR.ER.JCOMHA) GS TO IIT 6070100 
C FINISH THE FIELO.

212

110 FIELD (NUMFLD) $=$ NAM

215

216

216

220

222

222

223

231

234

236

240

242

242

246

245

245

246

246

252

255

256

257

260

261

262

263

265

266

270

271

273

276

277

301

302

c

$130 \mathrm{JU}_{M P \in 8}$ JUMPE?

Gó 90300

115 If (ICHAR.EQ.JSPACE) GJ TO 55 IF IICHAR,EA.ICQMMA? GJ TO GI GO TO 300

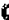

C PACK THE FSELD WITH BLANKS.

117 ICHKE1

I1. 00120 I I ICOUNT, T

IIP NAMENAM-ISHIFT ISPACE

FIELO CNUMFLOI ENAM

$c$ If (ICHK) S5.55,6)

C VUABER FIELD.

125 IF (NUMFLO.EQ.32) $60 \mathrm{TJ} 212$ ICHK $=0$

NUMFLDANUMFL $L+1$

MUN=0

IExp=0

ISET:O

Ċ EMECK FOR A SIGN.

- ISIN=O.

IF (ICHAR,EO. IPLUS) ISIN=3

IF IICHAR,EA. IHINUS, ISIN=-I

IF $\{I S I N, W E, 0\rangle$ GO TO 130

ist

JUMPa9

00 T0 138

6010300

135 IF (ICHAR.EO.ISPACE) GO TO 300

Jumpas 9

138 IF (LCHAR.EQ. ICOMMA) GJ TO 205 IOIGITEICHAR-IZERO

If (IOIGIT.LT.0) GO TO 140

If (IOIGIT.GT.9) 60 TO 140

NUMANUM $10+$ IOIGIT

IF (ISET,EO,O) GO TO 300

IEXPEIEXP-1

6

60 भo 300

C EHARACTER IS NOT a DIGIT.

C

GHECK FOR SPACE, DECIMAL POINT, E-VOTATION,

149 IF (ICHAR.EP.ISPACE) GD TO 206

IF (ICHAR.EQ.IPER) GO TO 155

IF IICHAR,EQ.ILETE! GO TO 160

$c$

Go 70220 
C PECIMAL POINT.

c

ISS IF (ISET,EOה 1$)$ GO TO 230

ISETAI

C

60. TO 300

Ë EFOPHAT.

c

160 ITEMP $=0$

JUMPAII

80 To 300

165 IF (ICHAR,EQ.1SPACE) GO TO 300

IEXSIN=O

IF IICHAR.EQ.IPLUS? IEXSIVII

IF (ICHAR,EQ.IMINUS) IEXSIN=-1

IF IIEXSIN.HE.O) GO TO I7O

IEXSINEI

JUMPE 13

00 TO i78

170 JUMP $=22$

6O TO 300

275 If (ICHAF, ER. ISPACE) GO TC 300 JUAP $=13$

170. IF IICHAR.EG.ICOMMA) GO. TO 179

IF (ICHAR,EO.ISPACẸ!) GO TO 180

IOIGIT I I CHAR-IZEAO

IF (IOIGIT.GT.9) GO TO 210

ITEHPEITEMP 10 -IDIGIT

BO To 300

179 TCHK=1

180 IEXPEIEXP•IEXSIN*ITEMF

GO TO 206

c

C ASSEMale the number.

205 ICHK=I

206 If (NUM) 207.209.207

207 If (IEXP.GT.40) GO TO 210

(F (IEXP.LT.-40) 60 TD 209

If (IEXP.EO.0) GO TO 200

VAL $=N U M * 10.0 * * I E X P$

IF (VAL.GT.1.OEPO) GO TO P10

If IVAL LLT.1.0E-40\} 60 TO 209

FIELO (NUMFLD) ISINEVAL

- If (ICHK) $55,55,6$ I

208 FIELD(NUMFLD $=I$ SIN NUUH

If (ICHK) $55,55,611$

209 F LELO (NUAFLD) $=0.0$

6

Ë EROR MESSAGES. If (ICHK) $55,55,61$

\section{IHALTEL}

PRINT 211, NJMFLO

211 FORMAT $1 / 15 \%, 0-000-20$ AEOVE CAAD MAS AN ERFOA IN FIELD ONIS/M - 60 T0 400

212 IHALT $=1$ PRINT 213 
435

436

440

442

444

447

450

451

45\%.

460

461

463

506

C13 FORMAT (//5X, ह

LOCAL SUBROUTINE TO GET NEXT CHAAACTER. THE POINT OF RETURN IS SETERMINEO BY \#JUMP *.

300 TFOPOSAIFDPOS+1

IF (IFDPOS.LT.9) GO TO 305

301 NOFLJ=NOFLD+1.

IF (NDFLLOGT ISTOP) Go To 310

IFLUEIFIELD (NOFLD)

IFDPpSe]

305 ICHAR=IFLD/JSHIFT

IFLDEIIFLD-ICHAR JSHIFTIOISHIFT GO TO 315

310 TCHAREISPACE

315 60 To $25,35,40,60,62,103,115,135,138,2100165,175,178,32$. 14351. JUMP

300 FORMAT (5X,20A8) END

SUAPROGRAM LENGTH

$0 \overline{00653}$

FUNCTION ASSIGNAENTS

\section{STATEMENT ASSTGNMENTS}

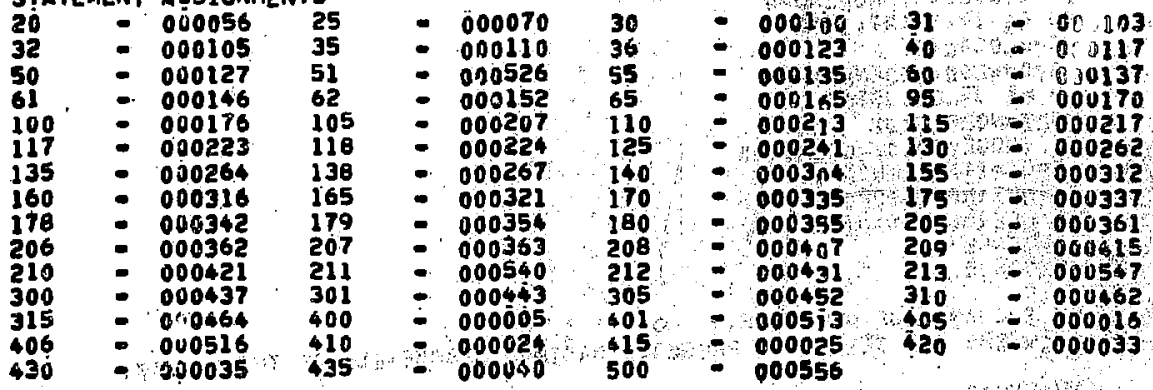

BLOCK NAMES AND LENGTHS

KILL - 000002 CARD - 000044

VARTABLE ASSTIGNYENTS

FIELD - OU0000SO?

ICARDI: GJG043502

ICOUNT : 000640

IEXP 000642

IfLO - 000652

IPER -.000620

ISIN - 000644

IZERO -0.0622

JOPT . OJ0626

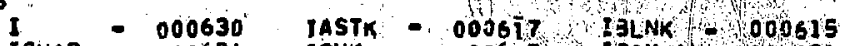

ICHAR - 000634 ICHK - 0006371 ICOMMA-1H000621

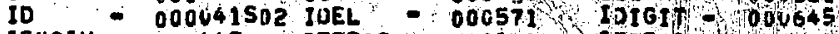

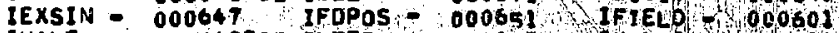

IHALT - 000U42S02 ILETE - 000675 4NINUS - 06002

IPLUS - 000623 ISET - 000643 ISHIFII 400610

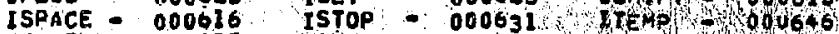

JCHAR — 000635 JEND - O00627

JSHIFT - 000014 JUHP - 000633
Neop 
SURROUTINE SETUP

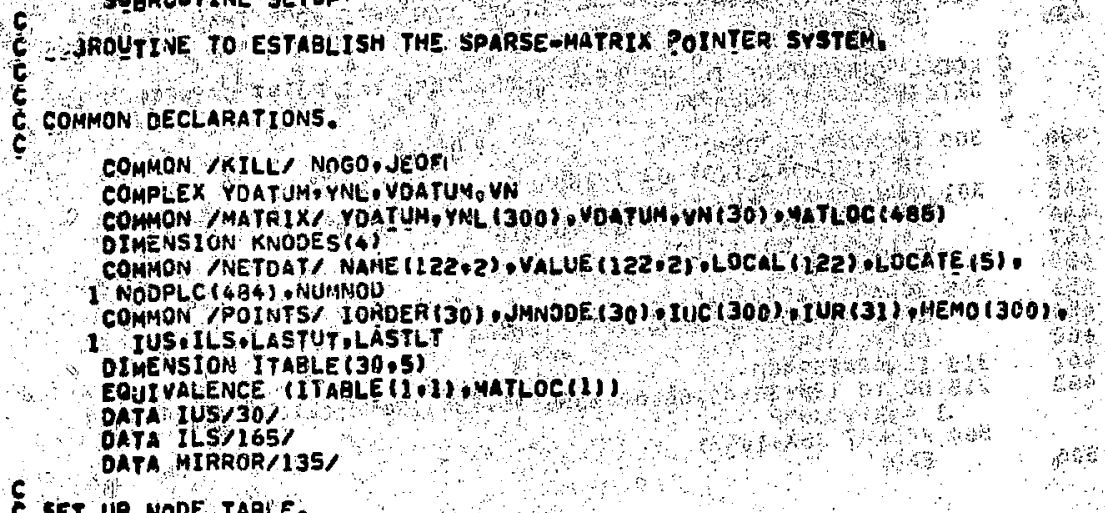

SET UP NODE TABLE.

$00 \mathrm{~s}$ I*I.NUMNOD

5 ITABLE $(I, I)=0$

$0550 \quad 10=1,4$

ISTART =LOCATE IIO)

ISTOP =LOCATE (ID०1)-1

IF IISTAAT GT.ISTOP GO TO 50

NODEND=2

IF (TO.ED.A) MOOENOA-

DO 40 IJISTART, ISTOP

LOC LOGAL (I)

$J S T O P=L O C+N O D E N D \div 2$

DC 60 JaLOC,JSTOP

NODE=NODPLC (J)

IF (NOUE,EO,O) 807040

ISPOT I I TAEL (NONE, i) *2

ITAGLE (NODE I ISPOT) $=1$

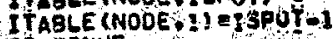

40 CONTINUE

set

51

5 S.

8

So CONTINUE

SET UP IJC AND ZUA POLNTERS.

IHE POINTERS ARE SET UP TO PAESERVE MAXIMUN SPARSENESS OF THE MATALX

IUCE.\$D $=0$

DO $2000 I=1$, NUMNOD

IUR (I) I ICEND + I

ISTOPEI TAELE $(I, 1)+1$

00 TBO0 JE2.1STDP

IELN $N M=I$ TABLE $(I, j)$

LOEELOCAL IIELNUMS

KNOSTPE2

IF IIELNUM,GE LOCATE (4) ) KNOSTPW4

D0. IOZ2 $l=1$, KNOSTP

LOCL L LOCOL-I

NODEANOUPLCILOC1) 
114

Iis

117

120

121

123

124

125

130

135

140

142

144

145

150

151

153

156

140

183

165

166

I71

172

174

176

177

201

202

204

206

207

212

211

212

214

217.

ट22

223

224

224

2दิ

230

231

KNOOESILIONODE

1025 CONTINUE

c

C YON ST THE POTNTER. IUR POINTS TU THE LOCATION OF, THE IFIRST

C CAOSS-TEAH FOR THAT NOUL. IUR IS TME CROSS-TERH YOSE.

$$
\text { c }
$$

$001600 \mathrm{Kal}$ ikNostP

NOOECaKNODES(K)

IF (YOOEO.EO,O) 60 TO 2400

If (NODEC.ER I) 60101600

ISTARTEIUR(I)

IF IIUCEND LT ISTARTI so TO 1320

DO I310 LEISTART, IUCENS

1310 IF INODEC.EO, IUCILIS 60 T0 1400

1320 IUCEND = IUCEND +1

IF IIUCEND ILT.2TI, 00701330

$\mathrm{NO}_{\mathrm{G}} \mathrm{O}=\mathrm{I}$

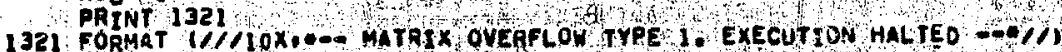
RETURN

1330 TE (IUCEND) ANODEC

1400 CONTINUE

IDOO CONTINUE

2000 CONTINUE

IUR $(N U M N D D+1)=1 U C E N D-1$

C MAKE OPTIMAL REORDERINO OF NODAL ADMTTTMNCE MATRIN.

C

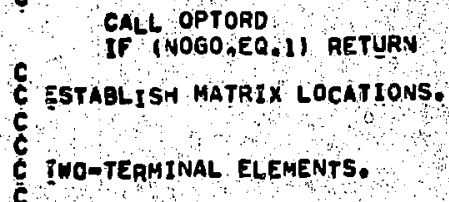

IF Tndeo

ISTOPELOCATE $(4)-1$

IF (ISTOP +LT I) 60 TO 130

Do $\$ 20$ IaI-ISTOP

DOCELOCALII)

NOOE $I=N O D P L C$ (LOC)

NODÉZ NNODPLLCLLOCH

IF (NODE 1.ED.NODE2I GO TO 100

MATLOC (IFIND AI) INOUEI

MATLOC (IF INOOZ) ENODEZ

IF (NDOE L EQQOO) GO TO 110

IF (NOOE2 EOOOO) GO TO 110

ISPOT I INDEX (NODEI,NODEZ)

MATLOC (IFIND+3) EISPOT

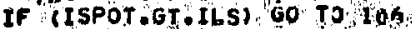

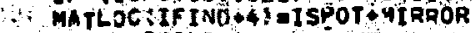

IF IND=It INO +4

GO TO 120

106 MATLOC IIf IND+4) 15 SOT-4IRROR

IF IND=IF IND +4

GC TO 120

108 MLTLOC IFINO+I) $=0$ 


$$
-244:
$$

232
233
235
236
23

242

243

245

251

253

254

285

257

260

262

266

272

276

302

303

306

310

311

312

313

314

316

321

323

324

326

331

332

334

336

300

343

344

346

350

353

356

360

361

362

366

367

MATLOC (IFIND+2) $=0$

110 MATLOC (IF IND 3 ) $=0$

MATLOC ITF INO $+47=0$

IFIND=IFIND th

120 CONTINUE

C VOLTAGE CONTHOLLEO CURRENT SOIITCES

c

130 ISTARTELOCATE (A)

ISTOPFLOCATE (5) -1

IF (ISTART.GT.ISTOP) GJ TO Io

DO 150 I=ISTART, ISIOP

LOCOLOCALIII

NODE $1=$ NODPLC (LOC)

NOOE $2=$ NODPLC $(L O C+1)$

NOOE $3=N O D P L C I L O C+2)$

NODE 4 WNODPLC $(L O C+3)$

MATLOC IIF IND + I) I INDEX ( VODEI NODE3)

MATLOCIIF IND+Z) I INDEX ( VDDE I NODE 4

MATLOC (IFIND+3) \& INUE X ( VOOEZ \& NODES3)

MATLOC (IF IND + 4) = INOEX (NOOEZ NODE\&)

IFINO=IF IND

ISO CONTINUE

C.

SET UP THE ARRAY HMEMON.

160 LENNUNANOD-1

IF ILE,EOOO) GO TO I7S

ISO $=0$

DO 171 LEL OLE

ISEIUR(L)

$I E=T \cup R(L+1)-1$

IF IIEOLT.ISI GO TO ITI

00170 ILsIS.IE

10=1UC (IL)

IOIOROER(IO)

Do 165 IUESS.1E

joeluc (IU)

JaloRUER ( JO)

JEINOEX $\{1: J\}$

IS0=150•1

If (IS0.GT.300) 60 To 100

$M E M O(I S O)=J$

165 CONTINUE

170 CONTINUE

IT1 CONTINUE

I75 LASTUTEIUS +IJR INUMNOD+1) - 1

LASTLT $=I L S-I U S * L A S T U T$

RETURN

180 NOGO=1

PRINT 185

105 FORMAT WIOX,-- MATZIX OVERFLOW TYPE Z EXECUTION HALTEO W RETURN

END 
SUgROUTINE OPTORL

C

AENUMBERS THE RONS OF A STRUETURALLY SYMMETAIC SPARSE MATATX IN

JADER TO MINIMISE THE MLMESEA OF MAJOA AAI THMETIC OPERATLONS REQUIREO

IO OECOMPOEE IT INTTO LU FOZM.

COMMON OECLARATIONS.

CO:TMON IRILLA NOGDIJEOF:

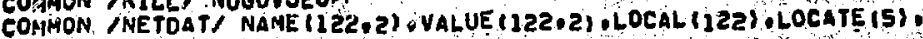

1 NOOPLC (484), NUMNOU

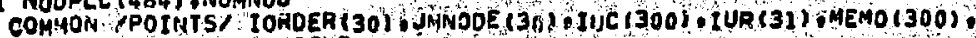

1. TUS. ILSILASTUT, iLASTLT

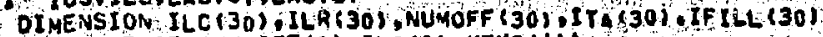

EQUIVALENCE (NUMOFF (I).TLC(1), MEMO(1))

EOUTVALENCE IITAlIJ ILF(1) MEMDI3III

\$

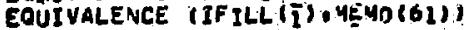

c

NHENUMANOD+1

LEDNUMNOD-1

ASCEATAIN THE MUMBEA OF OFFMDIAGONAL ELEMENTS IN EACH ROH.

00. 1 JEl, NUMNOD

gOAOER $(J)=J$ JNNDDE $(J)=J$

1 NUMOFF $(J)=\operatorname{IUR}(J+1)-I U R+j)$

IF (LE.EQ.OI GO TO 110

EINO ROHS WITH ONLY ONE OFF-OTAGONAL ELEMENT.

c

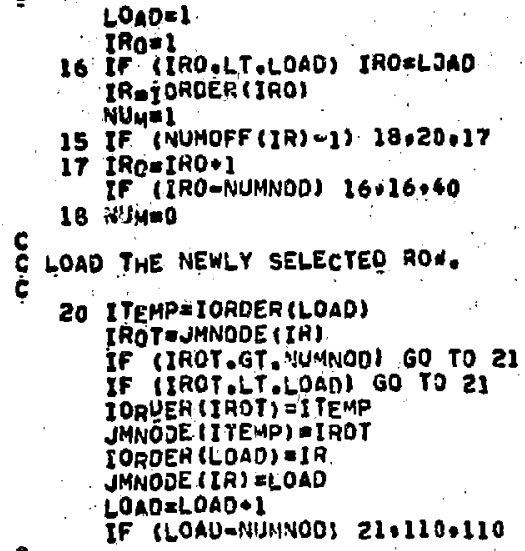

16 If (IRO OLT ILADS IROELJAO

IRETORDER (IRO)

NUM=1

15 IF (NUNOFF (IR) - I) 28.20 .17

17 IRgeIRO+I

18 inginos

IF (IRO-NUMNOD) $16,16,40$

C LOAD THE NEWLY SELECTEO RON.
20 ITEMPEIORDER (LOAD)
[ROT IJMNODE (IA)
If (IROT.GT. IUUMNODI 60 TO 21
IF IEROT OLT.LOADI GO TO 21
IORUEH (IADT) = ITEMP
JMNODE (ITEMP) I IROT
[ORDEA $(L O A D)=1$ ]
JMNODE (IR) =LOAD
$\angle O A O=L O A D+1$
IF (LOAUANIANOOS $21,120,110$

C SUBTRACT THE COLUHN ELEMENTS OF THE RON JUST LOABED

C TROM THE RESPECIIVE ROWS IV WHICH THE TERM ALSO APPEARS. 


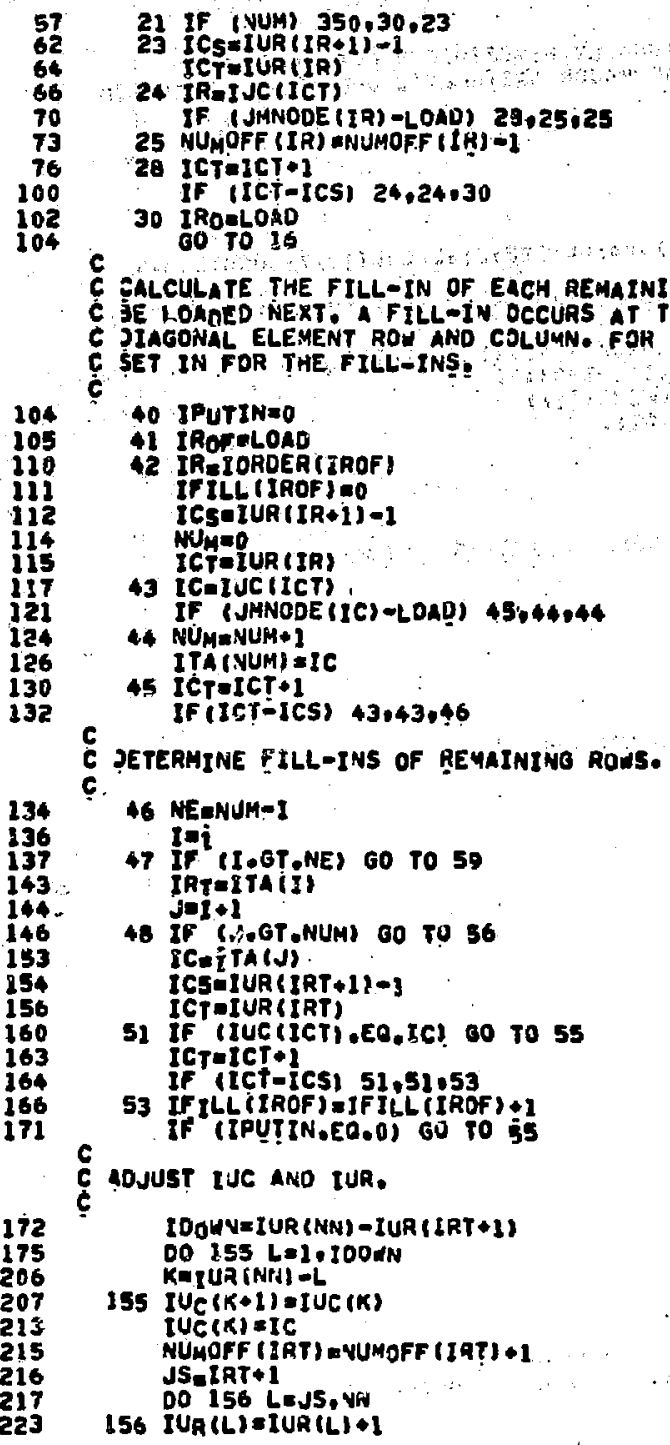


IF (IUR(NN),GT.300) GO TO 350 IOOWNEIUR (NN) - IUR (ICAI) $00157 \mathrm{~L}=1,100 \mathrm{WN}$ KEIUA (NN) \&L

$157 I U_{C}(K+1)=\pi U_{C}(K)$ IUC $(K)=I R T$ HUMUFF (IC) ENUMOFF (IC) \& $J 5=1 \mathrm{C} \cdot 2$ DO $15 B$ LEJS, NN

1SE IỤR $(L)=I U R(L) \bullet L$

$55 \mathrm{j} j \mathrm{j}$

56 Intol

$$
60 \text { To } 48
$$

60 TO 47

59 IF (IPUTIN.EQ.0) 00 TO 60

IPUTINaU

60 To 20

60 If (IFILL(IROF).0Tg09 30 TO 61 BO TO 20

61 IROFaIROF $\diamond$ I If (IROF-NUANOD) $42,42.70$

SEARCH FOR THE ROH THAT JILL CAUSE THE AINTMUM NUHBER OF

ILL-INS. IF TWO OA MOÁE ROUS SATISFY THIS CONDITION. SELECT

IHE ROW WITH THE GREATE़ST WUMBER OF OFF DIAGONAL ELEMENTS.

7O 0075 JELOAD DLE

ITEST =IOHOER (J)

KSaJ०1

DO 74 KaKS. NUANOD

IF IIFILL (K),GE.IFILLL(d) 00 To 74

IA-iOROER (K)

IOADER $(K)$ EIYEST

JMNODE IITESTI EK

IOADER (J) =IR

$J H A O D E$ (IR) $=J$

ITESTaIA

IRaIFILLIK)

IFILL (KI \&IFILLSJ)

IFILL (J) $\approx$ IR

74 CONTINUE

IF (IFILLLLOAD). NEgIFILL(J)) to TO 76

75 CONTINUE

76 KE, JEl

- ITESTEIOROER(LOAO)

KS $20200+1$

IF (KE.LT.KSI GO TO 00

DO Y8 KaKS OKE

IR $I$ JNUER (K)

IF (VUHOFF (IA) -LE.NUYOFF IITESTI) 60 TO 78

JORLEH (K) = ITEST

JMNÓDE (ITEST) $=K$

IORDEK (LOAD) =IR

JHNOJE (IR) $=\angle O A O$

ITESTaIA

78 CONTINUE

QI IPUTINEI

00 To $\$ 1$ 


\section{SUBPROGRAM LENGTH}

000365

FỤNCTION ASSSIGNMENTS

STIATEMENT ASSIGNMENTS

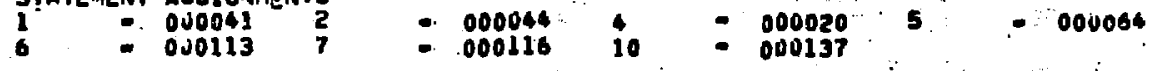

GLOCK NAHES AMD LENGTHS

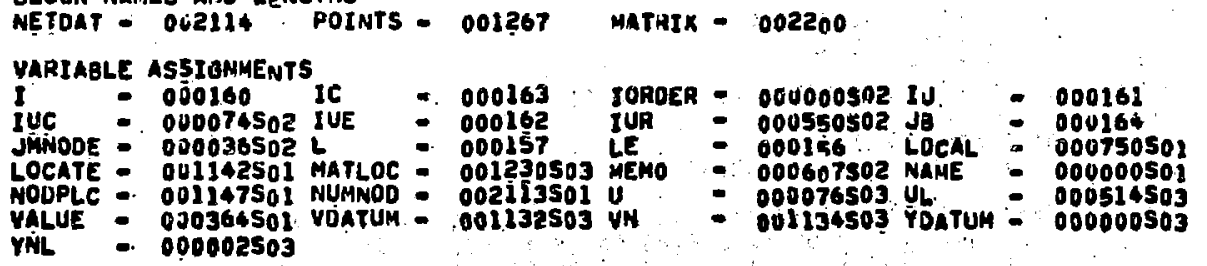


C. SUGAROUTINE SOLVEA

C ZOUTINE TO PEAFORM AOJOJNT FORWARD AND EACKUARO SUSSTITUTION

C ON THE DETOMPOSED NDDAL ADUITTANCE EQUATIOUS.

6

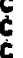

SOMMON DECLARATIONS.

COMMON INETOAT/ NAME(122,2), VALUE(122,2),LOCAL(TZ2),LOCATE 15),

1 NODPLC (4A4), NUMNOD

COMMDN /POINTS I IOHDER (3O) . JIANDOE (30) , IIJC (300), JUR IJ1). 4EMO 1300$)$. 1 IUSOILS.LASTUTOLÁSTLT

COMPLEX YORTUM,YNL. VOAYUM, VN

COMMON IMATRIX, YOATUM, YNL (300), VOATUM, UN (30), YATLOC (ABB) COMPLEX U.UL

OIAENSION U(135), ULL (135)

$\varphi$ EQUIVALENCE WUII, YNL (3I) , (UL (1), YNL (166))

3

5

17
21
24
35
36
40
43
45
46
61
62
63

66

67

ind

ing

105

105

112

117

120

122

134

136

136

141

LE=NLHNUD-1

IF (LE:GT.0) GO TO 4

ACCOUNF FOR CIRCUITS HAVING ONLY ONE MODE.

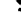

Logoagen!1?

VN(L) IEN (L) T YNLSL)

RETURN

c.

FOAUAPD SUESTITUTION.

c

4005 IVIOLE

LEIORDER (I)

VN $(L)=V N(L) / Y N L(L)$

YHaIUR (I)

IUE $I U H(I+1)-1$

1 If (IU-IUE) $2+2,5$

2 ICEIUC (IU)

ICEIORDERIICS

$V N(I C)=V A I I C)-U(I U) * V H(L)$

IU⿴囗十 $U \cdot 1$

00 To 1

5 comtinue

EACKUARO SUBSTITUTION.

LEIORDER (AUMNOD?

VN(L) $=V N$ (L.R SYNE (L)

DO IO IEI QLE

LAIOADET INESMOD-II

IUETUR (NUMNOD-I)

IUE ETUF INUMNOU- $1+1 ; \circ 1$

6 IF (IU-IUE) $7,7,10$

7 J7a IJCIIUI

JB $n$ ( $O A D E H \leqslant J B)$

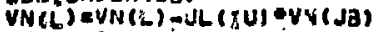

$I U=I J \cdot I$

ou to 6

do CONTINUE

IIETURN 
SUGROUTINE SOLVE

GOLTINE TO PERFORM FORAARU AND BACKWARD SUESTIIUTION ON THE PLCGIPOSEO YOOAL AOAITTANCE EQUATJOVE.

SOMMON DECLARATIONS.

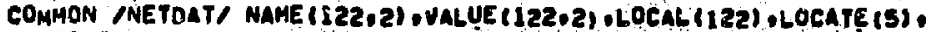

I. MOOPLC (\$ES) N NUANOU

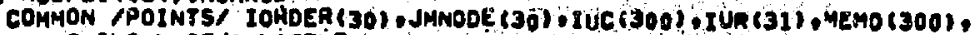

a IUSOILSOLASTUT ILASTLT

COMPLEX YDATUM,YNL OVDATUM, VN

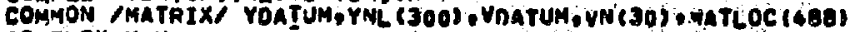

COMPLEX U.UL

DIMENSION U (135), UL (135)

c

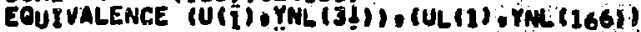

c.

LEaNUANOD-1

IF (LE.GT.0) 00 TES

ACCOUNT fOR eIRCUITS HAYINS OHLY ONE NODE.

VM(L) $=V N(L) / Y N L(L)$

C.

$$
\text { RETURN }
$$

6.

GORWARO SUBSTITUTION.

8

50020 JE1.LE JgEIUR (J)

LEIUR (J.) S)-1

IF (JELT.JSI GO TO 20

LETOHOER(J)

00 ig. ILaJS.JE

TOETUCRIL

IOEOAUER SLOT

15 VN(I) EVNCII-UL (IL) WVMt:

20 continue

\section{aACKUARD SUGSTITUTIOH.}

- Lejorder (NUMNCO-t)

JSEIUN (NUIANOD-I)

Je IUR (NUMNOD- $-1+1$ - 1

If IJE,LT.JSI Go TO 40

DO 35 IUEJS.JE

JO-iJC\{IU\}

Jaro ROE (JO)

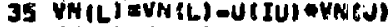

40 VN(L) RVN (L) /YML (L)

RETURN

EN 
104236 PRINT $27, / 5 x_{1}$, UNDERFLOA DIRING LU OECOMPOSITION OF ADMITTANCE AATR

110 IIX. EXECUTION TERMIMATEDES

111 RETIURN

112

END

SUBPROGRAM LENGTH

000162

FUNCTION ASSIENHENTS

STATEMENT ASSTGHENTS

21 - 0 - 002022

$27 \quad 000117$

$22,-000041 \therefore 25 \quad \therefore-000102-26:-000195$

BLOCK NAMES AND LENGTHS

KILL - O00002 NETOAT - 002114 POINTS - 001267 MATAIX - 002200

VARIAALE ASSIONMENTS

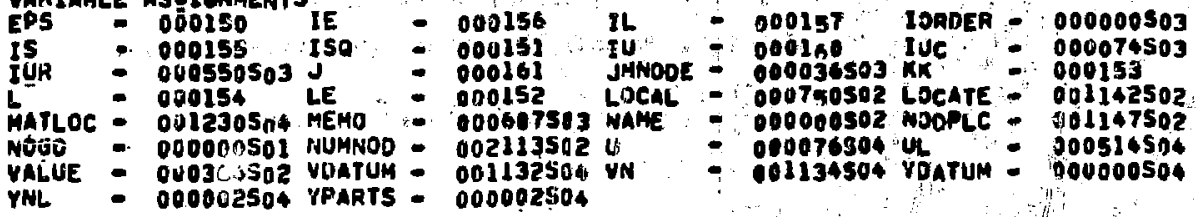

START OF COYSTAMTS

0 DOO115

START OF TEYPORARIES

000131

START OF INDIRECTS

000140

UHUSED COMPILEA SPACE

024600 
SUBROUTINE DECOMP

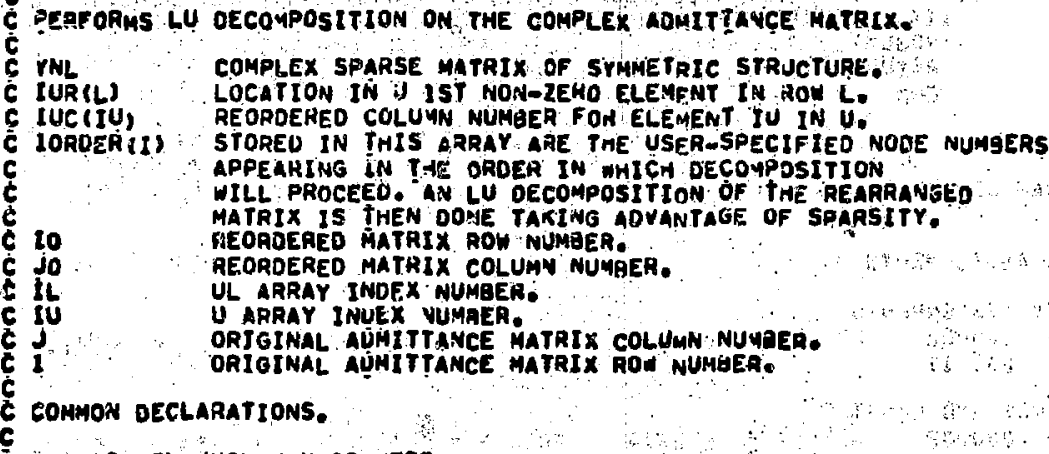

CQNMON IKILLA NOGOSJEOF,

COMHOH /NETOAT/ NAME (122,2) . VALAE (122,2) , LOCAL (122) .LOCATE (S):

1. MOOPLC (484) . HUMNOO

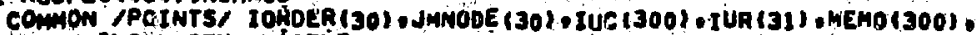

I IUS.ILSILASTUTILASTLT

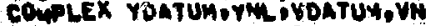

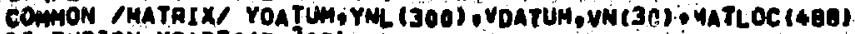

OTMEVSION YQARTS(z) 300$)$

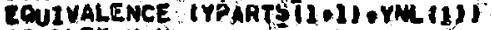

CONGLX U.UL

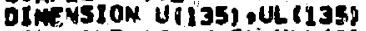

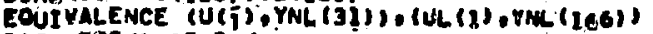

c

DATA EPS/1.0E-20/.

CEOIH LU DECTOHPOSITIONg

$180=0$

LENHANOD-1

KKEI OADER (NUMNOD)

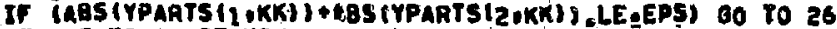

IF (LE.EO.O) RETURY

220025 LE1.LE

ISaIUR (L)

IEDI $(6 \circ 1)-1$

IF IIE.tT.IS\} 00 To 25

KKEI DADER (t)

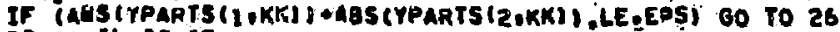

220024 ILEIS.IE

UL (ILIEUL (SLFPYNL (KK)

00 23 IUEIS.IE

IS0-150*1

JWAE पO (ISO)

23 CONTINUE

26 continuE

25 CONTINUE

AETUAN 
162

164

165

171

174

176

200

206

207

212

215

230

233

234

236

240

$24 ?$

243

247

252

254

256

264

265

267

272

274

275

301

317

321

$-323$

326

330

332

336

362

346

351

354

357

362

365

370

370

30 CONTINUE

LOC4=MATLOC. IF INDOA)

IF IND $=$ IFIND+4

YPARTS $(Z, L O C I)=Y P$ ARTS $(Z$ OLOCU + VAL

YPARTS $(2, L O C 2)=Y$ YAHTS $(2,1062)$ \& YAL

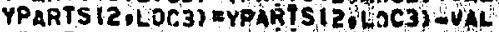

YPARTS $(2, L O C 6)$ WYPAATS $(2$ NOC 4$)$ YAL

C GoAD RétPROCAL INDUCTANCES

40 ISTART L DEATE(O)

ISTOP=LOCATE $(\varphi)-1$

IF. IISTART GTUISTOP) GO TO 60

DO : 50 I I ISTARTISTOP

VAL $=-V A L U E$ (I 11$) \%$ FAESO

LOCI IMATLOCIIF INO-BI

LOCZ =MATLOC IIF IND +Z)

LOCJ =MATLOC IIHIND+3)

LOCA aMATLOC IIF IND + HA

IF IND= IF IND 44

YPARTS 12 LOCI) Y YPAHTS $(2$ BLOCHIWWAL

YPARTS (2.LOCZI TYPAATS 62 , L EZ) \&AL

YPARTS $(2, L O C 3)$ EYPART'S $(2, L U O C 3)-V A L$

50 continue

YPARTS $(2, L O C 4)$ EYPARTS $(2, L O C S), W \mathrm{KAL}$

c 4040

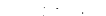

6O ISTARTELOCATE(4)

ISTOP $=$ LCATE (5:-1

IF IISTART,GT ISTOP AETURN

DO FO I=ISTART - ISTOP

ZFFEQ VALUE $(1,2)$

VALREAL $=$ YALUE $(I, 1)$ Cos $(2)$

VAL I YAG =-VALUEII II SI V $Z$ IZ

LOCi IHATLOC I IF IND - ( )

LOCEMMATLOC (IF IND.Ż)

LOC3=MATLOC (IF IND-3I

LOCA $=M A T L O C$ (IF IND +4$)$

IF IND $=$ If IND +4

YPAATS (IOLOCI) =YPARTS $(1, L O C 1)$ WVALOEL

YPARTS $(2 . \angle O C 1)$ EYPARTS $(2, L O C I)$ WAAL TMA

YPARTS (1 OLOC2) IYPAKIS (1 LOC2) -VALAEAL

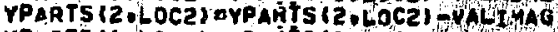

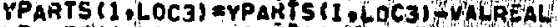

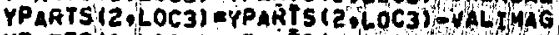

YPARTS $(1, L O C 4)=$ YPAKIS $(1,10 C+)$ VALHEAL

YPARTS (2)LOC 4 ) EYPARTS $(2 . L D C 4)+V A L J$ MAG

70 CONTIRUE

FETURT

END

SURPROGRAM LENGTH OCं0434

FUNCTION ASSIONHENTS 
SỤAROUT! INE LOAOY (FREEQ)

COOADS THE COMPLEX AOMITTANCE MATATX
C COMMON DECLARATIONS.

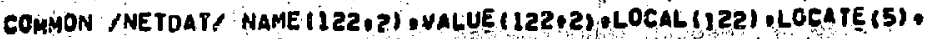

1 MODPLC (684) NUMNOD

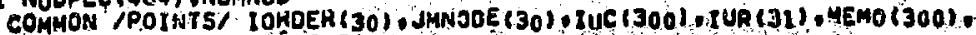

1 ZUS ILSOLASTUT ILASTLT

COMPLEX YOATUM, YNL OVDATUM, VN

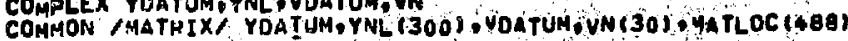

DIMENSTON YPARTS 2,300 )

EOUIVALENCE (YPARTSTIOI),YNLIII)

c

If IHODO

c

InItIALISE aOMITTANCE MATRIX to zERO?

YOATUMACMPLX $\times(0,0,0,0)$

0099 IF! , NUMNOD

YPARTS $(1: I)=0.000$

99 YPARTSIżll =0.000

Do 909 IEIUS.LASTUT

YPARTS $(1, I)=0.000$

999 YPARTS $(2,1)=0.000$

DO $9949 \mathrm{I=ILS,LASTLT}$

YPARTS $(: A)=0.000$

52

54

c

$\$ 999$ YPARTS1Z $11=0.000$

LOAD CONDUCTTAHEES.

55

60

74.

76

100

102

104

105

106

112

115

15TOPILOCATE(z) -1

iF (BSTOP.LT.1) GO TO 20

so to Iel.istop.

VALSHALUE (I.I)

LOCI minATLOE(IF IN $0+1)$

COGZaMATLOC (IF INO+Z)

LOC3 $A M A T L O C$ IIF IND +3 i

LOCAMATLOCIIF INDOÁ!

IF INO=IFIND०4

YPARTSII OLOC I ) EYPARTS (1 OLOCH) OVAL

YPARTS $(2, L O C Z)=$ YPANTS $(1, L O C 2)+V A L$

YPARTS $(1, L C C 3)$ EYPAH $(5, I, L O C 3)-V A L$

16. continut

YPARTSII.LOCAI =YPANTS:I LOCOI-VAL

C loAd Capacitances.

c

20 ISTARTELOCATE(2)

I5TOP=LOCATE $(3)-1$

IF IISTART GT.ISTOP, OO. TO 40

140

is?

DO JO IFISTARTIISTUP

VALEVALUE $(1,1)$ GHEU

154

LOCIOHATLOC (IF IND + i)

156

LOC2 EMATLDC (IF JND+2)

150

LOCJABA TLOC IIFIND•3I 
SUBROUTINE SCALE TGAADI

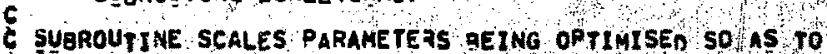

C IMEROVE CONVERGENCE OF IHE MINIHISATIOY ROUTINEO SCALIMO IS DONE

C TO NORMALISE TO UNITY IEE ORAOIENT VECTOA AT THE COMMENCEMENT

C JF OPTIMISATION.

c

GOMMON DECLARATIONS.

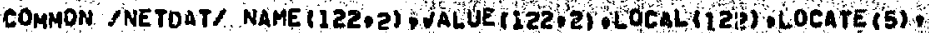

1 NODPLC (4B4) NUMNOO

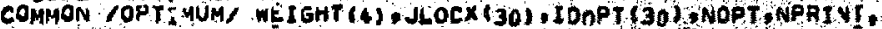

1 NITER,X (30) OSCALEX $(30)$

DIMENSION GRAD (30)

DATA EPS/2,OE-1QI

$\stackrel{C}{\complement}$

VERIFY THAT SCALING IS POSSTBLE, IF NOT, SET SCALE TO UNITY.

DO 5 : $1=1$. NOPT

IF (AGS (GAAD (L) : OGT EEPSI GO TO 5

PATNT 2

2 FOAMAT 1/SX, AAT LEAST ONE COMPONENT OF THE INITIAL UNSCALED GRAOT 1ENT VECTOR IS TOO SMALL TO PEAMII SCALING $/ / 5 X_{0}$ SCALES WILL THEREF 2OAE gE SET TO UNTTŸPI

15

OO 3 Jal,NOPT

3 SCALEX(J) $=1.0$

RETURM

S CONIINUE

C

ENAPUTE VECTOR OF SCALE FACTOAS.

30

36

37

40

61

42

63
51
60
61
62
65
73

74

102

107

111

112

C.

$0010 I=1$ NOPT

ZoGRAD (I)

$X(I)=x(I)=Z$

SCSLEX(I) $=1,0 / 2$

10 GAAD $(I)=1,0$.

RETUAN

c

JNSCALE X-VECTOG AND UPDATE LLEMENT STACKS:

C. ENTRY DESCALE

DO 20 I=1,NOPT

Logadiucx (?)

Jel 1

IF (IDOPT (I) ED.5) Jez

20 VALUE $(L O C, J)=X(1)=S C A L E X(1)$

$c$ RETURN

C AESCALE THE GRAGIENT VECTOZ.

C

ENTAY RESCALE DO 30. I=1, NOPT

30 GRAD (I) EGHAOCII SCALEX(T)

RETURN

EN? 


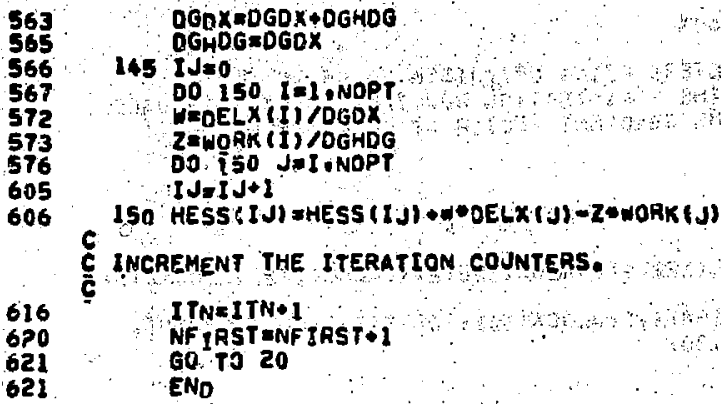

\section{SUEPROGRAM GENGTH}

00̈2243

FUNCTION ASSIGNMENTS

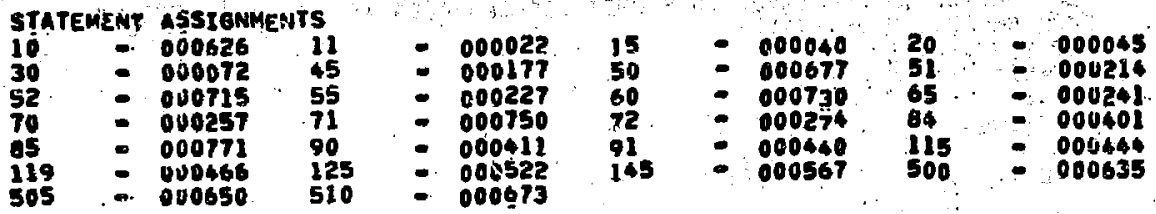

BLOCK MAMES AHO LENGTHS

KILL - DOBOD? NETDAT - 002116 OPTIAUN- 00017Y

YARTABLE ASSIONMENTS

\begin{tabular}{|c|c|c|c|c|c|c|c|}
\hline$\frac{1}{6 x}$ & $\begin{array}{l}=00 \\
=001 \\
=002 \\
=002 \\
=008 \\
=007 \\
=008\end{array}$ & $\begin{array}{l}\text { BOUND } \\
\text { OEOX } \\
\text { GUX } \\
\text { GRAD } \\
\text { IFIAST } \\
\text { J } \\
\text { LIHIT } \\
\text { NFCALL } \\
\text { NOGO } \\
\text { STEP } \\
\text { WOHK }\end{array}$ & $\begin{array}{l}=0 \\
=0 \\
=0 \\
=0 \\
=0 \\
=0 \\
=0 \\
=0 \\
=0\end{array}$ & 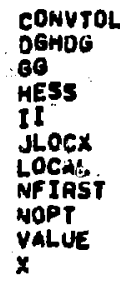 & $\dot{:}$ & & $\begin{array}{l}= \\
=1 \\
=1 \\
=1 \\
=1 \\
=8\end{array}$ \\
\hline
\end{tabular}

$22=002230$

START OF COYSTANTS objos.6

START OF TEMPORARIES 001017

START OF INJIRECTS 001035 
407

410

415

424

432

436

437

442

442

443

445

452

454

456

456

460

461

463

484

465

166

474

475

477

477

$5 n 1$

503

504

513

515

521

530

532

535

340

$5 \bullet 3$

546

551

553

560

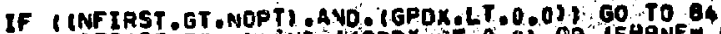

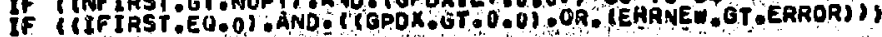

160 T0 90

3Z-60UHD

00 T0 91

a4 ITNEITN+1

PAINT 85, ITN

O5 FORMAT. //5X, UL TRA-GUADAATIC BEHAVIOUR DETECTED IN THE EKROR FUVC ITION ON THE OILO TH ITERATIONW//SX, HREVERSION TO STEEPEST DESCEN $2 T$ NECESSARYO)

GO TO 11

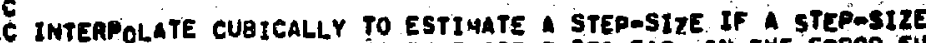

C JF ONE DIO NOT LEAD TO A SJFFICIENT OECREASE IN THE ERROR FUVCTION,

C SND IF THE INTERVAL BOUNDARY CONOITIONS ARE CORRECT.

c.

90 ZZ=3.0 (ERROR-ERRNEW) + 3PDX + GOUX

WESART (1. O-GODX/ZZ GPDX/ZZ) AdS (ZZ)

22-1.0-(GPDX+w-Z2) $/(D G D X+2+0 *$ in)

If (ZZgLT-BOJND) ZL=BOJNO

If instel

91 houndegouno*0.1

LIMITELIMIT+1

00 To 30

119 ENROA-ERANEW

DO $116 I=I$ PNOPT

126 GRAD $(I)=$ NOAK $(I)$

IF (OGOX,GT.0.0) G9 TO 119

OOX GPDX

$22=0$

BOUND=0.1

LEATTELIMIT +1

IFIRST=0

60 5070

139 STEPez?

C

C JPOATE THE INVERSE HESSIAN MATRIX.

$D B$ BOE $=0.0$

OO 135 IEI,NOPT

$z=0.0$

IJeI

If $(1, E Q, 1)$ GO TO 125

II $=1-1$

DO $120 \mathrm{~J}=1.11$

ZeZ HESS (IJ) ODELG(J)

120 IJEl J+NOPT -J

$12500130 \mathrm{~J}=I$.NOPT

$z=Z * H E S S(I J) * D E(B)$

130 IJeIJ+2

DGMOOUUGHDG+ 2 DELO(I)

135 HORK II I $=2$

IF (JGHOG.LT_0.0) UQHU3 ESBOX*0.02

If (DOOX,LT.DGHDG) 60 TO 145

WEI \& +LGHDG/OGOX

00 1४0 1EI,NOP?

140 $D E L X(I)=D$-OELX(I)-WORK (I) 
C EHECK FOR ROUND-OFF ERRORS OA SIMGJ AR HESS IAN:

C SHOULO THESE CONDITIONS OCCUR, TME SẸAREH WILL BE IN AN ASEEV!

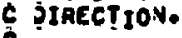

cे

55 If $\left(300 x_{0}, T_{0.0 .0)} 60\right.$ TO 65

ITHeITNi1

PATNT 6\%: ITN

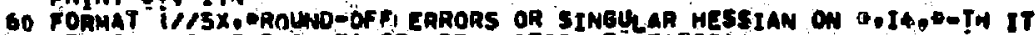
IERATION, REVERSION TO STEEPEST DESEENT MECESSAAYM

C 60 To 11

LINEAR search.

C

Estimate a sutTale step stze.

c

65221.0

Ifixts $=0$

LImIT

Goundo..1

If (NFIHST LLT.NOPT) ZZESTLP

U. OCOERROR/GOX

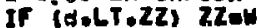

7. IF (LIMIT.LT.LO) 60 TO 72

ITMEITN+I

PRTAT 7!. ITNEEARNEN

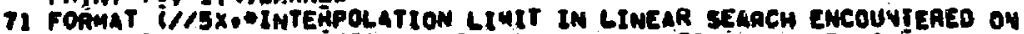

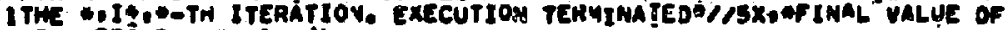

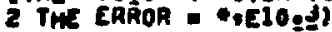
RETURN

$72600 x=60 \times 122$

DO 75 1al,NOPT

ZIALAIII)ZZ

Des, $x(1)=2$

$75 x(t)=x(1)+2$

CaLl UESCALE(MOAK)

call ERRFCM(dORKo EnRME I)

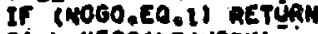

CALL RESEA: E (WOAK)

meAllenfoticlo

coxa0.0

Do 80 I I . NONT

ALE(I) $=$ WORKSII -GAAD (I)

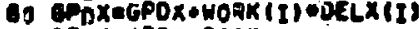

DGoxabPox-500x

c

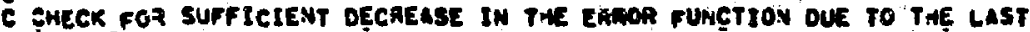

c Step raketi.

8

IF (EAROA.0T. (EARMEL-

DO OI IOLNODT

351

c

et $X(I)=X(I)=D E L X(I)$

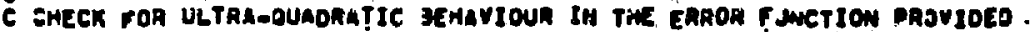

C AT LEAST NOPT ITEKATIONS MAVE UEEN EXECUTEOD SIHCE TME LABT

C AEVERSION TO STEEPEST UESCINT.

F 


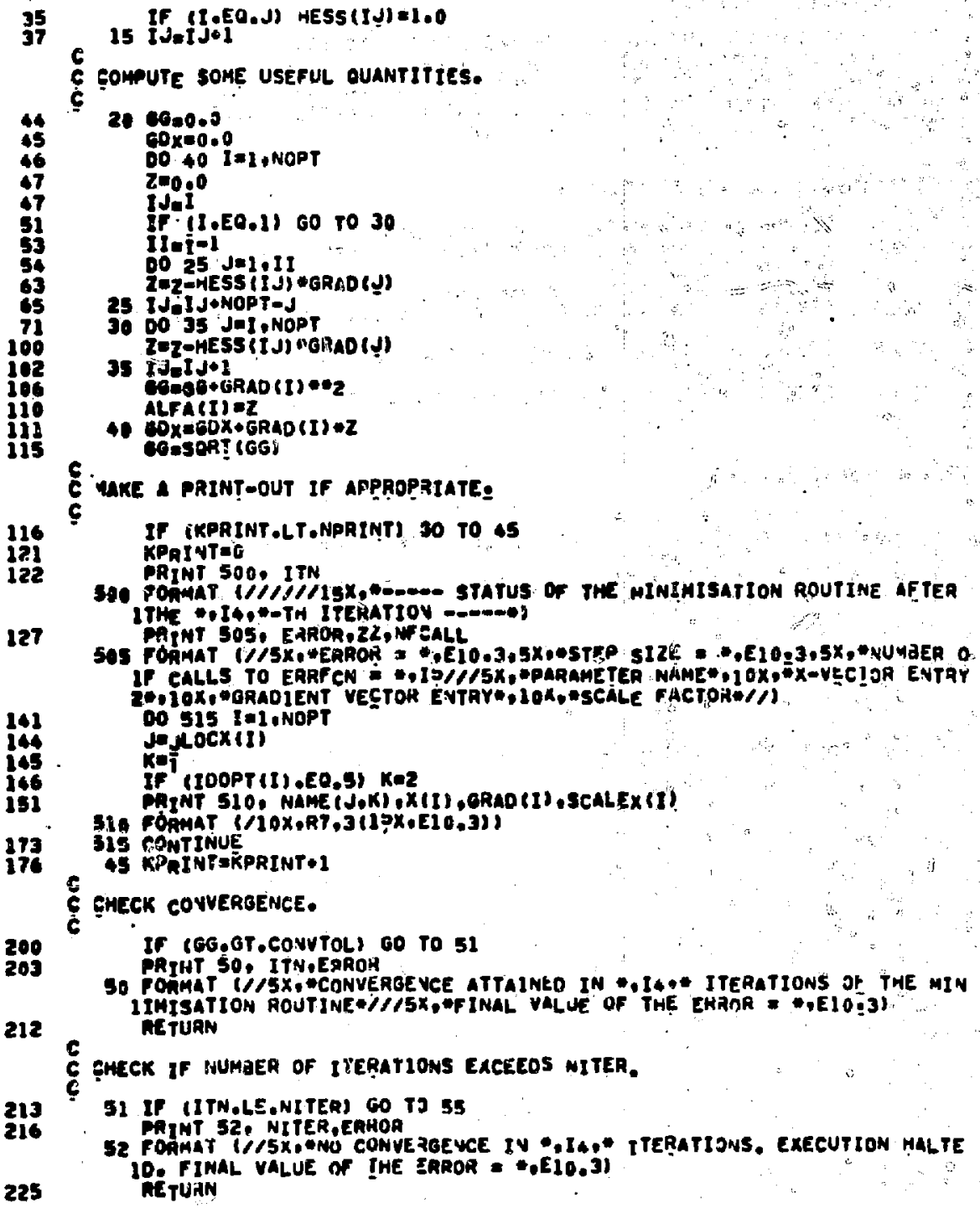


c

SUBROUTINE TO FIND THE MINIMUY OF THE ERROR FUNCTION. USING THE

jüAL-ÜPDATING VARIABLE METAIE ALgoRITHY OF R. FLETCHER.

THE MËTHOD IS FULLY DESCAIBEO QY FLETCHER IN. TA NEW APPAOACA

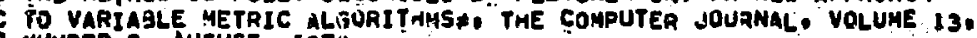

VUMBER 3, AUGUST. I97IIE

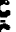

GRRAY IOENTITIES ARE AS FOLLOWS.

$X$ VECTOR OF PARAMETERS BEINO OPTIHISEO

DELX STORES THE CHANGE IN THE $X$ VECTOR BETWEEN LAST ANO

PRESENT ITERATIONS

ORAD VECTOR OF GRAÓIENT OF PARAMETERS BEING JPTIMISED

DELG STORES THE CHANNGE IN THE GRANIENT VECTOR. BETWEEN LAST AVO PRESENT ITERATIONS

HESS STOHES THE UPNER IAIANGULAR PORTION OF THE INUERSE MESSLAN MATRIX GY ROHS

ALFA STORES THE TRIAL STEPASIZE FOR THE LINEAR SEARCN

WORK WORKIMG SPACE

GOMMON DECLARATIONS.

COMHON /KILL/ NOGO JEOFI

COMHON /NETOAT/ NAME (I22,2) \&ALUE(122,2) LOCAL(122), LOCATE(5),

1 NODPLC (494), NUMNOD

COMYON $10 P$ I IUH WEI GHT (4) , JLOCX (30) IOGPT (30) ONOPT .NPRI VI.

1 NITER XX (30), SCALEX́(30)

DIMENSION GRAD (30) ALFA (30) DELX (30) -OELG (30) ONORK \$30) ,HESS(465)

C SET CONVERGENCE CRITERITONE

DATA CONVTOL/OOOOOZR

C INITIAL FUNCTION EVALUATIOV.

CALL ERRF CNIGRAD.EARORI

IF (NOGO,EO, I) RETURN

CALL SCALE (GRAD)

PRINT 10. ERROR

c

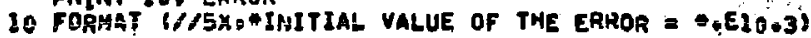

injtialise.

6
NFCALL $=1$
KPAIVT=O
$I T_{N=0}$

11 NF YAST $=0$

STEPai 0

c

get inVEHSE hESSIAN TO TRE UNIT MATALX:

c

I Jal

DO IS IFI,NOPT

DO is Jï. NOFT

HESS (IJ) $=0.0$ 


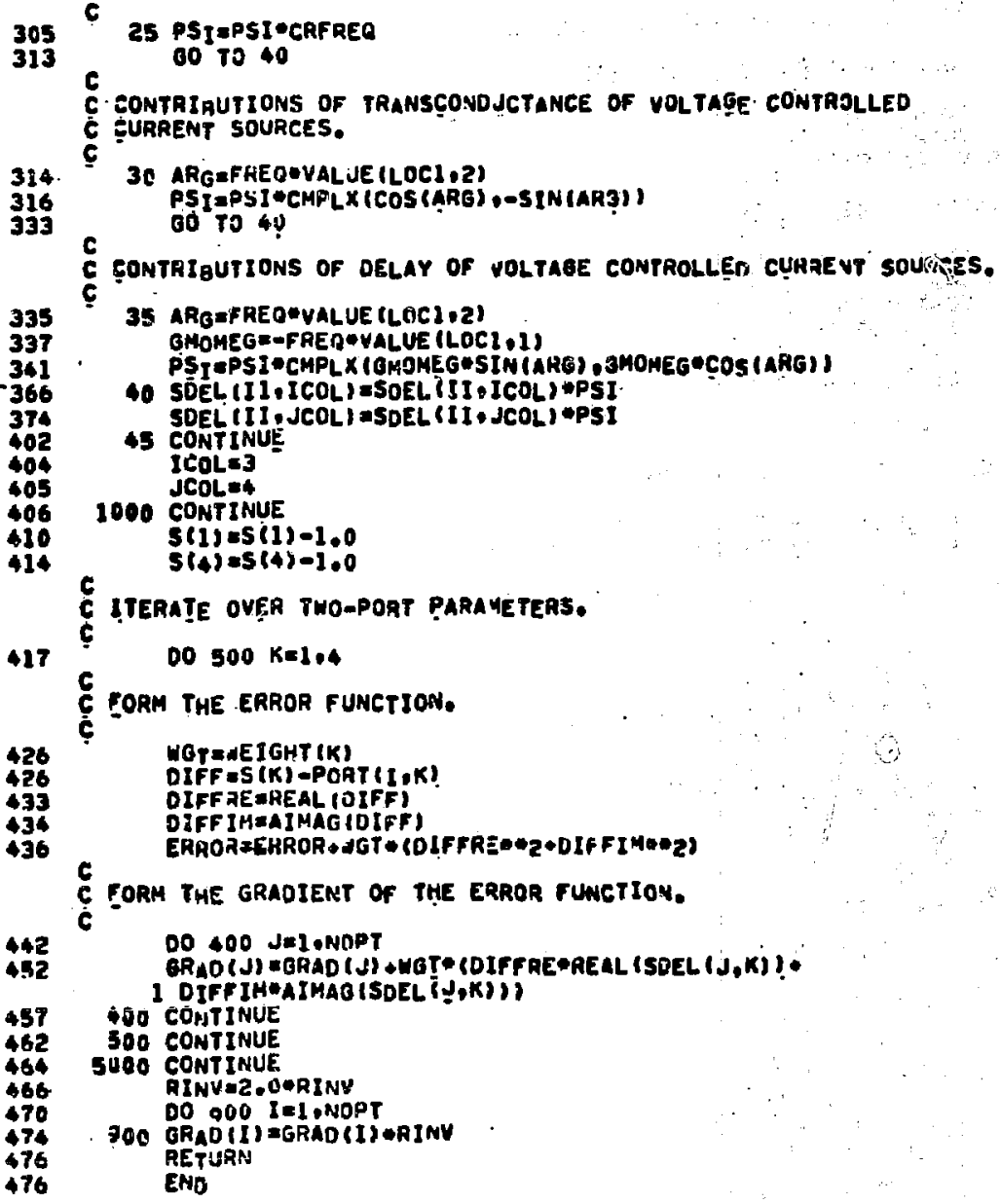

SUGPROGRAM EENGTH

$00 \$ 550$

FUNCTION ASSIGNHENTS 
62

63

74

106

107

115

116

120

122

227

130

350

170

204

205

67)

213

215

220

231

233

237

240

261

243

264

230

251

252

256

256

264

266

276

304

C SET MODE VOLTAGE VECTOA TO zEAO.

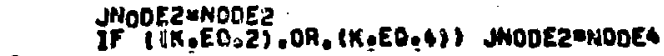

c

Do 5 II $I$, NUMNOD

VHPART (I. II) $=0.0$

5 VIPART $(2, I I)=0=0$

ESTABL15A ExCITATION.

C

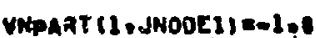

YNPART II. JNODEZ) $=01$ i.

VOAT.JMECMPLX X $(0.0 .000)$

C PROCESS THE ORIOINAL NETWOAK.

If (K.GT.2) so to is

c

C solve for scatteaIng parametTEas.

c

S (NCOL) =RINV $=($ (YN (NOOEZ) - YN (NOOEI))

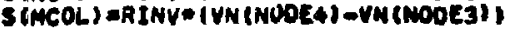

C ACCOUNT FOR CONTALBUTION Ț. THE GRARIEMT OF THE WETHOWK.

Do 10 II=l INOPT

LOcanocx (II)

LOCOLOCALILOC)

If TIOOPTIII. OT.3! LOCELOC.Z

MODEX1 $=$ NODPLC(LOC)

$M 0 O C \times 2=N O D P_{L} C(L O C+1)$

VENH (NODEXX)-VIN (NOUEX)

soCL (II.NCOL) $=V$

20 soll (11)MCOL)

Meal=2

medes

60 To 1000

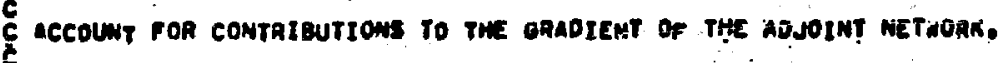

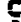

15 CALL SOLVEA

00 \&S II =I *NOPT

. LOCI $=J$ LOCXIII)

LOCOLOCALILOEIS

NOOEXI $=$ NODPLC (LOC)

MOOEX2 $=$ MODP ICILOC+1)

PS IOVN (KODEX1) - VN (NGOEEX2)

20-1DOPT (II)

co to $(40,20,25,30,35)$, 10

C CONTRIeutions of CADACitons.

20 psisepstocFReo

40 1T 40

C Fo:atrigutions of AECIPAOCAL: Inouctances. 
C SUBROUTINE ERRFCNIGRADAERRORI

C SUBROUTINE TO COMPUTE THE ERROR FUNCTION ANA ITS GRADIENT

C IN THE SPACE OF PARAMEIERS gEINO OPTIMISEO. THE ERAOR FUNCTION

C IS OF THE WEIGHTED SUM=OF-SQUARES TYPE.

c

GOMMON DEclaratzons.

c

COMANON MLLL' NOBO,JEOFi

COMHON INETOAT, NAME (122,2), VALUE $(122,2)$,LOGAL (12Z2) ,LOCATE (5),

1 NOPPLC I 84 , NUMNOD

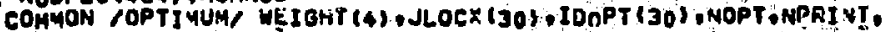

I MITER OX(30) , SCALEX (30)

COMPLEX PORT

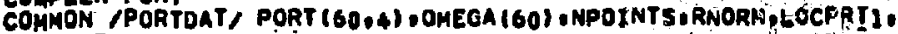

1 LOCPAT2

CONPLEX YDATUM, YNL, VDATUM,VN

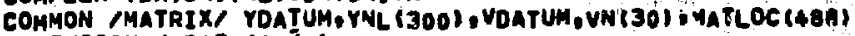

DIMENSION VMPART $(2,30)$

EOUTVALENCE (YNPART $(1,1) \cdot$ UNII))

COMPLEX CFREC,CAFREQ, Y,PSI.DIFF

COMPLEX S.SDEL.

OIMENSION SiG) USDEL $(60.4), 6 R A O(30)$

E

THITIALISE.

ERROA $=0.0$

002 I 1 , NOPT

15

2 RAOLII $=6.0$

MOLI ANODPLC (LOCPRT1)

NODE2=NUDPEC (LOCPRTI+1)

NOOK 3 NNODPLCCLOCPRTI:

NODT4ENOOPLC (LOCPRT̃ +1$\}$

8 RINY E. D/RNORH

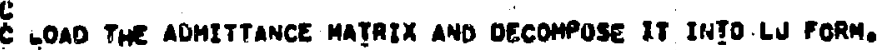

$005000 I=1, N P 0 I N T S$

FReQDOMEGAII)

CPREOCMPLX $X(10,0, F R E Q)$

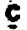

40

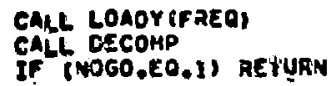

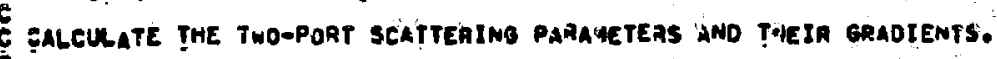

icoles

incoles

ICOL=1

Jet $=2$

$001000 \mathrm{kel}+4$

MoOE I ENIODEI

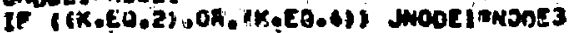


6
6
6

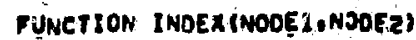

C NOUTIHE TO FINO MATAIX LOCATION OIVEN NOOE SPECIFICATIOH.

comman dẹclaRATIONS.

CGMHON /NETOAT/ NAME (122.2) VALUE (122 -2) -LOCAL (122) LOCATE (5) :

2 MOOPLC (484), NUMHOO

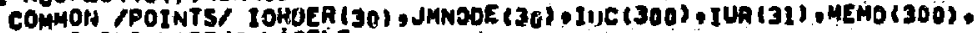

c

\& IUS ILLS OLASTUTILASTLT

5 If (NOOEL.EO.OI 60 TO IS

IF (NOOEI.NE.NODEZ) GO TO 1

INOEXNONOOEI

10 : RETÜคN

1 LOSJMMODE (NOOE L)

JOEJYKOUE (NODE2!

ItTaAT=IUS

IF (JO.OT.IO! 60 TO

ISTAATEILS

ITEM้องo

torio

IO-I YEAP

4 IF (Jo.le anjunOO) 60 To

ITemplo

IONJ0

SOEI TEMP

$\mathbf{E} \mathbf{b}$

3ugpadoRsh bEMTH

no007o

Fynction assienments

STATEMHT ASSTENHENYS

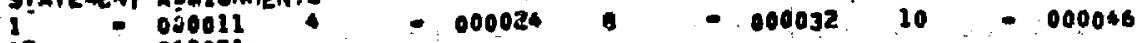

is - oposi

QLDẼX NAWES ANO LEHGTMS

nitoAi - OVZ114 Polnts - o01267

VARTAGLE ASS TONHENTS

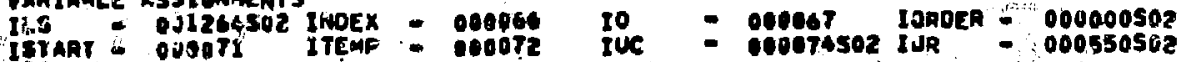




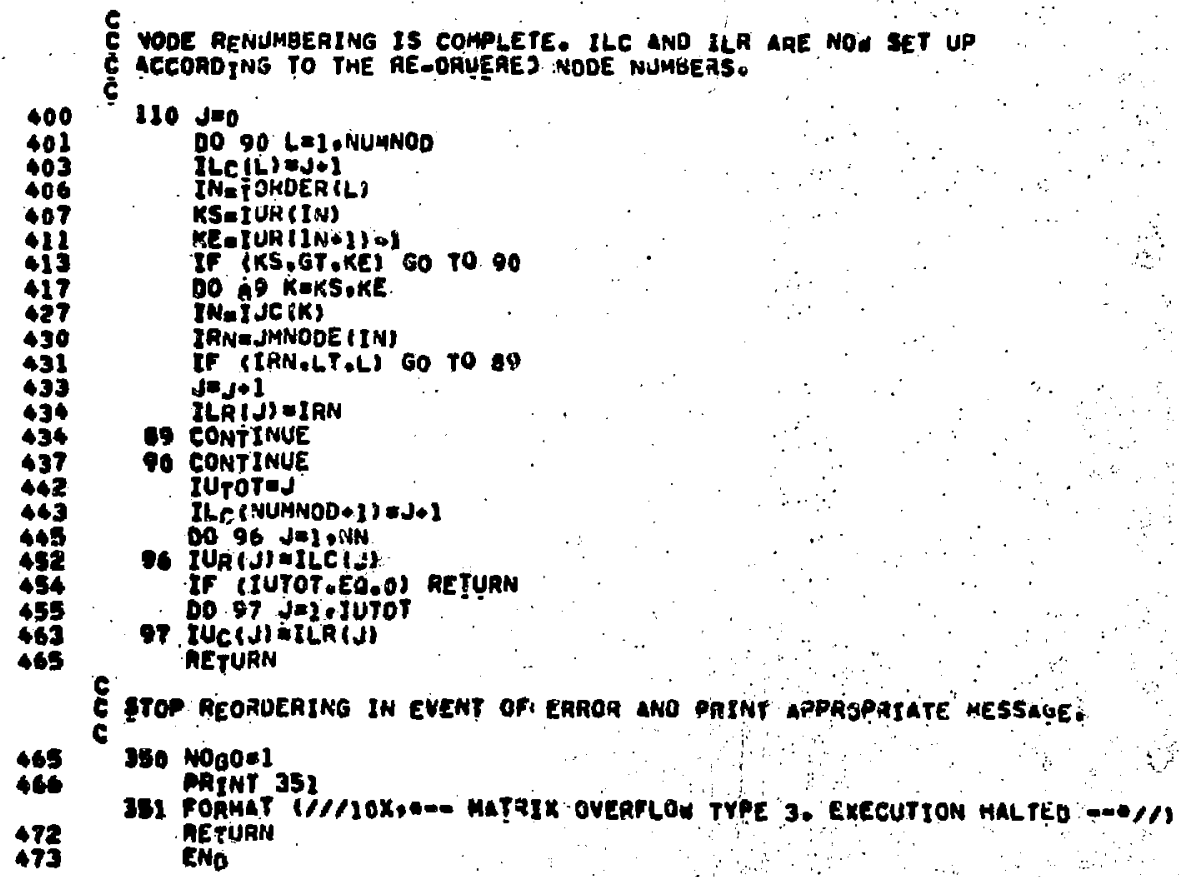

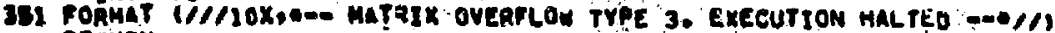
aetuan ENo

\section{SyaproghaM LENaTH}

\section{0̈056}

\section{Functson Agsionments}

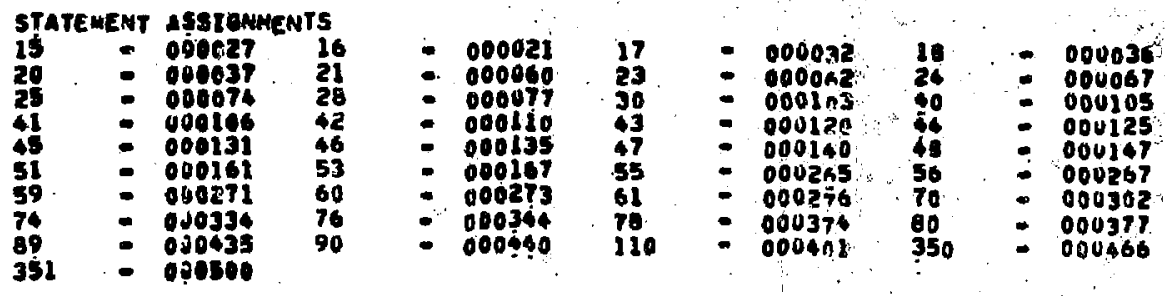

BLOCX NAHES AWO LENGTHS

KILL - g90002 NETOAT - OA2214 POINTS - 0012G7 